\title{
Thirteen years of SysML: a systematic mapping study
}

\author{
Sabine Wolny ${ }^{1} \cdot$ Alexandra Mazak $^{1} \cdot$ Christine Carpella $^{2} \cdot$ Verena Geist $^{3} \cdot$ Manuel Wimmer $^{1}$
}

Received: 7 March 2018 / Revised: 11 February 2019 / Accepted: 9 April 2019 / Published online: 13 May 2019

(c) The Author(s) 2019

\begin{abstract}
The OMG standard Systems Modeling Language (SysML) has been on the market for about thirteen years. This standard is an extended subset of UML providing a graphical modeling language for designing complex systems by considering software as well as hardware parts. Over the period of thirteen years, many publications have covered various aspects of SysML in different research fields. The aim of this paper is to conduct a systematic mapping study about SysML to identify the different categories of papers, (i) to get an overview of existing research topics and groups, (ii) to identify whether there are any publication trends, and (iii) to uncover possible missing links. We followed the guidelines for conducting a systematic mapping study by Petersen et al. (Inf Softw Technol 64:1-18, 2015) to analyze SysML publications from 2005 to 2017. Our analysis revealed the following main findings: (i) there is a growing scientific interest in SysML in the last years particularly in the research field of Software Engineering, (ii) SysML is mostly used in the design or validation phase, rather than in the implementation phase, (iii) the most commonly used diagram types are the SysML-specific requirement diagram, parametric diagram, and block diagram, together with the activity diagram and state machine diagram known from UML, (iv) SysML is a specific UML profile mostly used in systems engineering; however, the language has to be customized to accommodate domain-specific aspects, (v) related to collaborations for SysML research over the world, there are more individual research groups than large international networks. This study provides a solid basis for classifying existing approaches for SysML. Researchers can use our results (i) for identifying open research issues, (ii) for a better understanding of the state of the art, and (iii) as a reference for finding specific approaches about SysML.
\end{abstract}

Keywords SysML $\cdot$ Systematic mapping study $\cdot$ Systems engineering

\section{Introduction}

The Systems Modeling Language (SysML) is a standard from the Object Management Group (OMG) to support the design, the analysis, and verification of complex systems which may include software and hardware components. SysML reuses parts of UML and additionally offers new language elements like value types, quantity kind, as well as the opportunity to

Communicated by Jean-Michel Bruel.

Sabine Wolny

sabine.wolny@jku.at

1 Christian Doppler Laboratory for Model-Integrated Smart Production (CDL-MINT) Institute of Business Informatics Software Engineering, Johannes Kepler University Linz, Altenberger Straße 69, 4040 Linz, Austria

2 ENGEL AUSTRIA GmbH, Schwertberg, Austria

3 Software Competence Center Hagenberg GmbH (SCCH), Softwarepark 21, 4232 Hagenberg, Austria describe the functionality of continuous systems [29]. One of the first intention for SysML was to give systems engineers a modeling language in hand which is not too software oriented [51]. SysML enables to model a wide variety of systems from different perspectives such as behavior, structure, or requirement. The temporarily last version 1.5 was released in May 2017. SysML has been in place for about thirteen years, and various papers capturing different aspects of this standard have been published at different venues by different research communities. Since SysML is used in multi-disciplinary engineering, there are large application fields where the language is used.

To get a better overview of this huge number of contributions as well as to identify the relevance of SysML in scientific communities, we carried out a systematic mapping study by analyzing the abstracts of the different contributions. The study helps to generate knowledge by determining the application fields in which SysML is commonly used, which research groups are involved, etc. These insights help to iden- 
tify trends to which direction SysML should be developed in future, also with respect to the ongoing discussion about SysML 2.0.

To put the aim of this article in a nutshell, we present inputs as well as outputs of the SysML mapping study and show a comprehensive overview of the evolution of SysML over a period of more than 10 years. Additionally, we identify open issues and discuss these issues in the conclusion of this article with regard to SysML 2.0. According to Kitchenham et al. [28], the findings and outlook may support the work of the following stakeholders:

- Research: Scientists just started with research in the field of SysML may use this study as an overview and starting point for their work. Experienced researchers may also use it as reference to save time for in-depth studies and to accelerate the search for open issues.

- Industry: For industry, the findings give a good outline of the state of the art in SysML research. This may enable to transfer knowledge between academia and industry. Such knowledge transfer may push forward the realization of open issues in the vision of Industry 4.0 and cyber-physical systems [10]. At least, industry stakeholders may identify relevant and suitable research outputs for practical settings.

The remainder of this article is structured as follows: Section 2 discusses the related work. In Sect. 3, we present the research method, define the research questions, and describe the process of conducting the mapping study. In Sect. 4, we describe and analyze the extracted data and visualize the results. Section 5 covers possible threats to validity. In Sect. 6, we present the conclusions and an outlook to future work. In Appendices A and B we present references of all covered SysML papers, a list of books, and theses, which were not part of this survey.

\section{Related work}

In this section, we give an outline on the method of systematic literature review compared to the method of a systematic mapping study. Furthermore, we take a closer look on these methods applied to UML and to its profiles (e.g., SysML, MARTE).

\subsection{Systematic literature review versus systematic mapping study}

Evidence-based practices, originating from the medicine discipline, have been widely adopted in software engineering (SE) since 2004. In order to address evidence-based SE in the form of systematic literature reviews (SLRs), the cor- responding techniques were re-formulated by Kitchenham [26]. SLR is a well-defined methodology to identify, analyze, and interpret evidences in an unbiased and repeatable way [28]. A large majority of published SLRs in the domain of SE has been performed by following the approaches introduced by Kitchenham et al. [25,27]. In addition, there are some authors who have adopted surveys from medicine [35] as well as from social sciences [46], or they have applied refined guidelines like introduced in [11,14,60].

In this article, we apply a broader form of SLR which is known as systematic mapping study (SMS) according to [8], since our intention is to focus on evidences for a specific research topic instead of answering detailed research questions. Based on a set of primary studies, a SMS identifies gaps in the research area under consideration and discovers potential research trends. By doing so, we follow the guidelines for conducting SMS in SE introduced by Petersen et al. $[44,45]$. Additionally, we apply the survey of Kuhrmann et al. [31] for performing our SMS for SysML (see Sect. 3).

It seems that there are similarities between SMS and SLR; however, the approaches of these two methodologies and also their goals are quite different. For instance, in contrast to SLR, a SMS uses general research questions to classify and aggregate relevant studies to high-level categories [40].

\subsection{SMSs and SLRs applied to UML}

In empirical studies concerning the maintenance of UML diagrams and their use in the maintenance of code, FernándezSáez et al. [17] conducted a SMS. For this purpose, the authors studied 38 already published studies for discovering an empirical evidence by applying the guidelines of [25]. As a result, the authors identified the need for more experiments and case studies in industrial contexts.

In the particular research field of UML-driven software performance engineering, Garousi et al. [18] conducted a SMS to systematically categorize the current state of the art. Thereby, the authors applied the guidelines provided by Kitchenham and Charters [25] and Petersen et al. [44]. Among others, the authors identified emerging trends in this specialized research field based on a set of 90 (from 114 identified) papers published between 1998 and 2011 [18].

Torre et al. [56] deliver a comprehensive summary of UML consistency rules (regarding the different diagram types) by performing a SMS including 94 primary studies published until December 2012. For their SMS, they used in total seven search engines and followed the guidelines of Kitchenham [25]. There are related research works that address, e.g., a SLR on UML consistency management [33] by covering an earlier publication period (2001-2007), as well as, a SLR about the quality of UML diagrams [37]. Finally mentioned, there exist prior works on empirical evidence related to UML 
in general, e.g., a SLR [9] and a SMS [47], which consider papers on UML properties and features published until 2008.

In the area of Software Product Lines (SPL), a SMS on business process variability is conducted by Valença et al. [57]. This SMS includes 80 primary studies and considers one empirical study on a hierarchical representation method for UML 2.0 activity diagrams. They based their work mainly on the surveys presented in $[8,44]$ as well as on SMS best practice as introduced in [28].

All of these related works have in common that they do not consider SysML as main topic of the survey and that they apply other techniques than we follow in our mapping study. However, they represent interesting related work, not least because UML provides the basis for SysML.

\subsection{SMSs and SLRs applied to UML profiles}

Ameller et al. [1] classify UML and UML profiles used to specify functional and non-functional requirements based on SMS to assess the state of the art in the development of services-oriented architectures using model-driven development. The authors selected and analyzed 129 papers by adopting the guidelines presented in [25] and those described in $[28,44]$. There are related SMS investigating the alignment of requirements specification and testing such as presented in [5]. In [52], the authors conducted a survey to examine the use of UML profiles for testing Web services composition.

In the research field of domain-specific languages (DSLs), Nascimento et al. [13] perform a SMS to identify the most popular application domains of DSLs. The authors categorize 1440 (from 4450 identified) primary studies by applying the guidelines described in $[25,44]$. The technique of UML profiles is mentioned in 21 publications of their catalog. An extensive SLR in the specialized research area of modeldriven security was conducted by Nguyen et al. [39], where the authors also consider UML profiles (e.g., UMLSec, SecureUML, etc.) for the definition of security-oriented DSLs. In addition, Souag et al. [55] surveyed UML-based extensions for modeling security in the field of security requirements engineering.

The UML profile SysML is addressed as topic in a mapping study, which investigated the usability requirements elicitation [41]. The study was conducted based on the guideline presented in [25]. The authors formulated a sub-question on notations to elicit usability requirements, and they identified model-based notations and natural language as the most widely used notations in SE. There are similar SLRs related to this topic such as presented in [2], which covers modeldriven requirements engineering.

Regarding model-based requirements specifications, Rashid et al. [48] investigated how UML, SysML, and MARTE profiles have been used to specify aspects of embedded systems in the context of early design verification by con- sidering papers published between 2008 and 2015. In an additional SLR on tool selection in model-based systems engineering, Rashid et al. [49] classified selected research work in different categories like "modeling category," where modeling aspects of embedded systems using UML and its profiles SysML and MARTE were discussed. Additionally to model-based or model-driven requirements engineering and specification, SysML as topic was also investigated in the field of model-based testing like in the work presented in [54]. Wortmann et al. [62] explore in their SMS the state of the art of using modeling languages for model-based systems engineering of smart factories. The authors found out that SysML and its variants play a key role as modeling technique for realizing Industry 4.0 approaches.

In the research field of systems engineering, several SLRs include specific research questions concerning UML as well as its profiles SysML and MARTE. For instance, Guessi et al. [20] conducted a SLR on the topic of describing software architectures for systems of systems (SoS). The authors' second research question targets the techniques that have been used for describing SoS. They identified that most primary studies use UML or SysML as semi-formal architecture description languages.

In the previous past, SMSs were applied on safety and security topics in the research field of systems engineering. For instance, Nguyen et al. [40] conducted a SMS by covering primary studies that focus on several SysML profiles like SysML-Sec. Other SMSs such as presented in [16,22] only touch SysML in their explanations and findings.

There are a lot of SMSs addressing UML-based approaches and UML profiles (e.g., SysML), e.g., (i) an SMS on functional safety conducted by [7], (ii) a survey on SPL evolution presented by [32], or two SMS on SPL testing conducted by $[15,38]$.

\subsection{Synopsis}

In this section, we relate existing research to our mapping study. The presented research includes guidelines for conducting SLRs and SMSs such as the work of Kitchenham et al. [25,27] and Petersen et al. [44,45], or Kuhrmann et al [31]. We discussed works including empirical studies, case studies, and surveys on UML and UML profiles, in particular, applied in the domain of software engineering as well as systems engineering. The conducted studies and mentioned surveys investigate in the research fields of requirements engineering, embedded systems in the context of early design verification, model-based systems engineering, security engineering, performance engineering, and software testing, e.g., the quality and usability of UML and UML profiles.

All of these studies and surveys have in common that they do not consider SysML exclusively and that they apply other guidelines than we follow in our mapping study. For 
instance, the presented SLRs answer detailed research questions but they give no evidence on various aspects for SysML for systems and software engineering. However, they represent interesting related work and provide relevant entry points to our own mapping study.

\section{Research method}

As research method, we used the previously introduced SMS that enables to cover and classify publications in a specific area. In our study, we are focusing on the abstracts of publications, published in the time period from 2005 to 2017, that have SysML as their main topic.

The process for conducting this SMS is shown as SysML activity diagram in Fig. 1, which mainly bases on the guidelines introduced in Petersen et al. [44]. We modified this mapping process by adapting the last two activities.

Our systematic mapping process consists of five steps (see Fig. 1). It starts by the activity of defining research questions. The output of this activity are appropriate research questions that define the review scope for the next step. In that activity, we conduct a literature search. The output are all publications related to the previously defined research questions. The next step is the screening of those publications in order to select the relevant ones. These relevant publications are the input for the activity called "classification using abstracts," where we categorize the relevant publications by their abstracts based on the research type facets introduced by Petersen et al. [44] (see Table 1). We enhance this activity by further investigating to classify the abstracts based on systems engineering phases related to the VDI guideline 2206 [58] and contribution types as introduced by Shaw [53]. As output, we get classified abstracts of selected publications, which we use as input for the last activity "mapping of papers," After this final step, we get a systematic map, which enables us to extract main findings related to our research questions.

In the following, we describe four (Sects. 3.1-3.3) of the five SMS activities based on the research topic of our survey. Afterward, in Sect. 4, we present the final activity "mapping of papers."

All data (i.e., founded results, search strings, screened paper, classifications) can be also found on figshare ${ }^{1}$ at https://figshare.com/s/871aa0c03aa18eb3edf6.

\subsection{Activity 1: defining research questions}

In this subsection, we define our research questions to specify the review scope of the mapping study and we provide an insight into the intentions behind these questions.

${ }_{1}$ https://figshare.com/.
- RQ 1: What are the bibliometric key facts of SysML publications?

The intentions of this research question is to find out (i) the number of SysML publications that were contributed in the period from 2005 to 2017, (ii) the type of those publications (e.g., article, book chapter), (iii) the main venues where the publications have been submitted, and (iv) the main research background (i.e., communities) of these venues.

- RQ 2: Where are the scientific communities of SysML located and are there main contributors, who scientifically promote SysML topics?

The intention is to identify and analyze scientific communities working on topics of SysML, e.g., we are interested in the location of these communities. Moreover, we address the question if there are more single authors working on SysML topics, or rather (small) research groups. For instance, we are interested in the number of publications and their authors to identify those publications published by one and the same author. Last but not least, we consider the number of citations of each of the publications to identify the relevance for the respective community. By doing this analysis, we want to find out if there exists a huge network spanning over the world which is working on SysML approaches, or not.

- RQ 3: Which research type facets do the identified publications address?

The main intention is to categorize the different publications by a solid and already well-established schema ( $[31,59])$. Therefore, we use the research type facets introduced by Petersen et al. [44] as described in detail in Sect. 3.3 (see Table 1). Based on this type facets, we want to find out in which research contexts SysML topics are used, e.g., validation, evaluation, etc.

- RQ 4: What are the key aspects of applying SysML in the classified publications?

In addition to assigning the publications to type facets, we are interested to get a deeper insight in the research contribution of those publications. This research question aims to identify (i) in which phase of the engineering process [58] SysML is used, and (ii) the contribution type [53] of the publications.

\subsection{Activities 2 and 3: conducting search and screening of publications}

After identifying our research questions, the next activity is the definition of appropriate keywords to find all published papers regarding topics about SysML. 


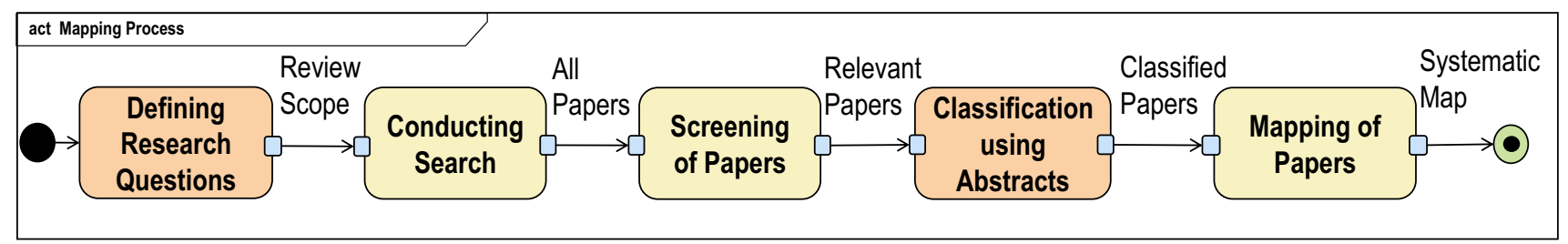

Fig. 1 Activity diagram of the systematic mapping process [44]

Table 1 Research Type Facet [44, p.4]

\begin{tabular}{|c|c|}
\hline Category & Description \\
\hline Validation Research & $\begin{array}{l}\text { Techniques investigated are novel } \\
\text { and have not yet been } \\
\text { implemented in practice. } \\
\text { Techniques used are, for } \\
\text { example, experiments, i.e., work } \\
\text { done in the laboratory }\end{array}$ \\
\hline
\end{tabular}

Evaluation Research

Solution Proposal

Philosophical Papers

Opinion Papers

Experience Papers
Techniques are implemented in practice, and an evaluation of the technique is conducted. That means, it is shown how the technique is implemented in practice (solution implementation) and what are the consequences of the implementation in terms of benefits and drawbacks (implementation evaluation). This also includes to identify problems in industry

A solution for a problem is proposed; the solution can be either novel or a significant extension of an existing technique. The potential benefits and the applicability of the solution are shown by a small example or a good line of argumentation

These papers sketch a new way of looking at existing things by structuring the field in form of a taxonomy or conceptual framework

These papers express the personal opinion of somebody whether a certain technique is good or bad, or how things should been done. They do not rely on related work and research methodologies

Experience papers explain on what and how something has been done in practice. It has to be the personal experience of the author
Conducting search In contrast to existing work (see Sect. 2), we do not want to cover just a single aspect of SysML. Our aim is to provide an overview of all published papers. Thus, we decide to search for the following keywords:

- SysML

- "Systems Modeling Language" (case insensitive)

- "System Modeling Language" (case insensitive)

There are many different digital literature libraries available on the Web for conducting a literature search. We have opted for the following four established ones:

- Scopus (www.scopus.com)

One of the largest abstract and citation databases of peerreviewed literature.

- ACM Digital Library (http://dl.acm.org/)

$\mathrm{ACM}$ is a research, discovery, and networking platform where a collection of full-text articles and bibliographic records can be found.

- IEEE Xplore Digital Library (http://ieeexplore.ieee.org) IEEE Xplore provides a full-text access to technical literature in engineering as well as technology.

- DBLP (http://dblp.uni-trier.de/)

The computer science bibliography database dblp offers open bibliographic information on computer science journals and proceedings.

In our piloting phase, we got more than 2000 papers resulting from the conducted search process in these libraries. In order to obtain more precise results regarding our intention to find out the state of the art of research on SysML in academia, we decided to restrict the search string by the following criteria:

- Publication in the period from 2005 to 2017: The first SysML Specification $^{2}$ v.0.9. is online since January 2005. Thus, we use this year as starting point in our systematic mapping study. Since the survey was conducted in late 2017/early 2018, we decided to define 2017 as end date.

- Title: In order to get as output more specific SysML publications, and not only papers mentioning SysML as related

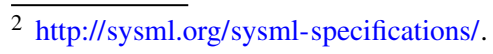


work, we restrict the search query to publications where the previously defined keywords are in the title. This decision should ensure that only publications that focus on SysML are included in our result set.

We updated our result set several times to receive a complete set of all relevant publications to answer our research questions. In addition during the revision process, we also made several updates for finding any further publication published in 2017. The final state of our result set, aligned with all libraries, was checked the last time on the 21 of January 2019.

Screening of publications For screening the publications, we defined the following exclusion criteria:

- Duplicates

- Papers:

- without available abstract

- without an English, German, or French abstract

- without any context to the language SysML For instance, SysML as abbreviation for "System Machine Learning."

- with similar abstracts

Some papers are covering different development stages of a project, and therefore, their abstracts are identical or have been just slightly extended. We deleted the older or shorter version and always kept the newer or longer version in the result set.

- with identical abstracts

There are papers with identical content and abstracts; however, they have been published at different venues (e.g., conferences and journals). We decided to leave one of them in the results set and deleted the other publication.

- Books: Books are deleted because they are not peerreviewed (e.g., A Practical Guide to SysML [B4]). The whole list of retrieved books can be found in Appendix B.

- Theses: Theses often cover several different aspects and therefore can be assigned to different type facets. In addition, most theses are also (partly) published as conference or journal papers and would be duplicates. Thus, we removed them from the result set. The list of excluded theses can be found in Appendix B.

Based on these exclusion criteria, we double-checked (extractor/checker) all extracted papers in order to ensure that there is consensus on all findings. After performing this screening process, our result set comprises 579 papers. For these papers, we additionally considered the number of citations provided by Google $\operatorname{Scholar}^{3}$ (see Sect. 4.2). The overall list of the 579 publications is provided in Appendix A.

\subsection{Activity 4: classification using abstracts}

According to the guidelines of Petersen et al. [44], it is sufficient to search only the abstract of a publication for categorization. In order to get a deeper insight of the research context of those publications and for a better mapping, we decide to apply the research type facets of Petersen et al., as presented in Table 1, already in this phase of the SMS. This means that we deviate from the original mapping process by using the research type facets as classification schema to categorize the abstracts of the selected publications. Thus, we modified the activity of "keywording of abstracts" in that we use an already established classification schema.

Besides the assignment of abstracts to these research type facets, it is important to find out in which engineering phase SysML is mainly used and to which contribution type the publications belong in order to get a deeper insight in the research field of the selected publications. For this purpose, we examine the different topics of the papers by analyzing the keywords of the abstracts and cluster the publications based on systems engineering phases and contribution types. In this respect, we adapted the mapping process introduced by Petersen et al. [44] by making a more fine grained categorization, as we describe in the following:

Systems engineering phase Based on the V-model related to the VDI guideline 2206 [58], we distinguish the following phases:

- Requirements: Defining the requirements and system properties such as the scope of functions and interfaces.

- Design: Designing the architecture of the system.

- Implementation: Phase of realization and integration to which simulations and code generators belong.

- Validation and Verification: The final phase of the Vmodel to analyze and check the system.

Contribution type On the basis of the types of research results introduced by Shaw [53], we define our categories for the contribution types. Shaw defines seven different types, in which she is also distinguishing between different data models (empirical, analytic, qualitative model). In our study, we do not focus on different data models. Thus, we adapt these types for our classification process. To give an overview, we briefly describe our contribution types in the following:

\footnotetext{
${ }^{3}$ https://scholar.google.at/.
} 
- Technique: Definition of a method or procedure.

- Process: Sequence of both interdependent as well as linked procedures.

- Notation: A formal language or graphical notation to support a method (e.g., SysML Profile) or to map SysML to other languages (e.g., translation).

- Tool: A specific implemented tool based on a certain technique.

- Specific Solution: Solution for an application problem, e.g., result of a specific analysis, evaluation, or comparison.

- Other: For all publications of our result set, which cannot be assigned to one of the contribution types specified above. For instance, this includes publications that use SysML in an educational context, or that compare SysML with other modeling languages.

The outcome of the first four activities of the mapping process is a result set of publications classified based on research type facets, systems engineering phases, as well as on contribution types. This outcome serves as an input to the final activity called "mapping of papers," which is described in detail in the next section.

\section{Mapping of papers}

In this section, we describe analysis and results to answer the research questions (RQ1-RQ4). This output bases on the last activity of our adapted SMS. Additionally, we briefly summarize the main findings related to these questions at the end of each subsection.

\subsection{RQ 1: bibliometrics of SysML publications}

To answer the first research question, we start with analyzing the distribution of published papers in the period from 2005 to 2017. In a second step, we relate the result set to the type of publications. Furthermore, we make a list of venues, where the publications have been submitted. Figure 2 depicts the absolute number of publications per year. The plot shows that this number subjects to fluctuations. We found out that in the years, in which a new version of the SysML standard was published, the number of publications is mostly higher than in the years before. The peak in Fig. 2 indicates that most of the publications were published in 2013.

For further analysis of these results, Fig. 3 illustrates the relationship among the number of publications, the years, and the type of publication. The orange line depicts that in the period from 2005 to 2017 there have been submitted much more inproceedings to scientific conferences than articles to scientific journals (see the blue line) or book chapters (see the green line). Regarding the publication type, $80 \%$ of the

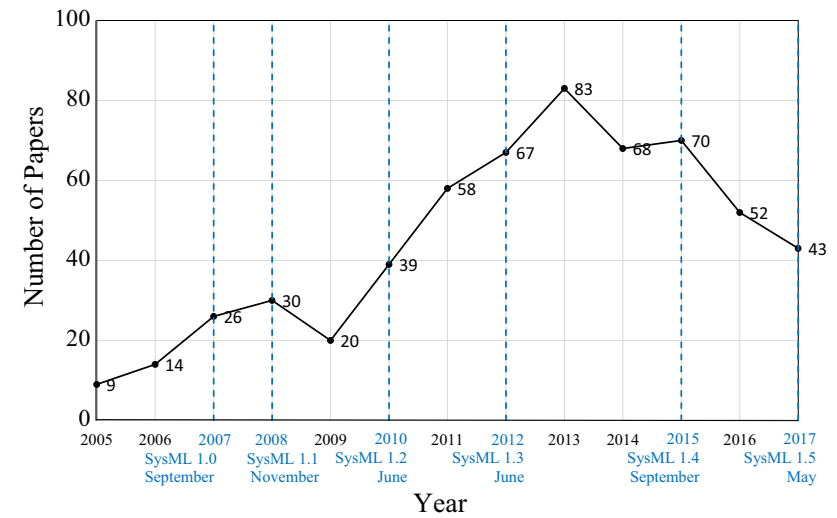

Fig. 2 Number of publications per year in the period from 2005 to 2017 (included number of studies: 579)

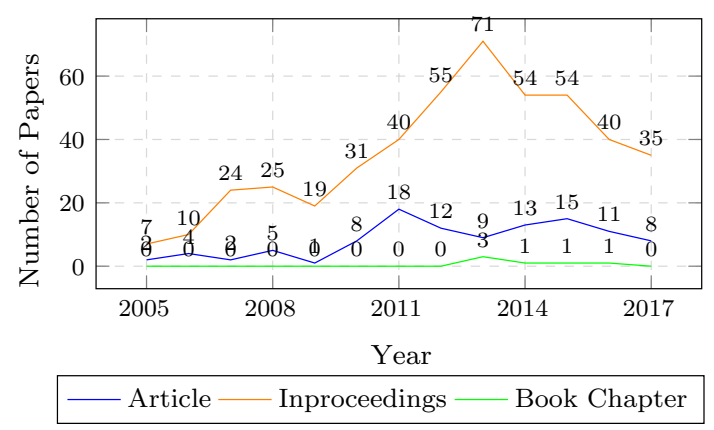

Fig. 3 Number of publications per year regarding publication type (included number of studies: 579)

screened SysML publications were published as inproceeding, $19 \%$ as article, and only $1 \%$ as book chapter.

Furthermore, we want to find out if there are few selected venues promoted by a handful research communities, or if the publications spread over various conferences, workshops, and journals which are promoted by very different research communities. The result set shows that there are 316 different venues, where the papers have been submitted. For the sake of relevance and clarity, we list in Table 2 those conferences with at least 8 SysML publications and in Table 3 the journals with at least 4 publications. In total, we present 12 different venues. The category column shows the main research community of these venues.

The main venue is the Annual International Symposium of the International Council on Systems Engineering (INCOSE), where more than 30 publications have been submitted in the last 10 years. A possible reason for INCOSE being so prominent may be that the development of the SysML language specification was a collaborative effort between members of OMG and INCOSE. Thus, the INCOSE community is interested in applications and innovations of SysML. Additionally, one of the main research topics of this conference is systems engineering, where SysML plays a key role. From a statistical point of view, we underpin INCOSE's 
Table 2 Most Prominent Conferences regarding the Number of Publications (at least 8 Papers) Sys. Eng. = Systems Engineering, Sof. Eng. = Software Engineering, Sim. = Simulation, Aut. $=$ Automation

Table 3 Most Prominent Journals regarding the Number of Publications (at least 4 Papers) Sys. Eng. = Systems Engineering, Sof. Eng. = Software Engineering, Sim. = Simulation, Aut. $=$ Automation

\begin{tabular}{|c|c|c|}
\hline Venue & Category & Number of Publications \\
\hline $\begin{array}{l}\text { INCOSE (Annual International } \\
\text { Symposium of the International } \\
\text { Council on Systems Engineering) }\end{array}$ & Sys. Eng. & 32 \\
\hline $\begin{array}{l}\text { IDETC/CIE (International Design } \\
\text { Engineering Technical } \\
\text { Conferences) }\end{array}$ & Sys. Eng. & 14 \\
\hline $\begin{array}{l}\text { ETFA (International Conference } \\
\text { on Emerging Technologies and } \\
\text { Factory Automation) }\end{array}$ & Aut. & 13 \\
\hline $\begin{array}{l}\text { SysCon (International Systems } \\
\text { Conference) }\end{array}$ & Sof. Eng. & 12 \\
\hline $\begin{array}{l}\text { MODELSWARD (Conference on } \\
\text { Model-Driven Engineering and } \\
\text { Software Development) }\end{array}$ & Sof. Eng. & 11 \\
\hline $\begin{array}{l}\text { CSER (Conference on Systems } \\
\text { Engineering Research) }\end{array}$ & Sys. Eng. & 10 \\
\hline $\begin{array}{l}\text { ISSE (International Symposium on } \\
\text { Systems Engineering) }\end{array}$ & Sys. Eng. & 9 \\
\hline $\begin{array}{l}\text { WSC (Winter Simulation } \\
\text { Conference) }\end{array}$ & Sim. & 9 \\
\hline $\begin{array}{l}\text { ICEIS (International Conference } \\
\text { on Enterprise Information } \\
\text { Systems) }\end{array}$ & Sof. Eng. & 8 \\
\hline
\end{tabular}

\begin{tabular}{lll}
\hline Venue & Category & Number of Publications \\
\hline Systems Engineering & Sys. Eng. & 11 \\
Innovations in Systems and Software Engineering & Sof. Eng. & 5 \\
Software and Systems Modeling & Sof. Eng. & 4 \\
\hline
\end{tabular}

main position by considering the statistical distribution based on the number of papers per venues, listed in Table 2. We get a mean value of $13(13,1)$ and a standard deviation of 7 $(6,9)$. Since we identified a spread of 6 to 20 publications per venue in this descriptive statistical analysis, we can classify INCOSE as an outlier compared to the averages of the other conferences.

The second prominent venue is the International Design Engineering Technical Conferences (IDETC/CIE), where 14 papers were submitted and presented. This conference is, among others, one of the main conferences for design engineering mostly related to the manufacturing domain, where SysML fits thematically well, since it is often used in the design phase of automation systems (see Sect. 4.3.1).

The third venue is the International Conference on Emerging Technologies and Factory Automation (ETFA), where 13 papers were submitted. Approaches based on SysML are in line with this conference, since the main topic of this conference is complex systems, and among others, one goal of SysML is to support the modeling of systems considering software as well as hardware components.
All other venues listed in Table 2 have at most 12 publications. Even though these venues are focusing on different subjects, all of them capture the main topics of SysML such as design, simulation, and complex systems. With regard to journals (see Table 3), the listed ones all deal with systems engineering or software engineering topics, whereby the journal Systems Engineering (with a number of 11 publications) has the most published articles with a focus on SysML.

The distribution curve across all these publications (most prominent venues: conferences, journals) in the time frame from 2005 to 2017 regarding the main research communities is shown in Fig. 4. Regarding the number of publications per year, it is obvious that most contributions were published in the field of systems engineering.

Based on the provided information in the relevant abstract of each publication, we classified the publication in various application fields in a double-checking process (extractor/checker). Those publications that do not clearly belong to a specific application field are discussed in the group. If no unambiguous assignment is possible even after this dis- 


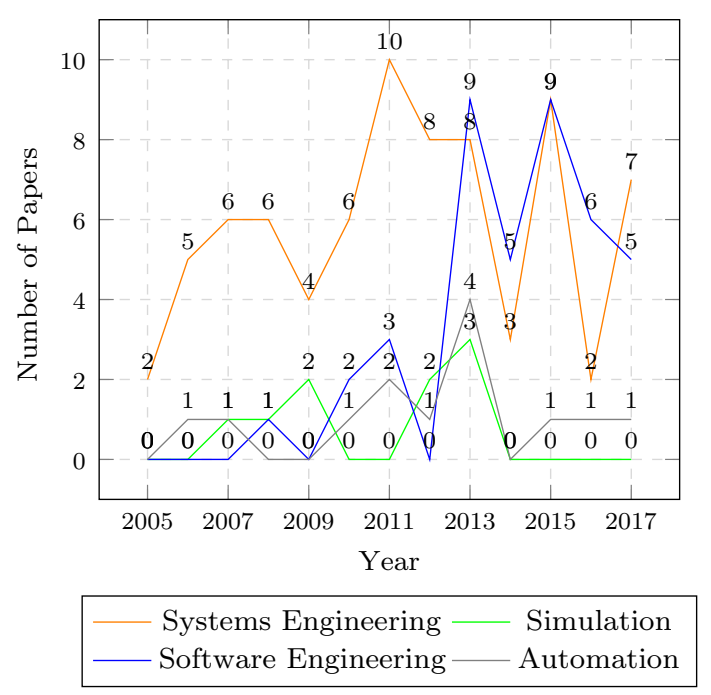

Fig. 4 Number of publications per year regarding the research fields of the 12 most prominent venues (included number of studies: 579)

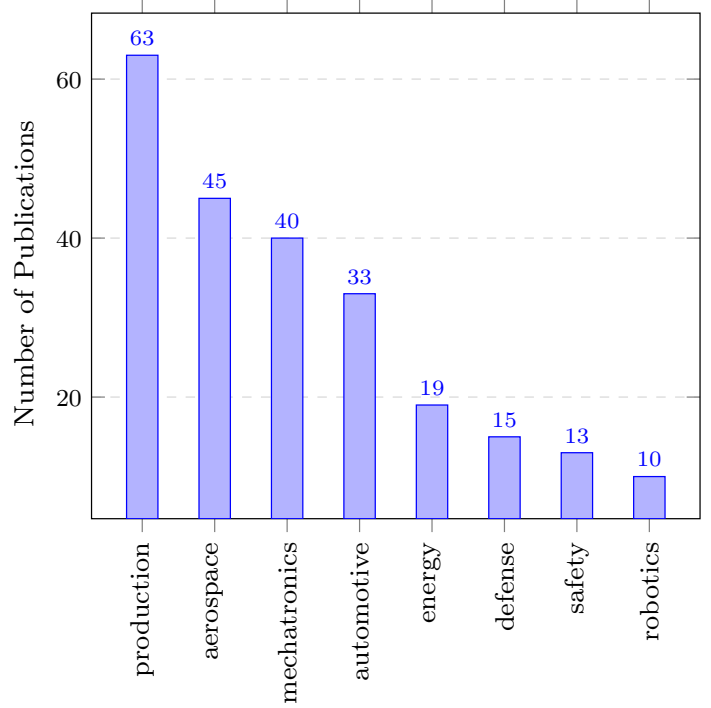

Fig. 5 Application domains with at least 10 publications (included number of studies: 579 )

cussion, the paper is identified as not classified. Based on these two processes, unfortunately 229 paper are not classified in our result set. Figure 5 shows the different application domains that have at least 10 publications. Summarized, SysML is experiencing a strong application in the production area, followed by the aerospace sector (both aircraft and space applications), which is closely followed by the application field of mechatronics. In addition, SysML is frequently used for system engineering modeling in the areas of automotive and energy.

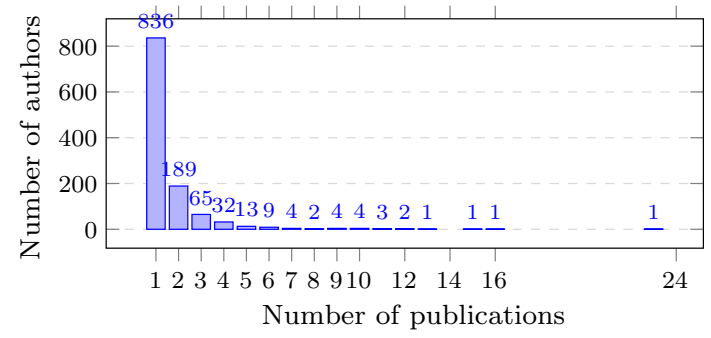

Fig. 6 Number of publications per author (included number of studies: 579)

RQ 1-Main Findings: Generally, SysML is a modeling language to support systems engineers in their work. The findings related to RQ1 show that most of the publications were published in venues with a systems engineering background. However, the analysis of contributions submitted to the main venues of Tables 2 and 3 shows that there is an emerging interest on SysML in the research field of software engineering since 2013 (see Fig. 4). This could be the fact, since systems are becoming more and more software intensive. Another indication is associated with the fact that from 2013 German initiatives increasingly have started to implement the concepts of Industry 4.0 in the production area such as Internet of Things (IoT), Cyber Physical Systems (CPS), Cyber Physical Production Systems (CPPS), which are focusing on both software and hardware. Besides the work of the German initiatives, changes to SysML 1.3 were made in June 2012 concerning the redefinition of physical flows and architectural alignments with UML, which could also be another effect for increasing the attractiveness of SysML in software engineering and systems engineering.

\subsection{RQ 2: research communities and main contributors of SysML topics}

In a first step, we analyzed the number of authors and their publications. We identified in total 1167 authors, of whom 30 are single authors without relationship to any other author of the result set. Twenty-seven of these single or "non-related" authors have published only one publication with a SysML topic. The "related" authors have at least one relationship to an author, who also has published a paper about SysML. Figure 6 illustrates the number of publications per author.

It should be noted that most of the related as well as nonrelated authors (in total 836) have published only a single publication about SysML. However, there are 13 authors, who worked more closely on the topic and wrote at least 10 papers. The specific affiliations of these authors are shown in Fig. 7. It is worth to mention that these 13 authors belong to eight different institutions. Some of them like Hammad, 


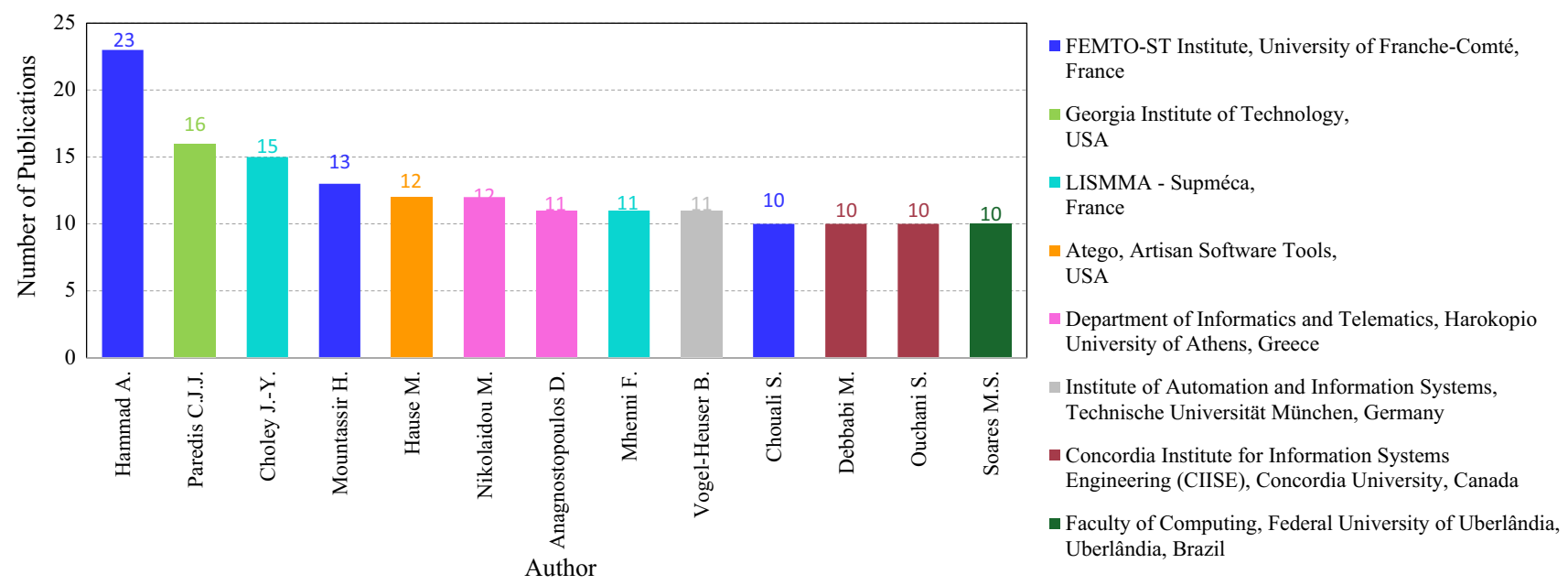

Fig. 7 Affiliation of authors with at least 10 papers (included number of studies: 579)

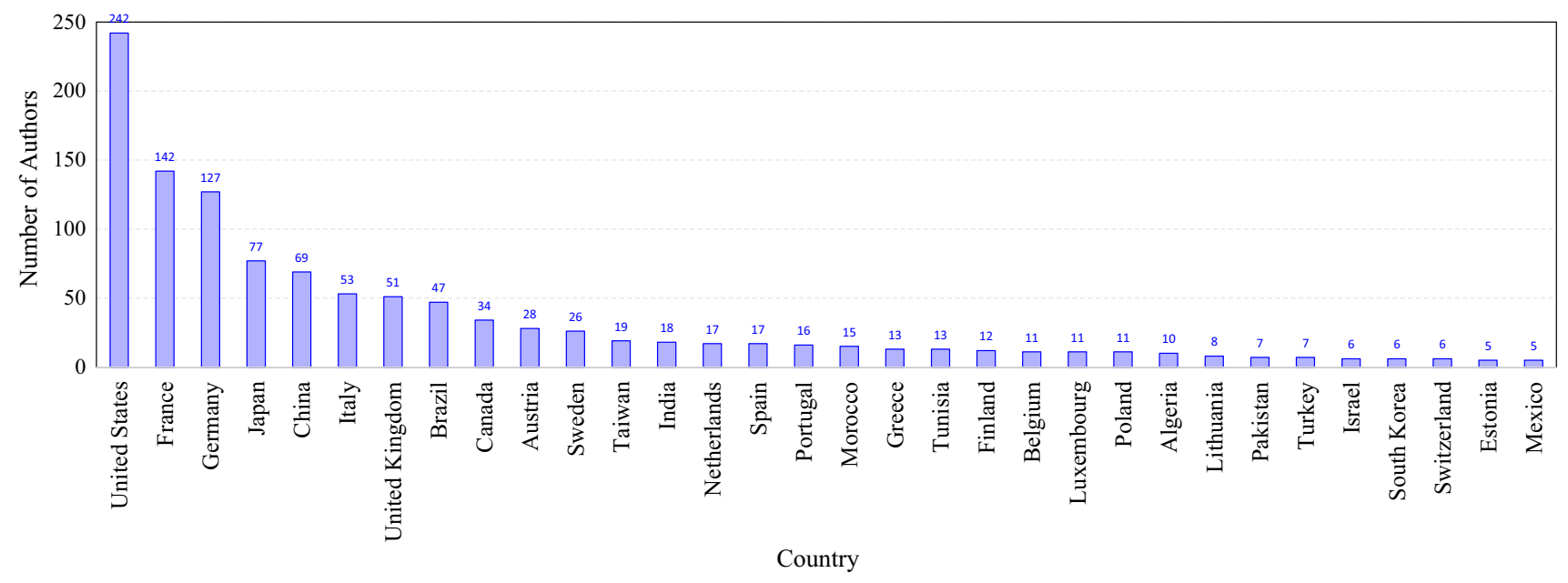

Fig. 8 Number of authors per country with at least 5 authors (included number of studies: 579)

Mountassir, and Chouali are working together in the same research group, whereas other prominent ones like Paredis, Hause, Vogel-Heuser, and Soares publish on behalf of their own research groups.

For deriving the distribution of related and non-related authors over the world, we took a look at their affiliation to a country. Thereby, we found out that most of the authors are from the USA, followed by France, and Germany (see Fig. 8). Figure 9 illustrates the distribution of authors from a continental perspective. Most of the authors are from Europe (48.8\%) followed by North America (23.7\%).

In a next step, we analyzed the relationship among these authors to get an overview of networks between them. For this network analysis, we used the free tool Gephi. ${ }^{4}$ The results of this analysis are shown in Fig. 10. It illustrates all links among the 1167 authors. A link exists as soon as

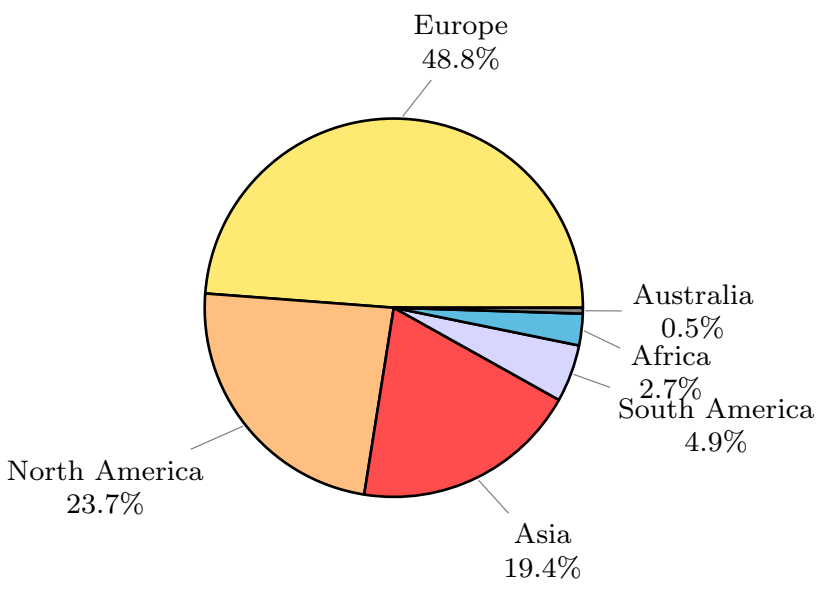

Fig. 9 Percentage of numbers of authors per continent (included number of studies: 579 )

\footnotetext{
${ }^{4}$ https://gephi.org.
} 


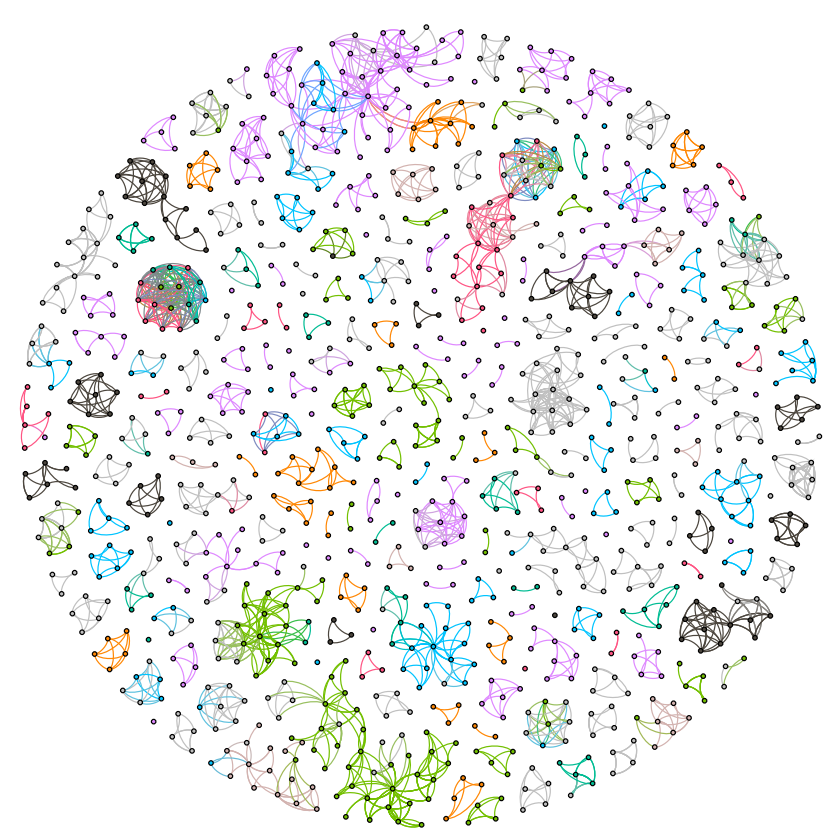

Fig. 10 Connections between authors (created by Gephi, included number of studies: 579 )

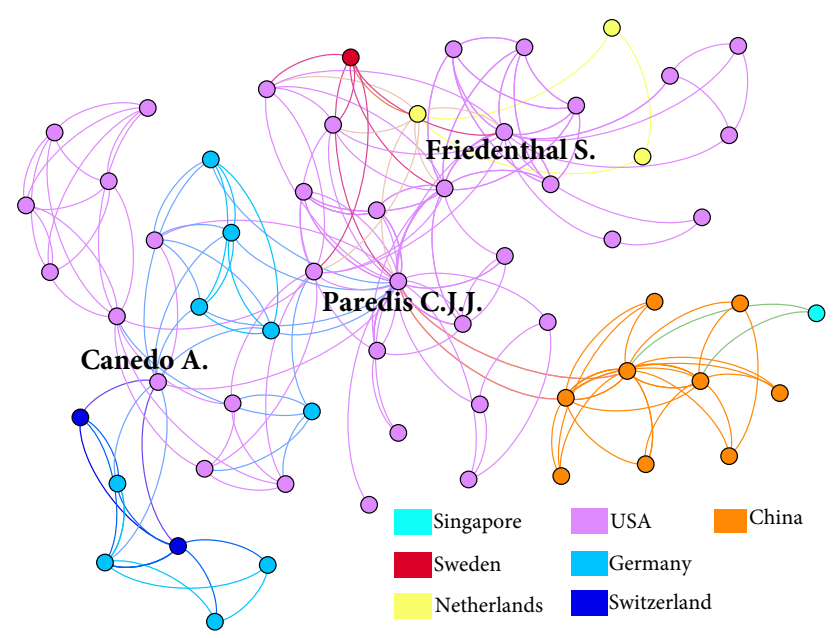

Fig. 11 Biggest network between authors with bridge builder (created by Gephi, included number of studies: 579)

one author worked with another author on the same publication. Based on Fig. 10, we identified that there are several research networks for SysML, but not a single big one. For a deeper analysis, we took a closer look at the largest network in the entire graph. This research network consists of 61 authors and is shown in Fig. 11. In this figure, we only name the so-called "bridge builders," who are the authors Paredis from the Georgia Institute of Technology in Atlanta (USA), Friedenthal from the Lockheed Martin Corporation in Fairfax (USA), and Canedo, who is working at the Siemens Corporation Research in Princeton (USA). These three authors are the anchor points linking the research networks across the world.

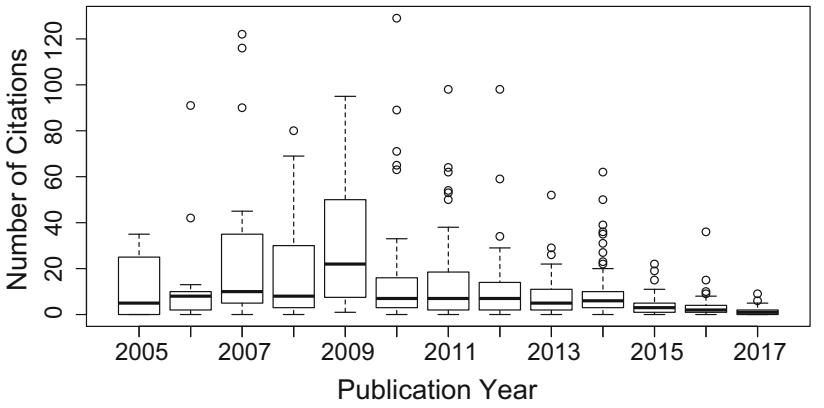

Fig. 12 Distribution of citations of publications by year (included number of studies: 579 )

Finally, we analyzed the influence of the selected publications on the scientific community. We used Google Scholar for counting the citations, since we found no information about citation count in the other used research libraries, except Scopus. In order to make the distribution of citations more comprehensible and to show which publications are cited most frequently in an annual comparison (see Fig. 12, outliers), we have chosen a boxplot for visualization as shown in Fig. 12. The top three papers [12,21,43] are each cited more than 100 times. These three papers are focusing on the SysML topics: simulation, physical systems, and design. These topics, as well as other SysML topics, are one of the most important issues, as the tag cloud shows (see Fig. 14), which we will discuss later on when presenting the results of RQ 4 .

RQ 2-Main Findings: SysML research takes place worldwide with major contributors especially located in the USA, France, and Germany. However, we discovered that the research interest on SysML topics seems to be stronger in Europe rather than in other continents (see Fig. 9). The social network analysis shows an active community that fostered the discussion on SysML over the years. This network created impact in several engineering domains, ranging from frequently cited basic knowledge (e.g., system and simulation modeling using SysML) to contributions on very specific approaches (e.g., SysML4Modelica, SysML4Mechatronic). In addition, the network analysis shows that there are many smaller research groups working on SysML topics. These groups are partly interconnected by so-called "bridge-builders." It can be concluded that the interest on SysML has been expanded, since researchers moved to other research groups, bringing their knowledge and interest on SysML topics in these groups in order to work on further SysML approaches.

\subsection{RQ 3: classification of SysML publications}

For the classification process, we used the definition of categories as described in Sect. 3.3. In a first step, each of us 


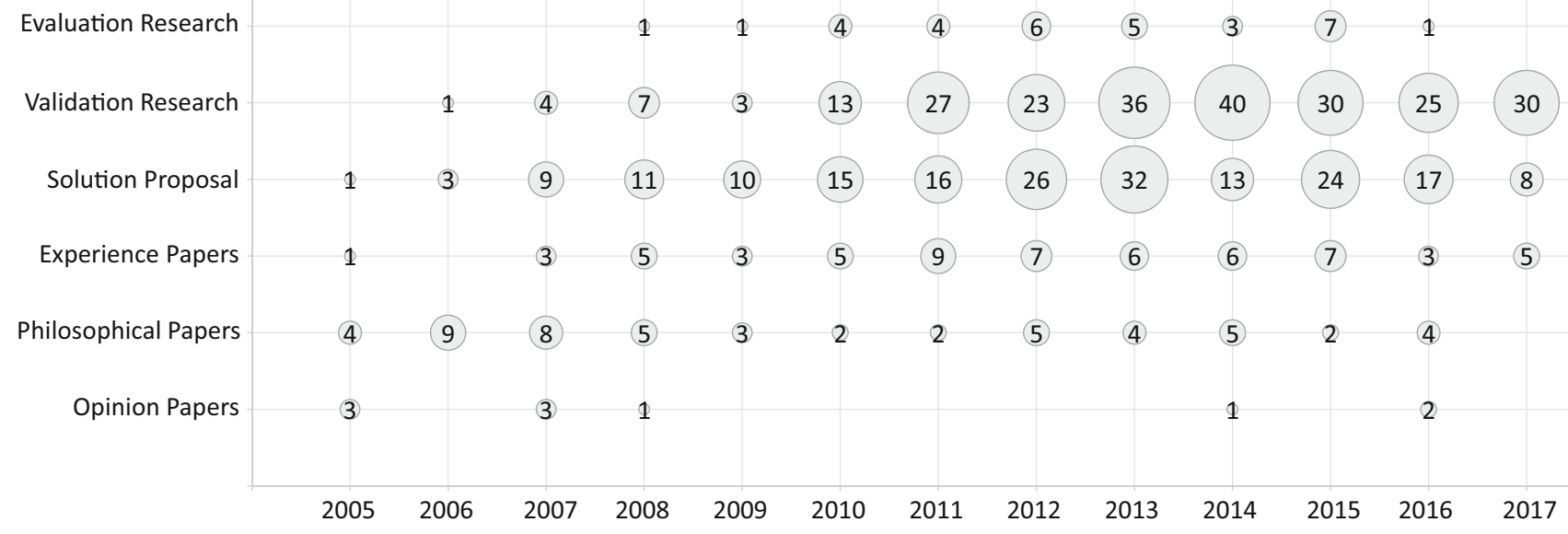

Fig. 13 Number of publications per year according to the type facet classification (included number of studies: 579)

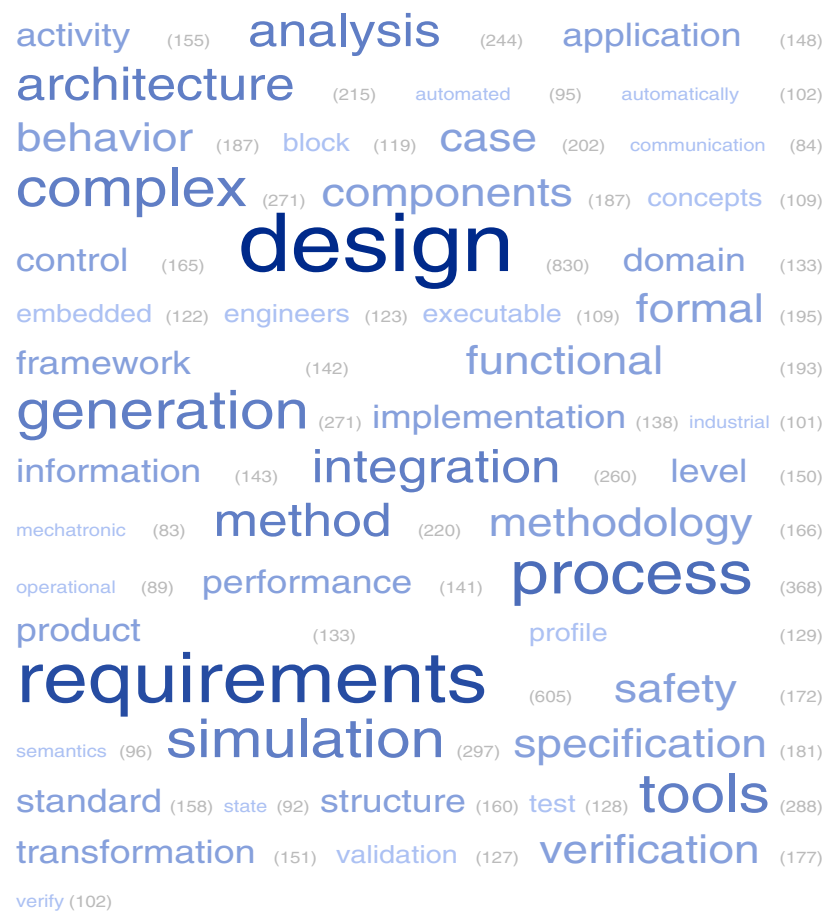

Fig. 14 Tag cloud of most important terms (created with http:// tagcrowd.com/, included number of studies: 579)

individually categorized the abstracts of the selected publications based on one of the six different type facets introduced by Petersen et al. [44] (see Table 1). This classification offers the possibility to find out whether SysML is used in own approaches, in experiments, or in theoretical considerations. In a second step, we discussed the categorizations and potential conflicts in the group. Based on these discussions, the conflicting papers were finally assigned to one category. The results of this classification process are shown in Fig. 13.

The result set comprises 10 opinion papers, 32 evaluation papers, 53 philosophical papers, and 60 experience papers. We found out that philosophical papers are so to speak the "pioneers" in the introductory phase of the standard until about 2007. There are negligibly few opinion papers in the result set. The majority of the publications are assigned to the categories solution proposals (185 papers) and validation research (239 papers). This means that the SysML topic of the majority of papers is an own approach and its sample implementation. Figure 13 shows the result set and its chronological sequence which indicates that from 2010 onward validation research and solution proposal become more and more prominent. There are only few evaluation papers, since this category requires a preceding solution implementation and based on this groundwork an evaluation within a practical setting with an industry partner.

$R Q$ 3-Main Findings: The higher number of philosophical papers in the time period from 2005 to 2007 could be explained by the fact that at the beginning of a new modeling language standard the comparison with other modeling standards is usually the focus. Over time when the standard is established, researchers are more interested to take advantage of the standard to realize own approaches and their implementations. This development has been in the foreground since 2010 .

\subsubsection{RQ 4: key aspects of applying SysML}

Additionally to the categorization of publications based on research type facets, we want to detect the key aspects for applying SysML. For this purpose, we firstly created a tag cloud based on all abstracts of the publications of our result set. (German and French abstracts were translated.) Figure 14 shows this tag cloud, which gives us an overview of the 50 most important keywords (with a frequency of at least 50 times) of the abstracts. It should be mentioned that we have deleted conjunctions and keywords like "SysML," "Systems," "Modeling," "Language" as well as "UML," since we already used them for our general keyword searching when 
conducting the second activity of the mapping process (see Sect. 3.2).

The most frequently used keywords are design, requirements, process, and simulation. Based on the frequency of these keywords, it can be derived that SysML is most frequently used in connection with design and requirement problems. It should be noticed that in this tag cloud every term is counted as often as it occurs in the selected abstracts. In addition, keywords like implementation, verification, and validation frequently appear.

For an even more detailed analysis of the application of SysML topics in the selected publications, we clustered the result set according to systems engineering phases and contribution types, as defined and described in Sect. 3. In the following, we give a summary of the result set analyzed based on engineering phases:

- Requirements: In this initial phase of the engineering process, SysML is used to describe system requirements. The requirements representation is enhanced by a graphical view and by an explicit mapping of the relationships between them. Additionally, the traceability is significantly improved by the so-called "requirements tables." This in SysML newly introduced diagram type helps to bridge the gap between documents written in natural language and modeled use cases. SysML is also used for modeling non-functional requirements. Besides the requirement diagram, the parametric diagram is used to formally describe design requirements for verification and validation purposes.

- Design: We found out that in the design phase, SysML is often used to get a better system understanding and to improve interoperability. In many publications, SysML is used to get a detailed picture of the designed system. Increasingly, SysML is used (i) as modeling language for hardware systems, (ii) for concurrent design processes, (iii) for mechanical concept designs, and (iv) for solving aerospace development problems. Additionally to fulfill special design requirements, SysML is extended by profiles, used in combination with, e.g., MARTE, or mapped to other models.

- Implementation: In the implementation phase, SysML is often used in combination with other languages like SystemC, Modelica, or DEVS to support the implementation of an executable architecture that provides a feasible systems engineering solution. Generally, SysML models are used as basis for the structural and behavioral description of systems. Based on SysML models, executable code is generated by code generators or model transformations are performed by model transformation languages like QVT.

- Validation and Verification: Regarding the V\&V phase, we identified that different approaches deal with (i) model checking for the assessment and evaluation of performance characteristics, (ii) generating automated test cases out of models, and (iii) reliability analysis. The formalization of SysML models allows to building frameworks for the verification and validation of systems design.

Regarding the research results of the contribution type, there are different research fields addressed in the result set, briefly described as follows:

- Technique: There are a lot of different techniques presented in the publications. Most of them deal with (i) efficient modeling of requirements (functional and non-functional), (ii) performing parametric analysis of complex systems, and (iii) verification of designed models.

- Process: It could be identified that the support of the development process of systems stands in the foreground. Most of the presented approaches deal with the development of requirements up to the entire design phase, whereas only few publications address the process beyond the design phase.

- Notation: We found out that in relation to language engineering, most of the publications of the result set deal with SysML profiles. There are extensions and profiles for (i) facilitating the verification of non-functional quantitative requirements, (ii) improving the application of SysML to complex systems, and (iii) using SysML in the automation, mechatronic system, or embedded system domain. In addition to profiles, there are approaches focusing on translation like transformation to Petri Net or Matlab/Simulink. SysML is also used in combination with OCL, OPM, or MARTE.

- Tool: Approaches in this category mostly engage in the development of tools, e.g., to create and versioning SysML models. There are, for example, requirements modeling tools based on SysML and also tools integrating SysML in a process and design optimization framework. Additionally, there exist approaches that use SysML in combination with simulation frameworks or engines like fUML $^{5}$ and James II. ${ }^{6}$

- Specific Solution: There are some specific solutions based on SysML, for example, for space systems, automotive systems, or embedded systems. It can be said that the focus of these solutions is on describing the special requirements of the respective projects.

- Other: The main aspects for assigning publications to the contribution type called "other" are: (i) the comparisons

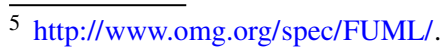

${ }^{6}$ http://jamesii.informatik.uni-rostock.de/jamesii.org/.
} 
Fig. 15 Distribution of publications by systems engineering and contribution (included number of studies: 579)

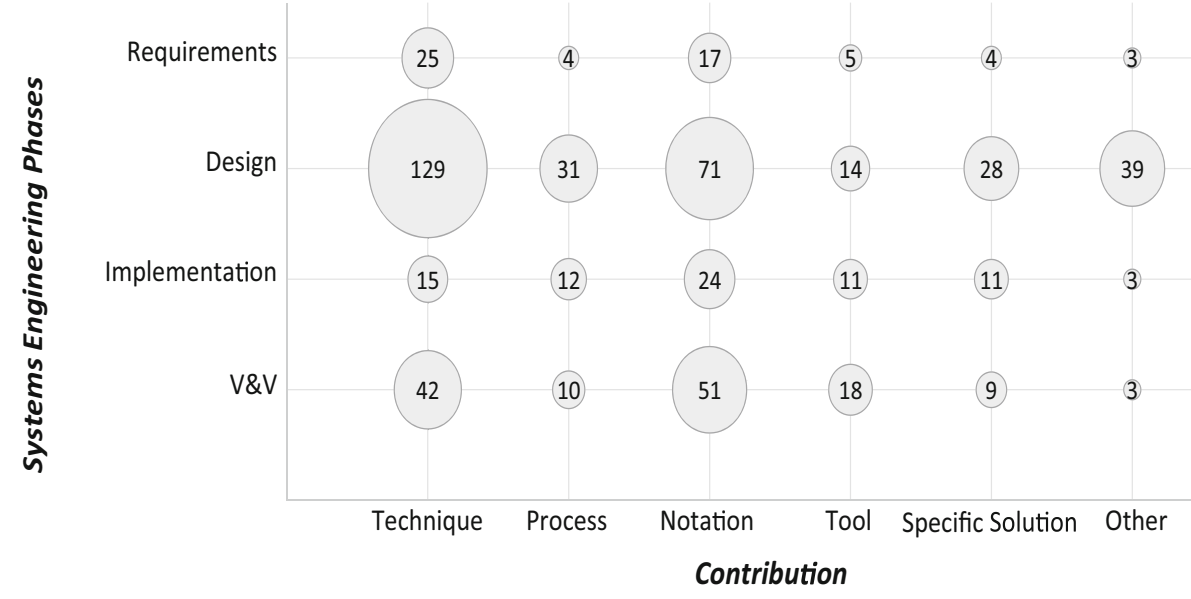

of SysML to other modeling languages, (ii) the analysis of the usability of SysML diagrams like requirement view and parametric diagram, and (iii) teaching systems modeling in SysML.

We connected the results of the systems engineering phases and the contribution types together and visualized it in Fig. 15. The distribution shows that most of the publications deal with problems in the design phase followed by the $\mathrm{V} \& \mathrm{~V}$ phase. To realize their approaches, the authors mostly develop their own techniques and notations.

There are many papers in our result set dealing with SysML extensions or transformations to other languages, techniques, tools, and concepts. Therefore, we have analyzed the information provided in the abstracts for creating a formalism transformation graph (FTG) [34], and additionally based on the same principle, we created a formalism extension graph (FEG).

The FTG graph in Fig. 16 shows the various transformations of SysML to other languages, techniques, tools, and concepts for different application scenarios such as simulation, verification, analysis, and extracting code. ${ }^{7}$ In addition, the FEG in Fig. 17 shows the different extensions of SysML used in the approaches, techniques, and methods introduced and presented in the papers of our result set. ${ }^{8}$ Besides the shown transformations and extensions, there are two publications describing linking techniques for SysML to other languages, one to Relax and one to Simulink.

It can be summarized that most of the SysML publications are directed toward individual approaches for the design or validation of systems. In most cases, established languages, mechanisms for extension, and transformations are used. To illustrate these main findings, we give an overall view in

\footnotetext{
$\overline{7}$ Graph also available at https://figshare.com/s/5de5b35ed2ef8 cdf8317.

${ }^{8}$ Graph also available at https://figshare.com/s/0f0f13ea189b89 1e312f.
}

Fig. 18 where we show the systematic map of SysML publications regarding type facets, systems engineering phases, and contribution types. This figure presents the interplay of all the probed categories and their classification as output of the last activity of the systematic mapping process (see Sect. 3, Fig. 1).

$R Q$ 4-Main Findings: It turns out that in the area of systems engineering the phases design and validation are predominant topics in all type facet categories. Thus, design and validation are clearly the dominant engineering phases in the usage of SysML. Regarding contribution types, we concluded that the types focusing on technology and notation are more likely to be found in the research type facets "Solution Proposals" and "Validation Research." In the other type facets categories, the main contribution type can differ. For instance, presentations of specific solutions is an important input for "Experience Papers."

\section{Threads to validity}

For identifying the threats of validity of our SMS, we follow the four basic types of validity threats according to Wohlin et al. [61]. We address each of these threats in the following subsections.

\subsection{Conclusion validity}

Conclusion validity takes care of issues that might arise when drawing conclusions and whether the SMS can be repeated. According to Wohlin et al. [61], the main focus is to draw a correct conclusion regarding relations between the design and outcome of the study. In the given SMS, threats to conclusion validity include: 


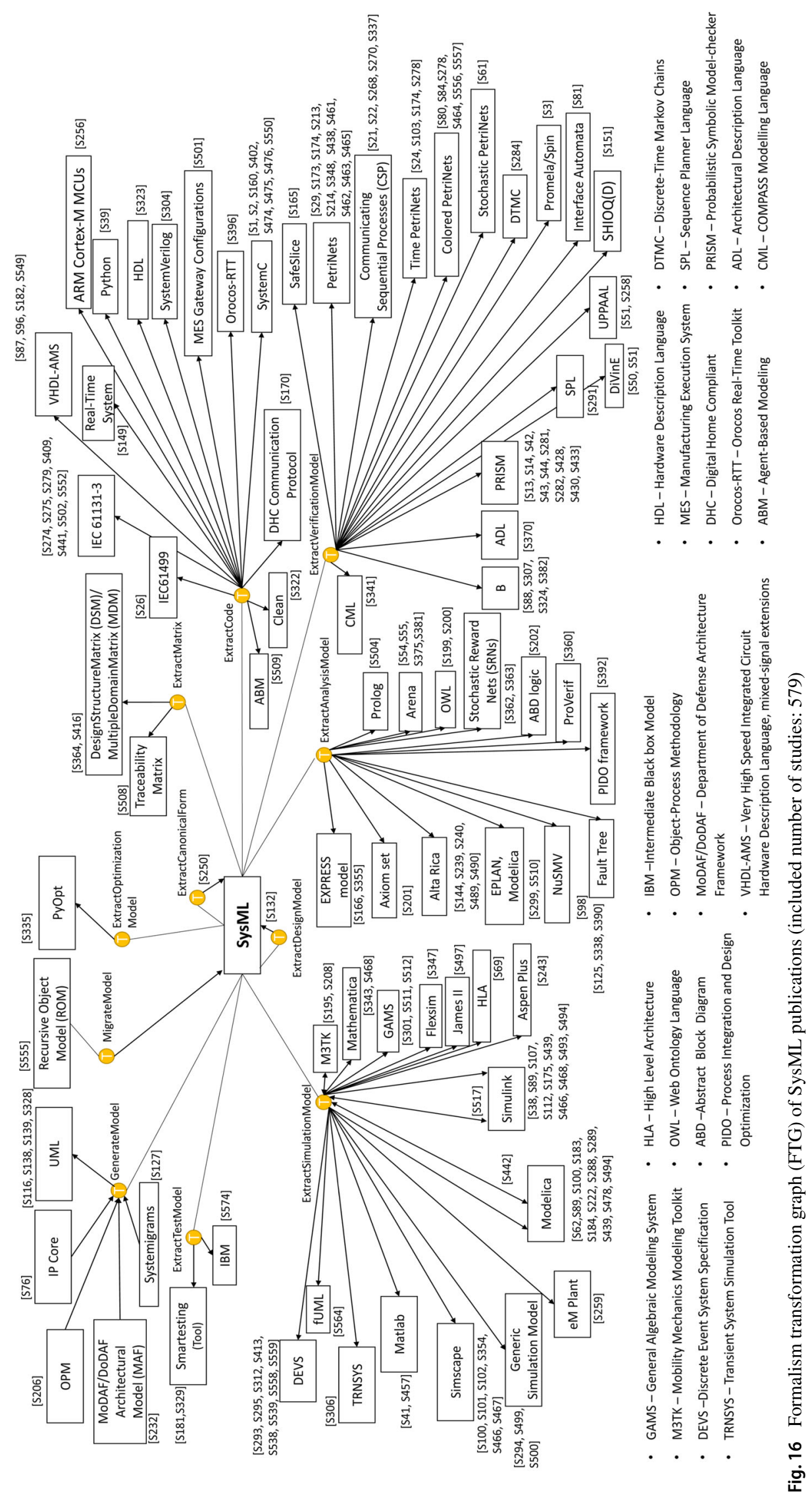




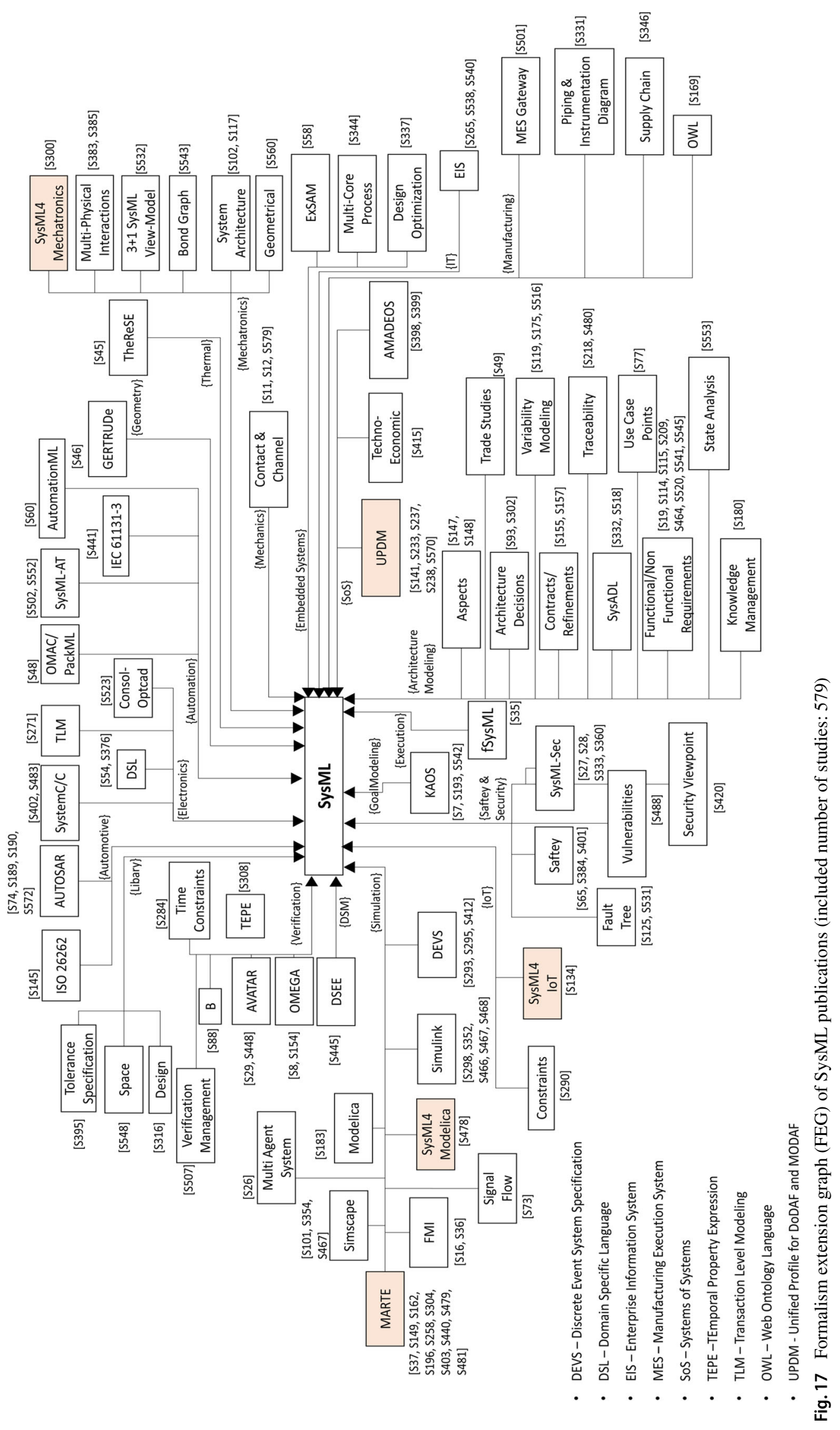


- Subjective measures, such as the manual categorization of abstracts to the research type facets of Petersen et al. [44].

- Low statistical power, due to the restricted amount of identified publications (e.g., a few publications may influence the ranking of prominent contributors).

- Fishing (searching) for specific results, since the results are influenced by the chosen selection of publications (see internal validity).

An additional threat to the validity of the conclusion of a SMS is the publication bias. The term "publication bias" occurs when studies with non-significant findings are either be not submitted by their authors, or may be rejected by reviewers and/or editors and then this could be a risk considering our research type facets. For instance, the risk could be based on the reason that opinion papers are less frequent, since they are more often rejected and become either unofficial technical reports or unpublished studies. To counteract to this risk, we use different databases with various scopes.

As mitigation strategy against subjective measures, the papers of the result set were classified by each of us based on the strategy introduced in Petersen et al. [44], presented in Table 1. Subsequently, these classifications were discussed among themselves. Thereby, occurred discrepancies were considered in more detail and discussed in the group before we re-classified them. Once again, our mitigation strategy against the low statistical power is the use of four different digital libraries to obtain the most complete possible set of papers focusing on SysML as research topic. A comparison with a sampling method such as introduced in [30] would be interesting in order to see whether the same publications would be found. Unfortunately, this investigation goes beyond the scope of this article.

\subsection{Internal validity}

Threats to internal validity address issues that indicate a causal relationship, such as hidden factors. This phenomenon is also known as spurious correlation. Therefore, the main goal is to guarantee that the methods used in the SMS cause the outcome of the survey. It should be mentioned that factors which impact the internal validity are also significantly influencing the process of the research subjects' (i.e., publications') selection. For a better understanding of the internal validity regarding our SMS, we describe in more detail the two influencing factors, selection and instrumentation, based on Wohlin et al. [61], in the following:

\section{- Publication selection based on:}

- Keywords: only the title of publications were searched for the following keywords: 'SysML' or 'System[s] Modeling Language'.
- Time frame: restricted from 2005 to 2017 , since the first draft of SysML specification was published in 2005. The idea of UML for Systems Engineering was already issued in 2003 but with a different naming.

- Literature repositories: we took into account four different literature repositories, which are Scopus, ACM Digital Library, IEEE Xplore Digital Library, as well as DBLP.

- Publication language: only publications with English, German, or French abstracts were considered, even though the repositories have provided additional abstracts satisfying the keywords as well as time frame, like Chinese or Spanish publications.

- Manual filtering: we deleted duplicates, books, and theses, as well as publications without abstract or research context to SysML.

- Instrumentation caused by design of artifacts:

This includes, for instance, timeliness and completeness of literature repositories to answer the question which venues are considered by those libraries. It may be possible to delay previously published articles like in the case of post-proceedings, and therefore, they are not available online.

Our mitigation strategy to address risks of publication selection and instrumentation was to avoid too tight restrictions by considering alternatives. For instance, (i) three different keywords based on our mapping scope were used for the search process, (ii) a time frame was applied that started with the first draft of SysML, and (iii) four broad-based literature repositories were taken into account for conducting the search. In contrast to [63], we use the four libraries ACM, IEEE, DBLP, and Scopus and not, for example, SpringerLink. However, SpringerLink references are included in DBLP and Scopus and therefore implicit in our mapping study. In addition, Scopus contains many publications in the field of systems engineering that do not appear in the other libraries. Thus, by this mitigation strategy, the result set may cover a representative set of relevant publications.

Regarding manual filtering, a certain bias remains according to publications with heterogeneous titles and abstracts, but identical content. We discussed this issue in the group. However, this uncertainty remains open due to method we have chosen for this SMS based on Petersen et al. [44].

\subsection{Construct validity}

Construct validity concerns the relationship between theory and observation. According to Wohlin et al. [61], construct threats to validity cope with issues that might arise during research design. Thus, it should be checked if the used concept is sufficient. There are two kinds of threats to construct 


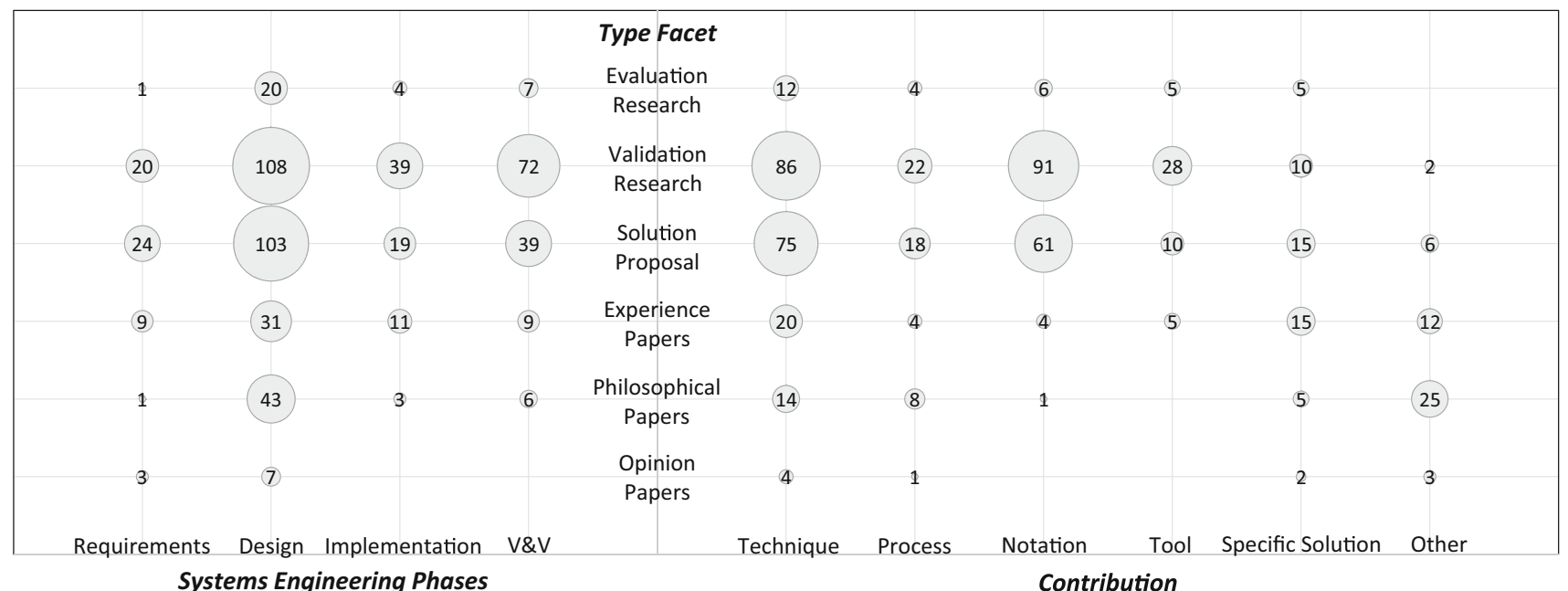

Fig. 18 Systematic map of SysML papers (included number of studies: 579)

validity, which are (i) design threats such as mono-operation bias, mono-method bias, or confounding constructs as well as levels of constructs, and (ii) social threats such as hypothesis guessing, evaluation apprehension, and experimenter expectancies [61]. It should be mentioned that social threats do not apply to non-personal subjects (such as publications); however, they may be relevant regarding the authors of this mapping study [61].

In the given SMS, threats to construct validity include:

- Mono-method bias: the study is mainly based on the systematic mapping process introduced by Petersen et al. [44]. In this context, the mitigation strategy was that two independent research groups have worked cooperatively in this study. In doing so, the first literature review has been independently carried out by each group.

- Confounding constructs and levels of constructs: for instance, in the case of categorization, there is more than only one type facet applicable (e.g., validation research vs. solution proposal). In cases where the levels of applicable type facets are relevant, we selected the most fitting category based on objective aspects and discussion within the group.

- Hypothesis guessing: since the authors of this article are familiar with systems engineering and SysML, some outcomes might be expected such as increasing publications over the years, or close relationships among research groups. We minimized this risk by using an open research design where we have generated knowledge instead of only checking it.

\subsection{External validity}

The external validity is concerned with "generalization," and whether the result of a study can be generalized outside the scope of the study or not. According to this validity, there are three main risk types [61]: (i) interaction of participants and treatment, (ii) interaction of environment/setting and treatment, and (iii) interaction of history/timing and treatment. However, in the presented SMS, we do not aim for generalization. Given our scope (keywords, time frame, etc.), the SMS aimed for completeness; however, no extensive literature survey can ever claim to be complete. Our SMS is concerned with scientific research on SysML and can not be generalized to closely related research field. Although some conclusions could be generalized to a broader topic (e.g., lack of evaluation research studies), we did not draw such general conclusions.

\section{Conclusion and outlook}

In this article, we report on our findings regarding the investigated research topics on SysML over the last thirteen years by performing a systematic mapping study. We found out that initially most of the publications were published in systems engineering venues, but since 2013, the research interest on SysML topics moves more toward software engineering. It may be concluded that this moving interest results from the fact that in 2013 Industry 4.0 initiatives started to implement their visions such as CPPS, IoT, IIoT, and others. Therefore, SysML has been very strongly represented in the production application area since that time. Also it seems that the research interest on SysML topics seems to be stronger in Europe than on other continents, since the Industry 4.0 vision started in Germany. However, in Asia and the USA, there started also similar initiatives known under the umbrella "advanced manufacturing" [10] which also stimulate research on software engineering and SysML.

It can be summarized that out of the nine SysML diagram types, the following ones are mainly used: requirement diagram, parametric diagram, activity diagram, state machine 
diagram, block definition diagram, and internal block diagram. It turned out that the two newly introduced diagram types-requirement diagram and parametric diagram-are accepted and frequently used by the academia research community. SysML is well established as modeling language for designing, analyzing, and verifying complex systems. However, many researchers customize SysML for their purposes, and therefore, define their own profiles since SysML seems still too generic for some domain-specific tasks (e.g., SysML4Modelica [42,50], SysML4Mechatronics [4,24] to mention just a few approaches). An additional finding is that SysML is lacking of operational semantics. Some approaches aim to overcome this gap such as fSysML [3] which is similar to fUML (a foundational subset of UML for executable UML models).

\section{Toward SysML v2}

The OMG is currently working on a new version of SysML in version 2 (abbreviated SysML v2). Based on the first insights from the draft SysML $v 2$ Requirements ${ }^{9}$, it becomes apparent that the main challenges regarding the usage of SysML, which we have identified and discussed in the presented mapping study, were also admitted in the current work of the standardization group. For instance, SysML v2 is intended to expand the requirement diagram by formal definitions of non-textual requirements in order to make these requirements more general and subject to automated validation. Additionally, the draft addresses the issue of ambiguous operational semantics of SysML, trying to solve this ambiguity similarly to the fUML initiative. There are also planned enhancements to have a timing component in models, which is an important issue, e.g., when modeling continuous systems in combination with discrete systems.

Based on the presented SMS and its results and main findings, we identified the following research directions for future work.

\section{Research direction 1: life cycle support}

The results show that there is only limited support when using SysML in the implementation phase, and very limited support for describing the whole life cycle of a system from design until operation and back again, for implementing so-called "liquid models" [36]. Therefore, a future research direction is to exploit and adapt SysML for supporting the execution and analysis of systems during runtime and to align operational data with design models.

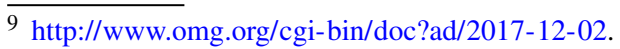

Research direction 2: modeling hybrid systems

Most of the selected publications consider either discrete or continuous challenges when designing systems $[6,23]$. This means that very rarely hybrid solutions in systems design are taken into account [19]. Therefore, further investigations should be undertaken for defining formal semantics for SysML to close the gap when combining discrete and continuous modeling and simulation.

Research direction 3: operational semantics for SysML Currently, there is no support, e.g., to shift property specification and verification tasks up to the model level. There is still a rule-based operational semantics missing to ensure a step-wise, state-based semantics, e.g., to describe a finite execution trace through a sequence of changes. In this context, a future research direction is to define a rule-based operational semantics for SysML, e.g., based on foundations done in the context of fUML.

Research direction 4: deeper analysis of the publication corpus for further research questions Our result set provides a good foundation for deeper analysis for specific topics related to SysML regarding particular research fields. For example, the contribution category notation can be further differentiated into various language engineering aspects (e.g., profiling, translation to another languages, etc.). Based on such analysis, it is possible to characterize similarities and differences among various approaches.

Acknowledgements Open access funding provided by Johannes Kepler University Linz. This work has been supported by the Austrian Federal Ministry for Digital and Economic Affairs, the National Foundation for Research, Technology and Development. The research reported in this paper has also partly been supported by the FWF in the Project TETRABox under the Grant Number P28519-N31, the Austrian Ministry for Transport, Innovation and Technology, and the Province of Upper Austria in the frame of the COMET center SCCH.

Open Access This article is distributed under the terms of the Creative Commons Attribution 4.0 International License (http://creativecomm ons.org/licenses/by/4.0/), which permits unrestricted use, distribution, and reproduction in any medium, provided you give appropriate credit to the original author(s) and the source, provide a link to the Creative Commons license, and indicate if changes were made.

\section{A SysML-papers}

[S1] Abdulhameed, A., Hammad, A., Mountassir, H., Tatibouët, B.: An Approach based on SysML and SystemC to Simulate Complex Systems. In: Proceedings of the 2nd International Conference on Model-Driven Engineering and Software Development (MODELSWARD 2014), Lisbon, Portu- 
gal, January 7-9, pp. 555-560. SciTePress (2014). https://doi.org/10.5220/0004809205550560

[S2] Abdulhameed, A., Hammad, A., Mountassir, H., Tatibouët, B.: An Approach Combining Simulation and Verification for SysML using SystemC and Uppaal. In: Proceedings of the 8th Conference Francophone sur l'Architecture Logicielle (CAL), Paris, France, June 10-11. Revue des Nouvelles Technologies de l'Information (RNTI) (2014)

[S3] Abdulhameed, A., Hammad, A., Mountassir, H., Tatibouet, B.: An approach to verify SysML functional requirements using Promela/SPIN. In: Proceedings of the 12th International Symposium on Programming and Systems (ISPS), Apr., pp. 323-331 (2015). https://doi.org/10.1109/ISPS.2015.7245003

[S4] Abid, A., Barkallah, M., Hammadi, M., Choley, J.Y., Louati, J., Rivière, A., Haddar, M.: Conceptual design of an intelligent welding cell using SysML and holonic paradigm. In: Proceedings of the 6th International Congress on Design and Modeling of Mechanical Systems, Mar 2015, Hammamet, Tunisia, Lecture Notes in Mechanical Engineering, vol. 789, pp. 3-10 (2015). https://doi.org/10.1007/ 978-3-319-17527-0_1

[S5] Abid, A., Hammadi, M., Choley, J.Y., Rivière, A., Barkallah, M., Louati, J., Haddar, M.: A SysML based-methodology for modelling disturbances in manufacturing systems using ADACOR holonic control architecture. In: Proceedings of the 11th France-Japan 9th Europe-Asia Congress on Mechatronics (MECATRONICS) /17th International Conference on Research and Education in Mechatronics (REM), pp. 97-102 (2016). https://doi.org/10.1109/ MECATRONICS.2016.7547123

[S6] Abid, H., Pernelle, P., Noterman, D., Campagne, J.P., Ben Amar, C.: SysML approach for the integration of mechatronics system within PLM systems. International Journal of Computer Integrated Manufacturing 28(9), 972-987 (2015). https://doi.org/10. 1080/0951192X.2014.941938

[S7] Ahmad, M., Bruel, J., Laleau, R., Gnaho, C.: Using RELAX, SysML and KAOS for Ambient Systems Requirements Modeling. In: Proceedings of the 3rd International Conference on Ambient Systems, Networks and Technologies (ANT 2012), the 9th International Conference on Mobile Web Information Systems (MobiWIS-2012), Niagara Falls, Ontario, Canada, August 27-29, Procedia Computer Science, vol. 10, pp. 474-481. Elsevier (2012). https://doi. org/10.1016/j.procs.2012.06.061

[S8] Ahmad, M., Dragomir, I., Bruel, J., Ober, I., Belloir, N.: Early Analysis of Ambient Systems SYSML Properties using OMEGA2-IFx. In: SIMULTECH
2013 - Proceedings of the 3rd International Conference on Simulation and Modeling Methodologies, Technologies and Applications, Reykjavík, Iceland, July 29-31, pp. 147-154. SciTePress (2013). https:// doi.org/10.5220/0004483101470154

[S9] Ahram, T., Karwowski, W.: Human Systems Integration Modeling Using Systems Modeling Language. In: Proceedings of the 53rd Human Factors and Ergonomics Society Annual Meeting, vol. 3, pp. 1849-1853 (2009)

[S10] Al-Fedaghi, S.: Systems Design: SysML vs. Flowthing Modeling. International Journal of Software Engineering and its Applications 8(1), 355-370 (2014). https://doi.org/10.14257/ijseia.2014.8.1.31

[S11] Albers, A., Zingel, C.: Interdisciplinary Systems Modeling Using the Contact \& Channel-Model for SysML. In: Proceedings of the 18th International Conference on Engineering Design - Impacting Society Through Engineering Design (ICED 11), vol. 9, pp. 196-207 (2011)

[S12] Albers, A., Zingel, C.: Extending SysML for Engineering Designers by Integration of the Contact \& Channel - Approach $\left(C \& C^{2}-A\right)$ for FunctionBased Modeling of Technical Systems. In: Proceedings of the Conference on Systems Engineering Research, CSER 2013, Atlanta, Georgia, USA, March 19-22, Procedia Computer Science, vol. 16, pp. 353-362. Elsevier (2013). https://doi.org/10. 1016/j.procs.2013.01.037

[S13] Ali, S., Basit-Ur-Rahim, M., Arif, F.: Formal verification of internal block diagram of SysML for modeling real-time system. In: Proceedings of the IEEE/ACIS 16th International Conference on Software Engineering, Artificial Intelligence, Networking and Parallel/Distributed Computing, SNPD 2015, Takamatsu, Japan, June 1-3, pp. 617-622. IEEE Computer Society (2015). https://doi.org/10.1109/ SNPD.2015.7176271

[S14] Ali, S., Basit-Ur-Rahim, M., Arif, F.: Formal Verification of Time Constrains SysML Internal Block Diagram Using PRISM. In: Proceedings of the 15th International Conference on Computational Science and Its Applications, ICCSA 2015, Banff, AB, Canada, June 22-25, pp. 62-66. IEEE Computer Society (2015). https://doi.org/10.1109/ICCSA.2015. 11

[S15] Alt, O.: Integration textueller Anforderungen und Modell-basiertem Testen mit SysML. Softwaretechnik-Trends 28(3) (2008)

[S16] Amálio, N., Payne, R., Cavalcanti, A., Woodcock, J.: Checking SysML Models for Co-simulation. In: Proceedings of the Formal Methods and Software Engineering: 18th International Conference on For- 
mal Engineering Methods, ICFEM 2016, Tokyo, Japan, November 14-18, LNCS, vol. 10009, pp. 450-465. Springer International Publishing (2016). https://doi.org/10.1007/978-3-319-47846-3_28

[S17] Ambert, F., Bouquet, F., Lasalle, J., Legeard, B., Peureux, F.: Applying a Def-Use Approach on Signal Exchange to Implement SysML Model-Based Testing. In: Proceedings of the 9th European Conference on Modelling Foundations and Applications (ECMFA 2013), Montpellier, France, July 1-5, Lecture Notes in Computer Science, vol. 7949, pp. 134-151. Springer (2013). https://doi.org/10.1007/ 978-3-642-39013-5_10

[S18] Ammar, N., Chaieb, H., Bouallegue, R.: From Modeling with SysML to Simulation with Contiki Cooja Simulator of Wireless Sensor Networks. In: Proceedings of the 30th International Conference on Advanced Information Networking and Applications Workshops (WAINA), pp. 760-765. IEEE Computer Society (2016). https://doi.org/10.1109/ WAINA.2016.64

[S19] Amyot, D., Anda, A.A., Baslyman, M., Lessard, L., Bruel, J.: Towards Improved Requirements Engineering with SysML and the User Requirements Notation. In: Proceedings of the 24th IEEE International Requirements Engineering Conference (RE 2016), Beijing, China, September 12-16, pp. 329334. IEEE (2016). https://doi.org/10.1109/RE.2016. 58

[S20] Andersson, H., Herzog, E., Johansson, G., Johansson, O.: Experience from introducing unified modeling language/systems modeling language at saab aerosystems. Systems Engineering 13(4), 369-380 (2010). https://doi.org/10.1002/sys.20156

[S21] Ando, T., Yatsu, H., Kong, W., Hisazumi, K., Fukuda, A.: Formalization and Model Checking of SysML State Machine Diagrams by CSP\#. In: Proceedings of the 13th International Conference on Computational Science and Its Applications (ICCSA 2013), Ho Chi Minh City, Vietnam, June 24-27, Part III, Lecture Notes in Computer Science, vol. 7973, pp. 114-127. Springer (2013). https://doi.org/10.1007/ 978-3-642-39646-5_9

[S22] Ando, T., Yatsu, H., Kong, W., Hisazumi, K., Fukuda, A.: Translation rules of SysML state machine diagrams into CSP\# toward formal model checking. International Journal of Web Information Systems 10(2), 151-169 (2014). https://doi.org/10. 1108/IJWIS-02-2014-0004

[S23] Andrade, E.C., Machida, F., Kim, D.S., Trivedi, K.S.: Modeling and Analyzing Server System with Rejuvenation through SysML and Stochastic Reward Nets. In: Proceedings of the 6th International Confer- ence on Availability, Reliability and Security (ARES 2011), Vienna, Austria, August 22-26, pp. 161-168. IEEE Computer Society (2011). https://doi.org/10. 1109/ARES.2011.28

[S24] Andrade, E.C., Maciel, P.R.M., de Almeida Callou, G.R., e Silva Nogueira, B.C.: A Methodology for Mapping SysML Activity Diagram to Time Petri Net for Requirement Validation of Embedded Real-Time Systems with Energy Constraints. In: Proceedings of the 3rd International Conference on the Digital Society (ICDS 2009), Cancun, Mexico, February 1-7, pp. 266-271. IEEE Computer Society (2009). https:// doi.org/10.1109/ICDS.2009.19

[S25] Antonio, E., Rovina, R., Fabbri, S.: Verification and Validation Activities for Embedded Systems - A Feasibility Study on a Reading Technique for SysML Models. In: Proceedings of the 16th International Conference on Enterprise Information Systems (ICEIS 2014), Volume 2, Lisbon, Portugal, April 27-30, pp. 233-240. SciTePress (2014). https://doi.org/10.5220/0004887302330240

[S26] Antonova, I., Batchkova, I.: Development of multiagent control systems using UML/SysML. In: Proceedings of the 4th International IEEE Conference Intelligent Systems (IS 2008), vol. 1, pp. 6-26-6-31 (2008). https://doi.org/10.1109/IS.2008.4670435

[S27] Apvrille, L., Roudier, Y.: Designing Safe and Secure Embedded and Cyber-Physical Systems with SysMLSec. In: Proceedings of the 3rd International Conference on Model-Driven Engineering and Software Development, MODELSWARD 2015, Angers, France, February 9-11, Communications in Computer and Information Science, vol. 580, pp. 293308. Springer (2015). https://doi.org/10.1007/9783-319-27869-8_17

[S28] Apvrille, L., Roudier, Y.: SysML-Sec Attack Graphs: Compact Representations for Complex Attacks. In: Proceedings of the 2nd International Workshop on Graphical Models for Security, GraMSec 2015, Verona, Italy, July 13, Lecture Notes in Computer Science, vol. 9390, pp. 35-49. Springer (2015). https://doi.org/10.1007/978-3-319-29968-6_3

[S29] Apvrille, L., de Saqui-Sannes, P.: Static Analysis Techniques to Verify Mutual Exclusion Situations within SysML Models. In: SDL 2013: Model-Driven Dependability Engineering - Proceeding of the 16th International SDL Forum, Montreal, Canada, June 26-28, Lecture Notes in Computer Science, vol. 7916, pp. 91-106. Springer (2013). https://doi.org/ 10.1007/978-3-642-38911-5_6

[S30] Arita, M., Kikuchi, M., Kato, T., Hui, P., Matsumoto, A., Sato, K., Matsuoka, Y.: Timeaxis Design of Health Monitoring Seat System Using M Method 
and SysML. In: Proceedings of the 6th International Conference on Applied Human Factors and Ergonomics and the Affiliated Conferences, AHFE 2015, Procedia Manufacturing, vol. 3, pp. 54355442. Elsevier B.V. (2015). https://doi.org/10.1016/ j.promfg.2015.07.670

[S31] Artery, G., De Spain, M.: Integrating the Life-cycle Process Utilizing SysML. In: Proceedings of the 21st Annual International Symposium of the International Council on Systems Engineering (INCOSE 2011), INCOSE International Symposium, vol. 21, pp. 597609 (2011)

[S32] Artery, G., De Spain, M., Griego, R.: Product life-cycle modeling utilizing SysML modeling. In: Proceedings of the 18th Annual International Symposium of the International Council on Systems Engineering (INCOSE 2008), INCOSE International Symposium, vol. 18, pp. 1406-1420 (2008)

[S33] Auriol, G., Baron, C.: New SysML based approach for integrated system design. In: Proceedings of the 7th International Industrial Simulation Conference (ISC 2009), Loughborough, UK, June 1-3, pp. 111115 (2009)

[S34] Azevedo, K., Bras, B., Doshi, S., Guldberg, T.: Modeling Sustainability of Complex Systems: A MultiScale Framework Using SysML. In: Proceedings of the ASME Design Engineering Technical Conference and Computers and Information in Engineering Conference (DETC 2009), vol. 2, pp. 1437-1448 (2009). https://doi.org/10.1115/DETC2009-87496

[S35] Badreddin, O., Abdelzad, V., Lethbridge, T., Elaasar, M.: fSysML: Foundational Executable SysML for Cyber-Physical System Modeling. In: Proceedings of the 4th International Workshop on the Globalization Of Modeling Languages co-located with ACM/IEEE 19th International Conference on Model Driven Engineering Languages and Systems (MODELS 2016), Saint Malo, France, October 4th, CEUR Workshop Proceedings, vol. 1731, pp. 38-51. CEURWS.org (2016)

[S36] Bagnato, A., Brosse, E., Quadri, I., Sadovykh, A.: SysML for modeling co-simulation orchestration over FMI: The INTO-CPS approach. In: Proceedings of the 21st International Conference on Reliable Software Technologies, Ada-Europe 2016, Ada User Journal, vol. 37, pp. 215-218 (2016)

[S37] Bagnato, A., Quadri, I., Brosse, E., Sadovykh, A., Indrusiak, L., Paige, R., Audsley, N., Gray, I., Kolovos, D., Matragkas, N., Rossi, M., Baresi, L., Crippa, M., Genolini, S., Hansen, S., MeiselBlohm, G.: MADES FP7 EU project: Effective high level SysML/MARTE methodology for real-time and embedded avionics systems. In: Handbook of
Research on Embedded Systems Design, pp. 181208. IGI Global (2014). https://doi.org/10.4018/ 978-1-4666-6194-3.ch008

[S38] Bailey, W.C., Che, J., Tsou, P., Jennings, M.: A Framework for Automated Model Interface Coordination Using SysML. In: Proceedings of the ASME International Design Engineering Technical Conferences \& Computers and Information in Engineering Conference (IDETC/CIE), vol. 1 (2017)

[S39] Balestrini-Robinson, S., Freeman, D., Browne, D.: An object-oriented and executable SysML framework for rapid model development. In: Proceedings of the 2015 Conference on Systems Engineering Research, Procedia Computer Science, vol. 44, pp. 423-432 (2015). https://doi.org/10.1016/j.procs. 2015.03.062

[S40] Balmelli, L.: An overview of the systems modeling language for products and systems development. Journal of Object Technology 6(6), 149-177 (2007)

[S41] Bank, D., Blumrich, F., Kress, P., Stöferle, C.: A systems engineering approach for a dynamic co-simulation of a sysml tool and matlab. In: Proceedings of the 10th Annual International Systems Conference, SysCon 2016, Orlando, FL, USA, April 18-21, pp. 1-6. IEEE (2016). https://doi.org/10. 1109/SYSCON.2016.7490534

[S42] Baouya, A., Bennouar, D., Mohamed, O., Ouchani, S.: A probabilistic and timed verification approach of SysML state machine diagram. In: Proceedings of the 12th International Symposium on Programming and Systems (ISPS), Apr., pp. 304-312 (2015). https://doi.org/10.1109/ISPS.2015.7245001

[S43] Baouya, A., Bennouar, D., Mohamed, O., Ouchani, S.: A quantitative verification framework of SysML activity diagrams under time constraints. Expert Systems with Applications 42(21), 7493-7510 (2015). https://doi.org/10.1016/j.eswa.2015.05.049

[S44] Baouya, A., Bennouar, D., Mohamed, O., Ouchani, S.: On the Probabilistic Verification of Time Constrained SysML State Machines. In: Proceedings of the 14th International Conference on Intelligent Software Methodologies, Tools and Techniques (SoMeT), Naples, Italy, September 15-17, Соттиnications in Computer and Information Science, vol. 532, pp. 425-441. Springer (2015). https://doi.org/ 10.1007/978-3-319-22689-7_33

[S45] Barbedienne, R., Penas, O., Choley, J.Y., Gasser, L.: TheReSE: SysML extension for thermal modeling. In: Proceedings of the 9th Annual IEEE Systems Conference, SysCon 2015, Vancouver, BC, Canada, April 13-16, pp. 301-308. IEEE (2015). https://doi. org/10.1109/SYSCON.2015.7116768 
[S46] Barbedienne, R., Penas, O., Choley, J.Y., Riviere, A., Warniez, A., Della Monica, F.: Introduction of geometrical contraints modeling in SysML for mechatronic design. In: Proceedings of the 10th FranceJapan / 8th Europe-Asia Congress on Mecatronics (MECATRONICS), pp. 145-150 (2014). https://doi. org/10.1109/MECATRONICS.2014.7018580

[S47] Barbieri, G., Kernschmidt, K., Fantuzzi, C., VogelHeuser, B.: A SysML based design pattern for the high-level development of mechatronic systems to enhance re-usability. In: Proceedings of the 19th IFAC World Congress, IFAC Proceedings Volumes, vol. 47, pp. 3431-3437 (2014)

[S48] Bareiß, P., Schütz, D., Priego, R., Marcos, M., Vogel-Heuser, B.: A model-based failure recovery approach for automated production systems combining SysML and industrial standards. In: Proceedings of the 21st IEEE International Conference on Emerging Technologies and Factory Automation, ETFA 2016, Berlin, Germany, September 6-9, pp. 1-7. IEEE (2016). https://doi.org/10.1109/ETFA.2016. 7733720

[S49] Barnes, P.: A NASA Space Communications and Navigation SysML Profile Adaptation. In: Proceedings of the 22nd Annual International Symposium of the International Council on Systems Engineering (INCOSE 2012) and the 8th Biennial European Systems Engineering Conference (EuSEC 2012), INCOSE International Symposium, vol. 22, pp. 1711-1725 (2012)

[S50] Basit Ur Rahim, M., Arif, F., Ahmad, J.: Modeling of Embedded System Using SysML and Its Parallel Verification Using DiVinE Tool. In: Proceedings of the 14th International Conference on Computational Science and Its Applications (ICCSA 2014), Guimarães, Portugal, June 30-July 3, Part V, Lecture Notes in Computer Science, vol. 8583, pp. 541555. Springer (2014). https://doi.org/10.1007/9783-319-09156-3_38

[S51] Basit-Ur-Rahim, M., Arif, F., Ahmad, J.: Modeling of real-time embedded systems using SysML and its verification using UPPAAL and DiVinE. In: Proceedings of the IEEE International Conference on Software Engineering and Service Sciences, ICSESS, pp. 132-136. IEEE (2014). https://doi.org/ 10.1109/ICSESS.2014.6933529

[S52] Bassam, S., Herrmann, J., Schmidt, L.: Using SysML for Model-based Vulnerability Assessment. In: Proceedings of the Conference on Systems Engineering Research, Procedia Computer Science, vol. 44, pp. 413-422 (2015). https://doi.org/10.1016/j.procs. 2015.03.025
[S53] Bassi, L., Secchi, C., Bonfé, M., Fantuzzi, C.: A SysML-Based Methodology for Manufacturing Machinery Modeling and Design. IEEE/ASME Transactions on Mechatronics 16(6), 1049-1062 (2011). https://doi.org/10.1109/TMECH.2010.2073480

[S54] Batarseh, O., McGinnis, L.: SysML to discrete-event simulation to analyze electronic assembly systems. In: Proceedings of the 2012 Symposium on Theory of Modeling and Simulation - DEVS Integrative M\&S Symposium, Orlando, FL, USA, March 26-29, pp. 48:1-48:8. SCS/ACM (2012)

[S55] Batarseh, O., McGinnis, L.F.: System modeling in SysML and system analysis in Arena. In: Winter Simulation Conference, WSC '12, Berlin, Germany, December 9-12, pp. 258:1-258:12. WSC (2012). https://doi.org/10.1109/WSC.2012.6465139

[S56] Batarseh, O.G., Goldlust, E.J., Day, T.E.: SysML for conceptual modeling and simulation for analysis: A case example of a highly granular model of an emergency department. In: Proceedings of the Winter Simulations Conference: Simulation Making Decisions in a Complex World, WSC 2013, Washington, DC, USA, December 8-11, pp. 23982409. IEEE (2013). https://doi.org/10.1109/WSC. 2013.6721614

[S57] Batchkova, I., Antonova, I.: Improving the software development life cycle in process control using UML/SysML. In: Proceedings of the 18th IFAC World Congress, IFAC Proceedings Volumes, vol. 44, pp. 14,133-14,138 (2011). https://doi.org/10.3182/ 20110828-6-IT-1002.03190

[S58] Behjati, R., Yue, T., Nejati, S., Briand, L.C., Selic, B.: Extending SysML with AADL Concepts for Comprehensive System Architecture Modeling. In: Proceedings of the 7th European Conference on Modelling Foundations and Applications (ECMFA 2011), Birmingham, UK, June 6-9, Lecture Notes in Computer Science, vol. 6698, pp. 236-252. Springer (2011). https://doi.org/10.1007/978-3-64221470-7_17

[S59] Belloir, N., Bruel, J., Hoang, N., Pham, C.: Utilisation de SysML pour la modélisation des réseaux de capteurs. In: Langages et Modèles à Objets, LMO 2008, Montréal, Québec, Canada, mars 5-7, RNTI, vol. L-1, pp. 169-184. Cépaduès-Éditions (2008)

[S60] Berardinelli, L., Biffl, S., Lüder, A., Mätzler, E., Mayerhofer, T., Wimmer, M., Wolny, S.: Crossdisciplinary engineering with AutomationML and SysML. At-Automatisierungstechnik 64(4), 253269 (2016). https://doi.org/10.1515/auto-2015-0076

[S61] Berrachedi, A., Rahim, M., Ioualalen, M., Ahmed, H.: Validation of a SysML based design for wireless sensor networks. In: AIP Conference Proceedings 
of the International Conference of numerical analysis and applied mathematics (ICNAAM 2016), vol. 1863 (2017)

[S62] Berrani, S., Hammad, A., Mountassir, H.: Mapping SysML to modelica to validate wireless sensor networks non-functional requirements. In: Proceedings of the 11th International Symposium on Programming and Systems, ISPS 2013, pp. 177-186 (2013). https://doi.org/10.1109/ISPS.2013.6581484

[S63] Bhatia, G., Mesmer, B.: Integrating SysML and value-based design with an NEA scout small satellite example. In: Proceedings of the AIAA SPACE and Astronautics Forum and Exposition, Orlando, FL. American Institute of Aeronautics and Astronautics (2017). https://doi.org/10.2514/6.2017-5234

[S64] Bhuvaneshwari, S., Vaideki, K., Kumar, K., Margret Anouncia, A.: Problem frames analysis over SysML model for critical goods transportation monitoring system. Journal of Theoretical and Applied Information Technology 43(2), 222-228 (2012)

[S65] Biggs, G., Sakamoto, T., Kotoku, T.: A profile and tool for modelling safety information with design information in SysML. Software \& Systems Modeling 15(1), 147-178 (2016). https://doi.org/10.1007/ s10270-014-0400-X

[S66] Bijan, Y., Yu, J., Graves, H., Stracener, J., Woods, T.: Using MBSE with SysML parametrics to perform requirements analysis. In: Proceedings of the $21 \mathrm{st}$ Annual International Symposium of the International Council on Systems Engineering (INCOSE 2011), INCOSE International Symposium, vol. 21, pp. 769782 (2011)

[S67] Biswas, N., Chattopadhyay, S., Mahapatra, G., Chatterjee, S., Mondal, K.C.: SysML Based Conceptual ETL Process Modeling. In: J.K. Mandal, P. Dutta, S. Mukhopadhyay (eds.) Computational Intelligence, Communications, and Business Analytics, pp. 242255. Springer Singapore (2017)

[S68] Bleakley, G., Lapping, A., Whitfield, A.: Determining the right solution using SysML and model based systems engineering (MBSE) for trade studies. In: Proceedings of the 21st Annual International Symposium of the International Council on Systems Engineering (INCOSE 2011), INCOSE International Symposium, vol. 21, pp. 783-795 (2011)

[S69] Bocciarelli, P., D’Ambrogio, A., Fabiani, G.: A Model-driven Approach to Build HLA-based Distributed Simulations from SysML Models. In: Proceedings of the 2nd International Conference on Simulation and Modeling Methodologies, Technologies and Applications, Rome, Italy, July 28-31, pp. 49-60. SciTePress (2012)
[S70] Bocciarelli, P., D’Ambrogio, A., Giglio, A., Gianni, D.: A SaaS-based automated framework to build and execute distributed simulations from SysML models. In: Proceedings of the Winter Simulations Conference: Simulation Making Decisions in a Complex World, WSC 2013, Washington, DC, USA, December 8-11, pp. 1371-1382. IEEE (2013). https://doi. org/10.1109/WSC.2013.6721523

[S71] Bock, C.: SysML and UML 2 support for activity modeling. Systems Engineering 9(2), 160-186 (2006). https://doi.org/10.1002/sys.20046

[S72] Bock, C.: Componentization in the systems modeling language. Systems Engineering 17(4), 392-406 (2014). https://doi.org/10.1002/sys.21276

[S73] Bock, C., Barbau, R., Matei, I., Dadfarnia, M.: An Extension of the Systems Modeling Language for Physical Interaction and Signal Flow Simulation. Systems Engineering 20(5), 395-431 (2017). https:// doi.org/10.1002/sys. 21380

[S74] Boldt, R.: Creating AUTOSAR systems models using the combined power of UML and SysML. Automotive Industries AI 187(11) (2007)

[S75] Bombieri, N., Ebeid, E., Fummi, F., Lora, M.: On the Reuse of RTL IPs for SysML Model Generation. In: Proceedings of the 13th International Workshop on Microprocessor Test and Verification (MTV 2012), Austin, TX, USA, December 10-13, pp. 54-59. IEEE Computer Society (2012). https://doi.org/10. 1109/MTV.2012.10

[S76] Bombieri, N., Ebeid, E., Fummi, F., Lora, M.: On the reuse of heterogeneous IPs into SysML models for integration validation. Journal of Electronic Testing: Theory and Applications (JETTA) 29(5), 647-667 (2013). https://doi.org/10.1007/s10836-013-5409-5

[S77] Bone, M., Cloutier, R.: Applying Systems Engineering Modeling Language (SysML) to System Effort Estimation Utilizing Use Case Points. In: Proceedings of the 21st Annual International Symposium of the International Council on Systems Engineering (INCOSE 2011), INCOSE International Symposium, vol. 21, pp. 114-127 (2011)

[S78] Bonnet, S., Voirin, J.L., Exertier, D., Normand, V.: Not (strictly) relying on SysML for MBSE: Language, tooling and development perspectives: The Arcadia/Capella rationale. In: Proceedings of the 10th Annual International Systems Conference, SysCon 2016, Orlando, FL, USA, April 18-21, pp. 1-6. IEEE (2016). https://doi.org/10.1109/SYSCON. 2016.7490559

[S79] Bostelman, R., Foufou, S., Hong, T., Shah, M.: Model of Mobile Manipulator Performance Measurement using SysML. Journal of Intelligent \& 
Robotic Systems (2017). https://doi.org/10.1007/ s10846-017-0705-4

[S80] Bouabana-Tebibel, T., Rubin, S.H., Bennama, M.: Formal modeling with SysML. In: Proceedings of the 13th IEEE International Conference on Information Reuse \& Integration (IRI 2012), Las Vegas, NV, USA, August 8-10, pp. 340-347. IEEE (2012). https://doi.org/10.1109/IRI.2012.6303029

[S81] Bouaziz, H., Chouali, S., Hammad, A., Mountassir, H.: Compatibility verification of SysML blocks using hierarchical interface automata. In: Proceedings of the 12th International Symposium on Programming and Systems (ISPS), Apr., pp. 313-322 (2015). https://doi.org/10.1109/ISPS.2015.7245002

[S82] Bouaziz, H., Chouali, S., Hammad, A., Mountassir, H.: Exploitation de la Hiérarchie pour la Vérification de la Compatibilité des Blocs SysML. In: Avancées récentes dans le domaine des Architectures Logicielles : articles sélectionnés et étendus de CAL 2015 et MODA 2015, Hammamet, Tunisie, 13-15 Mai, RNTI, vol. L-8, pp. 99-118. Hermann-Éditions (2015)

[S83] Bouaziz, H., Chouali, S., Hammad, A., Mountassir, H.: SysML Blocks Adaptation. In: Proceedings of the 17th International Conference on Formal Engineering Methods (ICFEM), Paris, France, November 3-5, Lecture Notes in Computer Science, vol. 9407, pp. 417-433. Springer (2015). https://doi.org/10. 1007/978-3-319-25423-4_27

[S84] Bouaziz, H., Chouali, S., Hammad, A., Mountassir, H.: A model-driven approach to adapt SysML blocks. In: Proceedings of the 22nd International Conference on Information and Software Technologies, ICIST 2016, Druskininkai, Lithuania, October 13-15, Communications in Computer and Information Science, vol. 639, pp. 255-268 (2016). https:// doi.org/10.1007/978-3-319-46254-7_21

[S85] Bougain, S., Gerhard, D.: A CBR approach for supporting ecodesign with SysML. In: Proceedings of the 21st International Conference on Engineering Design (ICED 17): Product, Services and Systems Design, Vancouver, Canada, 21-25.08, vol. 3, pp. 111-120 (2017)

[S86] Bougain, S., Gerhard, D.: Integrating Environmental Impacts with SysML in MBSE Methods. In: Proceedings of the 24th CIRP Conference on Life Cycle Engineering, Procedia CIRP, vol. 61, pp. 715 - 720 (2017). https://doi.org/10.1016/j.procir.2016. 11.196

[S87] Bouquet, F., Gauthier, J.M., Hammad, A., Peureux, F.: Transformation of SysML structure diagrams to VHDL-AMS. In: Proceedings of the 2nd Workshop on Design, Control and Software Implementation for Distributed (MEMS, dMEMS 2012), pp. 7481. IEEE (2012). https://doi.org/10.1109/dMEMS. 2012.12

[S88] Bousse, E., Mentré, D., Combemale, B., Baudry, B., Katsuragi, T.: Aligning SysML with the B method to provide V\&V for systems engineering. In: Proceedings of the Workshop on Model-Driven Engineering, Verification and Validation, MoDeVVa 2012, Innsbruck, Austria, September, pp. 11-16 (2012). https:// doi.org/10.1145/2427376.2427379

[S89] Branscomb, J.M., Paredis, C., Che, J., Jennings, M.J.: Supporting Multidisciplinary Vehicle Analysis Using a Vehicle Reference Architecture Model in SysML. In: Proceedings of the Conference on Systems Engineering Research, CSER 2013, Atlanta, Georgia, USA, March 19-22, Procedia Computer Science, vol. 16, pp. 79-88. Elsevier (2013). https:// doi.org/10.1016/j.procs.2013.01.009

[S90] Brecher, C., Nittinger, J.A., Karlberger, A.: Modelbased Control of a Handling System with SysML. In: Proceedings of the Conference on Systems Engineering Research, CSER 2013, Atlanta, Georgia, USA, March 19-22, Procedia Computer Science, vol. 16, pp. 197-205. Elsevier (2013). https://doi. org/10.1016/j.procs.2013.01.021

[S91] Breckenridge, J., Johnson, S.: Implementation of a goal-based systems engineering process using the Systems Modeling Language (SysML). In: Proceedings of the AIAA Infotech at Aerospace Conference, Boston, MA, USA, August 19-22 (2013)

[S92] Briand, L., Falessi, D., Nejati, S., Sabetzadeh, M., Yue, T.: Traceability and SysML Design Slices to Support Safety Inspections: A Controlled Experiment. ACM Transactions on Software Engineering and Methodology (TOSEM) 23(1), 9:1-9:43 (2014). https://doi.org/10.1145/2559978

[S93] Broadwell, D., Paredis, C.: Using SysML to Elicit a Value Model in Multi-Stakeholder Value-Driven System Design. In: Proceedings of the ASME 2014 International Design Engineering Technical Conferences and Computers and Information in Engineering Conference, Buffalo, New York, USA, August 17-20, vol. 1B (2014). https://doi.org/10. 1115/DETC201434370

[S94] Browne, D., Kempf, R., Hansen, A., O’Neal, M., Yates, W.: Enabling Systems Modeling Language Authoring in a Collaborative Web-based Decision Support Tool. In: Proceedings of the Conference on Systems Engineering Research, CSER 2013, Atlanta, Georgia, USA, March 19-22, Procedia Computer Science, vol. 16, pp. 373-382. Elsevier (2013). https://doi.org/10.1016/j.procs.2013.01.039 
[S95] Bryans, J., Fitzgerald, J., Payne, R., Miyazawa, A., Kristensen, K.: SysML contracts for systems of systems. In: Proceedings of the 9th International Conference on System of Systems Engineering: The Socio-Technical Perspective, SoSE 2014, Glenelg, Australia, June 9-13, pp. 73-78. IEEE (2014). https://doi.org/10.1109/SYSOSE.2014.6892466

[S96] Café, D.C., Hardebolle, C., Jacquet, C., dos Santos, F.V., Boulanger, F.: Discrete-Continuous Semantic Adaptations for Simulating SysML Models in VHDL-AMS. In: Proceedings of the 8th Workshop on Multi-Paradigm Modeling co-located with the 17th International Conference on Model Driven Engineering Languages and Systems, MPM@ MODELS 2014, Valencia, Spain, September 30, CEUR Workshop Proceedings, vol. 1237, pp. 11-20. CEUR-WS.org (2014)

[S97] Calà, A., Lüder, A., Vollmar, J., Foehr, M.: Evaluation of migration scenarios towards cyber-physical production systems using SysML. In: Proceedings of the IEEE International Systems Engineering Symposium (ISSE), pp. 1-5 (2017). https://doi.org/10. 1109/SysEng.2017.8088287

[S98] Caltais, G., Leitner-Fischer, F., Leue, S., Weiser, J.: SysML to NuSMV Model Transformation via Object-Orientation. In: Proceedings of the 6th International Workshop on Cyber Physical Systems. Design, Modeling, and Evaluation (CyPhy 2016), Pittsburgh, PA, USA, October 6, Lecture Notes in Computer Science, vol. 10107, pp. 31-45. Springer (2016). https://doi.org/10.1007/978-3-31951738-4_3

[S99] Cano, L.: Using SysML to model complex systems for security. In: Proceedings of the 44th Annual International Carnahan Conference on Security Technology, pp. 66-70. IEEE (2010). https://doi.org/10. 1109/CCST.2010.5678679

[S100] Cao, Y., Liu, Y., Fan, H., Fan, B.: SysML-based uniform behavior modeling and automated mapping of design and simulation model for complex mechatronics. CAD Computer Aided Design 45(3), 764-776 (2013). https://doi.org/10.1016/j.cad.2012. 05.001

[S101] Cao, Y., Liu, Y., Paredis, C.: Integration of SystemLevel Design and Analysis Models of Mechatronic System Behavior Based on SysML and Simscape. In: Proceedings of the ASME Design Engineering Technical Conference and Computers and Information in Engineering Conference, vol. 3, pp. 1099-1108 (2010). https://doi.org/10.1115/DETC2010-28213

[S102] Cao, Y., Liu, Y., Paredis, C.: System-level model integration of design and simulation for mechatronic systems based on SysML. Mechatronics 21(6), 1063-
1075 (2011). https://doi.org/10.1016/j.mechatronics. 2011.05.003

[S103] Carneiro, E., Maciel, P., Callou, G., Tavares, E., Nogueira, B.: Mapping SysML State Machine Diagram to Time Petri Net for Analysis and Verification of Embedded Real-Time Systems with Energy Constraints. In: Proceedings of the International Conference on Advances in Electronics and Microelectronics (ENICS 2008), pp. 1-6 (2008). https:// doi.org/10.1109/ENICS.2008.19

[S104] Carrillo, O., Chouali, S., Mountassir, H.: Formalizing and verifying compatibility and consistency of SysML blocks. ACM SIGSOFT Software Engineering Notes 37(4), 1-8 (2012). https://doi.org/10.1145/ 2237796.2237813

[S105] Carrillo, O., Chouali, S., Mountassir, H.: Incremental Modeling of System Architecture Satisfying SysML Functional Requirements. In: Proceedings of the 10th International Symposium on Formal Aspects of Component Software FACS 2013, Nanchang, China, October 27-29, 2013, Lecture Notes in Computer Science, vol. 8348, pp. 79-99. Springer (2013). https://doi.org/10.1007/978-3-319-07602-7_7

[S106] Chabibi, B., Anwar, A., Nassar, M.: Towards an alignment of SysML and simulation tools. In: Proceedings of the 12th IEEE/ACS International Conference of Computer Systems and Applications, AICCSA 2015, Marrakech, Morocco, November 17-20, pp. 1-6. IEEE (2015). https://doi.org/10. 1109/AICCSA.2015.7507216

[S107] Chabibi, B., Douche, A., Anwar, A., Nassar, M.: Integrating SysML with Simulation Environments (Simulink) by Model Transformation Approach. In: Proceedings of the 25th International Conference on Enabling Technologies: Infrastructure for Collaborative Enterprises (WETICE), pp. 148-150. IEEE Computer Society (2016). https://doi.org/10.1109/ WETICE.2016.39

[S108] Chami, M., Ammar, H., Voos, H., Tuyls, K., Weiss, G.: A Nonparametric Evaluation of SysML-based Mechatronic Conceptual Design. In: Proceedings of the 24th Benelux Conference on Artificial Intelligence (BNAIC) (2012)

[S109] Chami, M., Ammar, H., Voos, H., Tuyls, K., Weiss, G.: Swarm-based evaluation of nonparametric SysML mechatronics system design. In: Proceedings of the IEEE International Conference on Mechatronics (ICM), pp. 436-441. IEEE (2013). https://doi.org/ 10.1109/ICMECH.2013.6518576

[S110] Chami, M., Seemüller, H., Voos, H.: A SysML-based integration framework for the engineering of mechatronic systems. In: Proceedings of IEEE/ASME International Conference on Mechatronic and Embed- 
ded Systems and Applications (MESA), pp. 245250. IEEE (2010). https://doi.org/10.1109/MESA. 2010.5552066

[S111] Chamis, C.: Application of SysML Standards to Space Mission Operations. In: Proceedings of the SpaceOps Conference, Huntsville, Alabama (2010). https://doi.org/10.2514/6.2010-2024

[S112] Chandler, S., Matthews, P.: Through-life systems engineering design \& support with SysML. In: Proceedings of the 2nd International Through-life Engineering Services Conference, Procedia CIRP, vol. 11, pp. 425-430 (2013). https://doi.org/10.1016/ j.procir.2013.07.002

[S113] Chang, C., Lu, C., Hsueh, N., Chu, W.C., Shih, C., Yang, C., Hsiung, P., Koong, C.: SysML-based requirement modeling environment for multicore embedded system. In: Proceedings of the ACM Symposium on Applied Computing (SAC), Sierre, Switzerland, March 22-26, pp. 2224-2228. ACM (2010). https://doi.org/10.1145/1774088.1774555

[S114] Chang, C.H., Lu, C.W., Chu, W.C., Hsiung, P.A., Chang, D.M.: SysML-Based Requirement Management to Improve Software Development. International Journal of Software Engineering and Knowledge Engineering 26(3), 491-511 (2016). https://doi. org/10.1142/S0218194016500200

[S115] Chang, C.H., Lu, C.W., Kao, K.F., Chu, W.C., Yang, C.T., Hsueh, N.L., Hsiung, P.A., Koong, C.S.: A SysML-Based Requirement Supporting Tool for Embedded Software. In: Proceedings of the 5th International Conference on Secure Software Integration and Reliability Improvement (SSIRI), Jeju Island, Korea, June 27-29, pp. 202-206. IEEE Computer Society (2011). https://doi.org/10.1109/ SSIRI-C.2011.34

[S116] Chang, C.H., Lu, C.W., Yang, W., Chu, W.C., Yang, C.T., Tsai, C.T., Hsiung, P.A.: A SysML Based Requirement Modeling Automatic Transformation Approach. In: Proceedings of the IEEE 38th Annual Computer Software and Applications Conference, COMPSAC Workshops 2014, Vasteras, Sweden, July 21-25, pp. 474-479. IEEE Computer Society (2014). https://doi.org/10.1109/COMPSACW.2014. 80

[S117] Chen, R., Liu, Y., Cao, Y., Xu, J.: A SysMLbased modeling language for mechatronic system architecture. In: Proceedings of the ASME International Design Engineering Technical Conferences \& Computers and Information in Engineering Conference (IDETC/CIE), Boston, Massachusetts, USA, August 2-5, vol. 1B (2015). https://doi.org/10.1115/ DETC2015-46738
[S118] Chhaniyara, S., Saaj, C., Maediger, B., AlthoffKotzias, M., Langpap, B., Ahrns, I.: SysML based system engineering: A case study for Space Robotics Systems. In: Proceedings of the 62nd International Astronautical Congress (IAC 2011), Cape Town, South Africa, vol. 9, pp. 7271-7278 (2011)

[S119] Chiquitto, A., Gimenes, I., Oliveira, E.: SyMPLESCVL: A SysML and CVL Based Approach for Product-Line Development of Embedded Systems. In: Proceedings of the 9th Brazilian Symposium on Components, Architectures and Reuse Software (SBCARS), Sept., pp. 21-30 (2015). https://doi.org/ 10.1109/SBCARS.2015.13

[S120] Chiron, F., Kouiss, K.: Design of IEC 61131-3 function blocks using SysML. In: Proceedings of the Mediterranean Conference on Control and Automation (MED 2007), pp. 1-5. IEEE (2007). https://doi. org/10.1109/MED.2007.4433695

[S121] Chouali, S., Carrillo, O., Mountassir, H.: Specifying System Architecture from SysML Requirements and Component Interfaces. In: Proceedings of the 7th European Conference on Software Architecture (ECSA 2013), Montpellier, France, July 1-5, Lecture Notes in Computer Science, vol. 7957, pp. 348352. Springer (2013). https://doi.org/10.1007/9783-642-39031-9_36

[S122] Chouali, S., Hammad, A.: Formal verification of components assembly based on SysML and interface automata. Innovations in Systems and Software Engineering 7(4), 265-274 (2011). https://doi.org/ 10.1007/s11334-011-0170-3

[S123] Chouali, S., Hammad, A., Mountassir, H.: Assembling components using SysML with non-functional requirements. Electronic Notes in Theoretical Computer Science 295, 31-47 (2013). https://doi.org/10. 1016/j.entcs.2013.04.003

[S124] Christophe, F., Sell, R., Coatanéa, E.: Conceptual design framework supported by dimensional analysis and system modelling language. Estonian Journal of Engineering 14(4), 303-316 (2008). https://doi. org/10.3176/eng.2008.4.02

[S125] Clark, T., Rabelo, L., Yazici, H.: Extending SysML Models to Enable Automatic Generation of Fault Trees. In: Proceedings of the IIE Annual Conference, pp. 1085-1090 (2017)

[S126] Claver, C., Dubois-Felsmann, G., Delgado, F., Hascall, P., Marshall, S., Nordby, M., Schalk, T., Schumacher, G., Sebag, J.: Using SysML for MBSE analysis of the LSST system. In: Proceedings of SPIE - The International Society for Optical Engineering, vol. 7738, pp. 77,381D-77,381D-10 (2010). https:// doi.org/10.1117/12.857227 
[S127] Cloutier, R., Sauser, B., Bone, M., Taylor, A.: Transitioning systems thinking to model-based systems engineering: Systemigrams to SysML models. IEEE Transactions on Systems, Man, and Cybernetics: Systems 45(4), 662-674 (2015). https://doi.org/10. 1109/TSMC.2014.2379657

[S128] Colombo, P., Del Bianco, V., Lavazza, L.: Towards the integration of SysML and Problem Frames. In: Proceedings of the 3rd International Workshop on Applications and Advances of Problem (IWAAPF 2008), pp. 1-7 (2008). https://doi.org/10. 1145/1370811.1370813

[S129] Colombo, P., Del Bianco, V., Lavazza, L., CoenPorisini, A.: A Methodological Framework for SysML: a Problem Frames-based Approach. In: Proceedings of the 14th Asia-Pacific Software Engineering Conference (APSEC 2007), Nagoya, Japan, December 5-7, pp. 25-32. IEEE Computer Society (2007). https://doi.org/10.1109/APSEC.2007.9

[S130] Colombo, P., Khendek, F., Lavazza, L.: Requirements Analysis and Modeling with Problem Frames and SysML: A Case Study. In: Proceedings of the 6th European Conference on Modelling Foundations and Applications (ECMFA 2010), Paris, France, June 15-18, Lecture Notes in Computer Science, vol. 6138, pp. 74-89. Springer (2010). https://doi.org/10. 1007/978-3-642-13595-8_8

[S131] Colombo, P., Khendek, F., Lavazza, L.: Generating Early Design Models from Requirements Analysis Artifacts Using Problem Frames and SysML. In: Proceedings of the 7th European Conference on Modelling Foundations and Applications (ECMFA 2011), Birmingham, UK, June 6-9, Lecture Notes in Computer Science, vol. 6698, pp. 97-114. Springer (2011). https://doi.org/10.1007/978-3-64221470-7_8

[S132] Colombo, P., Khendek, F., Lavazza, L.: Bridging the gap between requirements and design: An approach based on Problem Frames and SysML. Journal of Systems and Software 85(3), 717-745 (2012). https://doi.org/10.1016/j.jss.2011.09.046

[S133] Constantine, J., Solak, S.: SysML modeling of Offthe-Shelf-Option acquisition for risk mitigation in military programs. Systems Engineering 13(1), 8094 (2010). https://doi.org/10.1002/sys.20134

[S134] Costa, B., Pires, P.F., Delicato, F.C.: Modeling IoT Applications with SysML4IoT. In: Proceedings of the 42th Euromicro Conference on Software Engineering and Advanced Applications, SEAA 2016, Limassol, Cyprus, August 31-Sept. 2, pp. 157-164. IEEE Computer Society (2016). https://doi.org/10. 1109/SEAA.2016.19
[S135] Costa, T., Sampaio, A., Alves, G.: Using SysML in Systems Design. In: Proceedings of the International Conference on Information Management, Innovation Management and Industrial Engineering (ICIII 2009), vol. 4, pp. 615-618. IEEE (2009). https://doi. org/10.1109/ICIII.2009.607

[S136] Ćwikła, G., Gwiazda, A., Banaś, W., Monica, Z., Foit, K.: Analysis of the possibility of SysML and BPMN application in formal data acquisition system description. In: IOP Conference Series: Materials Science and Engineering, vol. 227 (2017)

[S137] Da Silva, A., Linhares, M., Padilha, R., Roqueiro, N., De Oliveira, R.: An Empirical Study of SysML in the Modeling of Embedded Systems. In: Proceedings of the IEEE International Conference on Systems, Man and Cybernetics, Taipei, Taiwan, October 811, pp. 4569-4574. IEEE (2006). https://doi.org/10. 1109/ICSMC.2006.384866

[S138] Da Silva Melo, M., França, J., Oliveira E., J., Soares, M.: A Model-driven Approach to Transform SysML Internal Block Diagrams to UML Activity Diagrams. In: Proceedings of the 17th International Conference on Enterprise Information Systems (ICEIS), Barcelona, Spain, April 27-30, vol. 2, pp. 92-101. SciTePress (2015). https://doi. org/10.5220/0005372700920101

[S139] Da Silva Melo, M., Soares, M.: Model-driven Structural Design of Software-intensive Systems Using SysML Blocks and UML Classes. In: Proceedings of the 16th International Conference on Enterprise Information Systems (ICEIS), Lisbon, Portugal, April 27-30, vol. 2, pp. 193-200. SciTePress (2014). https://doi.org/10.5220/0004871301930200

[S140] Dahlweid, M., Brauer, J., Peleska, J.: Model-Based Testing: Automatic Generation of Test Cases, Test Data and Test Procedures from SysML Models. In: Proceedings of the SAE 2015 AeroTech Congress \& Exhibition (AEROTECH), no. 2015-01-2553 in SAE Technical Papers, Sept. SAE International (2015). https://doi.org/10.4271/2015-01-2553

[S141] Dahmann, J., Markina-Khusid, A., Doren, A., Wheeler, T., Cotter, M., Kelley, M.: SysML executable systems of system architecture definition: A working example. In: Proceedings of the Annual IEEE International Systems Conference, SysCon 2017, Montreal, QC, Canada, April 24-27, pp. 16. IEEE (2017). https://doi.org/10.1109/SYSCON. 2017.7934816

[S142] David, P., Idasiak, V., Kratz, F.: Towards a better interaction between design and dependability analysis: Fmea derived from uml/sysml models. In: Proceedings of the ESREL 2008 and 17th SRA- 
Europe Conference, Valencia, Spain, September, pp. 2259-2266 (2008)

[S143] David, P., Idasiak, V., Kratz, F.: Improving reliability studies with SysML. In: Proceedings of the Annual Reliability and Maintainability Symposium, pp. 527-532. IEEE (2009). https://doi.org/10.1109/ RAMS.2009.4914731

[S144] David, P., Idasiak, V., Kratz, F.: Reliability study of complex physical systems using SysML. Reliability Engineering and System Safety 95(4), 431-450 (2010). https://doi.org/10.1016/j.ress.2009.11.015

[S145] David, P., Shawky, M.: Supporting ISO 26262 with SysML, benefits and limits. In: Proceedings of the ESREL 2010, pp. 2000-2008 (2010)

[S146] Day, J., Donahue, K., Ingham, M., Kadesch, A., Kennedy, A., Post, E.: Modeling off-nominal behavior in SysML. In: Proceedings of the AIAA Infotech at Aerospace Conference and Exhibit 2012, Garden Grove, CA, USA (2012)

[S147] De Oliveira, K., França, J., Soares, M.: Extensions of SysML for Modeling an Aspect Oriented Software Architecture with Multiple Views. In: Proceedings of the 10th International Conference on Information Technology: New Generations, ITNG 2013, Las Vegas, Nevada, USA, April 15-17, pp. 680-685. IEEE Computer Society (2013). https://doi.org/10. 1109/ITNG.2013.105

[S148] De Oliveira, K., Soares, M.: Modeling Aspects in Requirements using SysML Extensions. In: Proceedings of the 15th International Conference on Enterprise Information Systems (ICEIS 2013), Volume 2, Angers, France, July 4-7, pp. 126-133. SciTePress (2013). https://doi.org/10.5220/0004419601260133

[S149] Detommasi, G., Vitelli, R., Boncagni, L., Neto, A.: Modeling of marte-based real-time applications with sysml. IEEE Transactions on Industrial Informatics 9(4), 2407-2415 (2013). https://doi.org/10.1109/ TII.2012.2235073

[S150] Deveci, O., Onkol, M., Unver, H., Ozturk, Z.: Design and development of a low-cost solar powered drip irrigation system using Systems Modeling Language. Journal of Cleaner Production 102, 529544 (2015). https://doi.org/10.1016/j.jclepro.2015. 04.124

[S151] Ding, S., Tang, S.Q.: An approach for formal representation of SysML block diagram with description logic SHIOQ(D). In: Proceedings of the 2nd International Conference on Industrial and Information Systems (IIS 2010), vol. 2, pp. 259-261 (2010). https://doi.org/10.1109/INDUSIS.2010.5565700

[S152] Dominguez-Bonilla, C., Gutierrez, A., Jimenez, F., Chamorro, H.R.: SysML methodology for FPGAbased Controller design for quadcopters. In: Pro- ceedings of the 7th Annual Information Technology, Electronics and Mobile Communication Conference (IEMCON), Oct., pp. 1-6 (2016). https://doi.org/10. 1109/IEMCON.2016.7746362

[S153] Dou, Z., Li, H.: Optimization of the border port logistics and the key-factors recognition based-on HLA/SysML. Journal of Coastal Research pp. 104107 (2015). https://doi.org/10.2112/SI73-019.1

[S154] Dragomir, I., Ober, I., Lesens, D.: A Case Study in Formal System Engineering with SysML. In: Proceedings of the 17th IEEE International Conference on Engineering of Complex Computer Systems (ICECCS 2012), Paris, France, July 18-20, pp. 189198. IEEE Computer Society (2012). https://doi.org/ 10.1109/ICECCS.2012.1

[S155] Dragomir, I., Ober, I., Percebois, C.: Integrating verifiable Assume/Guarantee contracts in UML/SysML. In: Proceedings of the 6th International Workshop on Model Based Architecting and Construction of Embedded Systems co-located with ACM/IEEE 16th International Conference on Model Driven Engineering Languages and Systems (MoDELS 2013), Miami, Florida, USA, September 29th, CEUR Workshop Proceedings, vol. 1084. CEUR-WS.org (2013)

[S156] Dragomir, I., Ober, I., Percebois, C.: Safety Contracts for Timed Reactive Components in SysML. In: Proceedings of SOFSEM 2014: Theory and Practice of Computer Science - 40th International Conference on Current Trends in Theory and Practice of Computer Science, Nový Smokovec, Slovakia, January 26-29, Lecture Notes in Computer Science, vol. 8327, pp. 211-222. Springer (2014). https://doi.org/ 10.1007/978-3-319-04298-5_19

[S157] Dragomir, I., Ober, I., Percebois, C.: Contract-based modeling and verification of timed safety requirements within SysML. Software \& Systems Modeling pp. 1-38 (2015). https://doi.org/10.1007/s10270015-0481-1

[S158] Durugbo, C.: Integrated product-service analysis using SysML requirement diagrams. Systems Engineering 16(1), 111-123 (2013). https://doi.org/10. 1002/sys. 21229

[S159] Dutenhoffer, C., Tirona, J.: The value of SysML modeling during system operations: A case study. In: Proceedings of the IEEE Aerospace Conference, pp. 1-10. IEEE (2013). https://doi.org/10.1109/AERO. 2013.6496850

[S160] é, D.C., dos Santos, F.V., Hardebolle, C., Jacquet, C., Boulanger, F.: Multi-paradigm semantics for simulating SysML models using SystemC-AMS. In: Proceedings of the Forum on specification and Design 
Languages, FDL 2013, Paris, France, September 2426, pp. 1-8. IEEE (2013)

[S161] Eisenbart, B., Mandel, C., Gericke, K., Blessing, L.: Integrated function modelling: Comparing the IFM framework with SYSML. In: Proceedings of the International Conference on Engineering Design, ICED, 27-30 July, Politecnico di Milano, Italy, vol. 5, pp. 145-156. Design Society (2015)

[S162] Espinoza, H., Cancila, D., Selic, B., Gérard, S.: Challenges in Combining SysML and MARTE for Model-Based Design of Embedded Systems. In: Proceedings of the 5th European Conference on Model Driven Architecture - Foundations and Applications (ECMDA-FA 2009), Enschede, The Netherlands, June 23-26, Lecture Notes in Computer Science, vol. 5562, pp. 98-113. Springer (2009). https://doi.org/ 10.1007/978-3-642-02674-4_8

[S163] Evensen, K., Weiss, K.: A comparison and Evaluation of Real-Time Software Systems Modeling Languages. In: Proceedings of the AIAA Infotech at Aerospace 2010, Atlanta, Georgia, April 20-22 (2010)

[S164] Evrot, D., Petin, J.F., Morel, G., Lamy, P.: Using SysML for identification and refinement of machinery safety properties. In: Proceedings of the 1 st IFAC Workshop on Dependable Control of Discrete Systems, IFAC Proceedings Volumes (IFACPapersOnline), vol. 40, pp. 127-132 (2007)

[S165] Falessi, D., Nejati, S., Sabetzadeh, M., Briand, L.C., Messina, A.: SafeSlice: a model slicing and design safety inspection tool for SysML. In: Proceedings of the 19th ACM SIGSOFT Symposium on the Foundations of Software Engineering (FSE-19) and 13th European Software Engineering Conference (ESEC-13), Szeged, Hungary, September 5-9, pp. 460-463. ACM (2011). https://doi.org/10.1145/ 2025113.2025191

[S166] Fan, H., Liu, Y., Liu, D., Ye, X.: Automated generation of the computer-aided design model from the system structure for mechanical systems based on systems modeling language. Proceedings of the Institution of Mechanical Engineers, Part B: Journal of Engineering Manufacture 230(5), 883-908 (2016). https://doi.org/10.1177/0954405414560619

[S167] Fan, H., Liu, Y., Liu, Y.: SysML-based model integration for online collaborative design of mechatronic systems. In: Proceedings of the 19th International Conference on Engineering Design (ICED), Seoul, Korea, August 19-22, vol. 9 DS75-09, pp. 237-246 (2013)

[S168] Faria, J., Mahomad, S., Silva, N.: Practical Results from the Application of Model Checking and Test Generation from UML/SysML Models of On-Board
Space Applications. In: Proceedings of the Conference on DAta Systems In Aerospace (DASIA 2009), Noordwijk, Netherlands, ESA SP, vol. 669 (2009)

[S169] Feldmann, S., Kernschmidt, K., Vogel-Heuser, B.: Combining a SysML-based Modeling Approach and Semantic Technologies for Analyzing Change Influences in Manufacturing Plant Models. In: Proceedings of the 47th CIRP Conference on Manufacturing Systems - Variety Management in Manufacturing, Procedia CIRP, vol. 17, pp. 451-456 (2014). https:// doi.org/10.1016/j.procir.2014.01.140

[S170] Fernández, M., Alonso, I., Casanova, E.: Improving the Interoperability in the Digital Home Through the Automatic Generation of Software Adapters from a SysML Model. Journal of Intelligent \& Robotic Systems pp. 1-11 (2016). https://doi.org/10.1007/ s10846-016-0419-z

[S171] Florian, M., Albert, A., Daniel, W., Matthias, B.: Multi-View Modeling in SysML: Thematic Structuring for Multiple Thematic Views. In: Proceedings of the Conference on Systems Engineering Research, CSER 2014, Redondo Beach, CA, USA, March 20-22, Procedia Computer Science, vol. 28, pp. 531-538. Elsevier (2014). https://doi.org/10.1016/j. procs.2014.03.065

[S172] Follmer, M., Hehenberger, P., Punz, S., Zeman, K.: Using SysML in the product development process of mechatronic systems. In: Proceedings of the 11th International Design Conference (DESIGN 2010), pp. 1513-1522 (2010)

[S173] Foures, D., Albert, V., Pascal, J., Nketsa, A.: Automation of SysML activity diagram simulation with model-driven engineering approach. In: Proceedings of the Symposium on Theory of Modeling and Simulation - DEVS Integrative M\&S Symposium, Orlando, FL, USA, March 26-29, pp. 11:1-11:6. SCS/ACM (2012)

[S174] Foures, D., Albert, V., Pascal, J.C.: Activitydiagram2petrinet : Transformation-based model in accordance with the OMG SysML specifications. In: Proceedings of the European Simulation and Modelling Conference (ESM 2011), Guimaraes, Portugal, October, pp. 429-433 (2011)

[S175] Fragal, V.H., Silva, R.F., de Souza Gimenes, I.M., de Oliveira Junior, E.A.: Application Engineering for Embedded Systems - Transforming SysML Specification to Simulink within a Product-Line based Approach. In: Proceedings of the 15th International Conference on Enterprise Information Systems (ICEIS 2013), Volume 2, Angers, France, July 4-7, pp. 94-101. SciTePress (2013). https://doi.org/ 10.5220/0004402600940101 
[S176] Friedl, M., Kellner, A., Weingartner, L.: Integration of domain-specific simulation models into descriptive system models by using SysML. In: Proceedings of the IEEE International Systems Engineering Symposium (ISSE), pp. 1-5 (2017). https://doi.org/10. 1109/SysEng.2017.8088256

[S177] Friedland, B., Eschbacher, G.: Implementing SysML into a feasible systems engineering solution. In: Proceedings of the IIE Annual Conference and Expo 2013, pp. 4066-4075 (2013)

[S178] Gaeta, J., Czarnecki, K.: Modeling aerospace systems product lines in SysML. In: Proceedings of the 19th International Conference on Software Product Line, SPLC 2015, Nashville, TN, USA, July 20-24, pp. 293-302. ACM (2015). https://doi.org/10.1145/ 2791060.2791104

[S179] Gans, H.: Development of a Space Vehicle CONOPS Using SysML and the Unified Profile for DoDAF and MoDAF (UPDM). In: Proceedings of the AIAA SPACE and Astronautics Forum and Exposition, Orlando, FL. American Institute of Aeronautics and Astronautics (2017). https://doi.org/10.2514/6. 2017-5298

[S180] Gardan, J., Matta, N.: Enhancing Knowledge Management into Systems Engineering through New Models in SysML. In: Proceedings of the 27th CIRP Design Conference - Complex Systems Engineering and Development, Cranfield University, UK 10th - 12th May, Procedia CIRP, vol. 60, pp. 169-174 (2017). https://doi.org/10.1016/j.procir.2017.01.052

[S181] Gauthier, J.M.: Test Generation for RTES from SysML Models: Context, Motivations and Research Proposal. In: Proceedings of the 6th IEEE International Conference on Software Testing, Verification and Validation, ICST 2013, Luxembourg, Luxembourg, March 18-22, pp. 503-504. IEEE Computer Society (2013). https://doi.org/10.1109/ICST.2013. 83

[S182] Gauthier, J.M., Bouquet, F., Hammad, A., Peureux, F.: Verification and Validation of Meta-model based Transformation from SysML to VHDL-AMS. In: Proceedings of the 1st International Conference on Model-Driven Engineering and Software Development (MODELSWARD 2013), Barcelona, Spain, February 19-21, pp. 123-128. SciTePress (2013). https://doi.org/10.5220/0004317601230128

[S183] Gauthier, J.M., Bouquet, F., Hammad, A., Peureux, F.: A SysML Formal Framework to Combine Discrete and Continuous Simulation for Testing. In: Proceedings of the 17th International Conference on Formal Engineering Methods, ICFEM 2015, Paris, France, November 3-5, Lecture Notes in Computer
Science, vol. 9407, pp. 134-152. Springer (2015). https://doi.org/10.1007/978-3-319-25423-4_9

[S184] Gauthier, J.M., Bouquet, F., Hammad, A., Peureux, F.: Tooled Process for Early Validation of SysML Models Using Modelica Simulation. In: Proceedings of the 6th International Conference on Fundamentals of Software Engineering,FSEN 2015 Tehran, Iran, April 22-24, Lecture Notes in Computer Science, vol. 9392, pp. 230-237. Springer (2015). https://doi. org/10.1007/978-3-319-24644-4_16

[S185] Gaye, K., Coulibaly, A., Gardoni, M.: Product metamodel based on the coupling of the extended design matrix X -DSM and SysML formalism. In: Proceedings of the 5th International Conference on Industrial Engineering and Operations Management (IEOM), pp. 1-7 (2015). https://doi.org/10.1109/IEOM.2015. 7093881

[S186] Geyer, P.: Systems modeling for building design: A method based on the systems modeling language. In: 18th International Workshop of the European Group for Intelligent Computing in Engineering, EG-ICE 2011, Twente UniversityEnschede, Netherlands, July 6-8 2011 (2014)

[S187] Geyer, P.: Using the Systems Modelling Language (SysML) for decision modelling for sustainable building design. In: eWork and eBusiness in Architecture, Engineering and Construction - Proceedings of the 10th European Conference on Product and Process Modelling, ECPPM 2014, pp. 361-366 (2015)

[S188] Gezer, D., Unver, H., Tascioglu, Y., Celebioglu, K., Aradag, S.: Design and simulation of a SCADA system using SysML and Simulink. In: Proceedings of International Conference on Renewable Energy Research and Applications (ICRERA 2013), pp. 1058-1062 (2013). https://doi.org/10.1109/ICRERA. 2013.6749909

[S189] Giese, H., Hildebrandt, S., Neumann, S.: Towards Integrating SysML and AUTOSAR Modeling via Bidirectional Model Synchronization. In: Proceedings of the Dagstuhl-Workshop MBEES: Modellbasierte Entwicklung eingebetteter Systeme V, Schloss Dagstuhl, Germany, 2009, Tagungsband Modellbasierte Entwicklung eingebetteter Systeme, Informatik-Bericht, vol. 2009-01, pp. 155-164. TU Braunschweig, Institut für Software Systems Engineering (2009)

[S190] Giese, H., Hildebrandt, S., Neumann, S.: Model Synchronization at Work: Keeping SysML and AUTOSAR Models Consistent. In: Graph Transformations and Model-Driven Engineering - Essays Dedicated to Manfred Nagl on the Occasion of his 65th Birthday, Lecture Notes in Computer Science, 
vol. 5765, pp. 555-579. Springer (2010). https://doi. org/10.1007/978-3-642-17322-6_24

[S191] Giorgetti, A., Hammad, A., Tatibouët, B.: Using SysML for Smart Surface Modeling. In: Proceedings of the 1st Workshop on Hardware and Software Implementation and Control of Distributed MEMS (dMEMS 2010), pp. 100-107. IEEE (2010). https:// doi.org/10.1109/dMEMS.2010.22

[S192] Globe, J.: Using SysML to create a simulation conceptual model of a basic ISR survivability test thread. In: Proceedings of the Spring Simulation Interoperability Workshop (Spring SIW), pp. 356-363 (2007)

[S193] Gnaho, C., Semmak, F.: Une extension sysml pour l'ingénierie des exigences non fonctionnelles orientée but. Ingénierie des Systèmes d'Information 16(1), 9-32 (2011). https://doi.org/10.3166/isi.16.1. 9-32

[S194] Gnaho, C., Semmak, F., Laleau, R.: An overview of a SysML extension for goal-oriented NFR modelling: Poster paper. In: Proceedings of the IEEE 7th International Conference on Research Challenges in Information Science, RCIS 2013, Paris, France, May 29-31, pp. 1-2. IEEE (2013). https://doi.org/ 10.1109/RCIS.2013.6577734

[S195] Godart, P., Gross, J., Mukherjee, R., Ubellacker, W.: Generating real-time robotics control software from SysML. In: Proceedings of the IEEE Aerospace Conference, pp. 1-11 (2017). https://doi.org/10.1109/ AERO.2017.7943610

[S196] Gomez, C., DeAntoni, J., Mallet, F.: Multi-view Power Modeling Based on UML, MARTE and SysML. In: Proceedings of the 38th Euromicro Conference on Software Engineering and Advanced Applications (SEAA 2012), Cesme, Izmir, Turkey, September 5-8, pp. 17-20. IEEE Computer Society (2012). https://doi.org/10.1109/SEAA.2012.66

[S197] González Alonso, I., García Fuente, M., Brugos, J.: Using SysML to Describe a New Methodology for Semiautomatic Software Generation from Inferred Behavioral and Data Models. In: Proeceedings of the 4th International Conference on Systems (ICONS 2009), Gosier, Guadeloupe, France, March 1-6, pp. 210-215. IEEE Computer Society (2009). https:// doi.org/10.1109/ICONS.2009.50

[S198] Gotoh, T., Eguchi, T., Koga, T., Aoyama, K.: Modeling for product requirements based on logical structure of product (Model-driven development method for mechanical/electrical/soft integrated products using SysML). Nihon Kikai Gakkai Ronbunshu, C Hen/Transactions of the Japan Society of Mechanical Engineers, Part C 76(771), 2754-2763 (2010)

[S199] Graves, H.: Integrating SysML and OWL. In: Proceedings of the 6th International Conference on
OWL: Experiences and Directions, Chantilly, VA, OWLED'09, vol. 529, pp. 117-124. CEUR-WS.org (2009)

[S200] Graves, H.: Structural Models in Axiomatic SysML. In: Proceedings of the 24th International Workshop on Description Logics (DL 2011), Barcelona, Spain, July 13-16, CEUR Workshop Proceedings, vol. 745. CEUR-WS.org (2011)

[S201] Graves, H.: Integrating Reasoning with SysML. In: Proceedings of the 22nd Annual International Symposium of the International Council on Systems Engineering (INCOSE 2012) and the 8th Biennial European Systems Engineering Conference (EuSEC 2012), INCOSE International Symposium, vol. 22, pp. 2228-2242 (2012)

[S202] Graves, H., Bijan, Y.: Using formal methods with SysML in aerospace design and engineering. Annals of Mathematics and Artificial Intelligence 63(1), 53-102 (2011). https://doi.org/10.1007/s10472-0119267-5

[S203] Grecki, M., Geng, Z., Ayvazyan, G., Simrock, S., Aminov, B.: Application of SysML to design of ATCA based LLRF control system. In: 2008 IEEE Nuclear Science Symposium Conference Record, pp. 44-52 (2008). https://doi.org/10.1109/NSSMIC. 2008.4775248

[S204] Griego, R., Mayes, L., McGrath, D.: Enterprise domain modelling process using sysml for the tooling enterprise at the u.s. nnsa's pantex plant. In: Proceedings of the 17th Annual International Symposium of the International Council on Systems Engineering (INCOSE 2007), INCOSE International Symposium, vol. 17, pp. 1358-1372 (2007)

[S205] Grobshtein, Y., Dori, D.: Evaluating aspects of systems modeling languages by example: SysML and OPM. In: Proceedings of the 18th Annual International Symposium of the International Council on Systems Engineering (INCOSE 2008), INCOSE International Symposium, vol. 18, pp. 1023-1037 (2008)

[S206] Grobshtein, Y., Dori, D.: Generating SysML views from an OPM model: Design and evaluation. Systems Engineering 14(3), 327-340 (2011). https://doi. org/10.1002/sys.20181

[S207] Grobshtein, Y., Perelman, V., Safra, E., Dori, D.: Systems Modeling Languages: OPM Versus SysML. In: Proceedings of the 1st International ICST Conference on Systems Engineering and Modeling (ICSEM 2007), Herzliyya-Haifa, Israel, March 20-23, pp. 102-109. IEEE (2007). https://doi.org/10.1109/ ICSEM.2007.373339

[S208] Gross, J., Mukherjee, R.: Integrating Multibody Simulations With SysML. In: Proceedings of the 
11th International Conference on Multibody Systems, Nonlinear Dynamics, and Control, Boston, Massachusetts, USA, August 2-5, ASME International Design Engineering Technical Conferences and Computers and Information in Engineering Conference, vol. 6 (2015). https://doi.org/10.1115/ DETC2015-48095

[S209] Gruber, K., Huemer, J., Zimmermann, A., Maschotta, R.: Integrated Description of Functional and NonFunctional Requirements for Automotive Systems Design Using SysML. In: Proceedings of the 7th International Conference on System Engineering and Technology (ICSET 2017), Shah Alam, Malaysia, October 2-3, pp. 1-5. IEEE (2017)

[S210] Güdemann, M., Kegel, S., Ortmeier, F., Poenicke, O., Richter, K.: SysML in digital engineering. In: Proceedings of the 1st International Workshop on Digital Engineering (IWDE 2010), Magdeburg, Germany, June 14, pp. 1-8. ACM (2010). https://doi.org/10. $1145 / 1837154.1837155$

[S211] Guillerm, R., Demmou, H., Sadou, N.: Sysml Knowledge base for Designing Dependable Complex System. CoRR abs/1212.4246 (2012)

[S212] Gulias, E., Torreblanca, L., Aguilar, J., Fernandez, C.: Using SysML Modeling to Accurately Represent Automotive Safety Requirements. In: Proceedings of the 4th International Conference in Software Engineering Research and Innovation (CONISOFT), pp. 21-26 (2016). https://doi.org/10.1109/CONISOFT. 2016.12

[S213] Gutierrez, A., Chamorro, H., Jimenez, J.: Hardwarein-the-Loop based SysML for model and control design of interleaved boost converters. In: Proceedings of the IEEE 15th Workshop on Control and Modeling for Power Electronics (COMPEL). IEEE (2014). https://doi.org/10.1109/COMPEL.2014. 6877155

[S214] Gutierrez, A., Chamorro, H., Jimenez, J., Villa, L., Alonso, C.: Hardware-in-the-loop simulation of PV systems in micro-grids using SysML models. In: Proceedings of the IEEE 16th Workshop on Control and Modeling for Power Electronics (COMPEL) (2015). https://doi.org/10.1109/COMPEL.2015.7236466

[S215] Gutierrez, A., Chamorro, H.R., Villa, L.F.L., Jimenez, J.F., Alonso, C.: SysML methodology for HIL implementation of PV models. In: Proceedings of the 17th European Conference on Power Electronics and Applications (EPE'15 ECCE-Europe), Sept., pp. 1-7 (2015). https://doi.org/10.1109/EPE.2015.7309196

[S216] Haan, B.: Examination of the interplay of reliability and security using system modeling language. In: Proceedings of the Annual Reliability and Main- tainability Symposium, pp. 475-480. IEEE (2008). https://doi.org/10.1109/RAMS.2008.4925842

[S217] Haidrar, S., Anwar, A., Roudiès, O.: Towards a generic framework for requirements traceability management for SysML language. In: Proceedings of the 4th IEEE International Colloquium on Information Science and Technology (CiSt 2016), Tangier, Morocco, October 24-26, pp. 210-215. IEEE (2016). https://doi.org/10.1109/CIST.2016.7805044

[S218] Haidrar, S., Anwar, A., Roudiès, O.: A SysMLbased Approach to Manage Stakeholder Requirements Traceability. In: 14th IEEE/ACS International Conference on Computer Systems and Applications, AICCSA 2017, Hammamet, Tunisia, October 30Nov. 3, 2017, pp. 202-207. IEEE (2017). https://doi. org/10.1109/AICCSA.2017.183

[S219] Haley, T., Cerenzia, J., Diederich, D., Friedenthal, S.: Using SysML and UML to develop and implement interoperable system components for engagement simulations. In: Proceedings of the 18th Annual International Symposium of the International Council on Systems Engineering (INCOSE 2008), INCOSE International Symposium, vol. 18, pp. 1011-1022 (2008)

[S220] Haley, T., Friedenthal, S.: Assessing the application of SysML to systems of systems simulations. In: Proceedings of the Simulation Interoperability Workshop Spring 2008, pp. 651-662 (2008)

[S221] Hamilton, M., Hackler, W.: A formal universal systems semantics for SysML. In: Proceedings of the 17th Annual International Symposium of the International Council on Systems Engineering (INCOSE 2007), INCOSE International Symposium, vol. 17, pp. 1333-1357 (2007)

[S222] Hammad, A., Mountassir, H., Chouali, S.: Combining SysML and Modelica to Verify the Wireless Sensor Networks Energy Consumption. In: Proceedings of the 1st International Conference on Model-Driven Engineering and Software Development (MODELSWARD 2013), Barcelona, Spain, February 19-21, pp. 198-201. SciTePress (2013). https://doi.org/10. 5220/0004319601980201

[S223] Hampson, K.: Technical evaluation of the Systems Modeling Language (SysML). In: Proceedings of the Conference on Systems Engineering Research, Procedia Computer Science, vol. 44, pp. 403-412 (2015). https://doi.org/10.1016/j.procs.2015.03.054

[S224] Hanai, R., Saito, H., Nakabo, Y., Fujiwara, K., Ogure, T., Mizuguchi, D., Homma, K., Ohba, K.: RT-component based integration for IEC61508 ready system using SysML and IEC61499 function blocks. In: Proceedings of the IEEE/SICE International Symposium on System Integration (SII 2012), pp. 
105-110 (2012). https://doi.org/10.1109/SII.2012. 6426952

[S225] Handley, H., Amissah, M., Kandemir, C.: Levels of SysML Compatibility for Collaborative Human System Development. In: Proceedings of the Human Factors and Ergonomics Society Annual Meeting, vol. 60, pp. 1711-1715 (2016)

[S226] Hause, M.: Cross-Cutting Concerns and Ergonomic Profiling Using UML/SysML. In: Proceedings of the 16th Annual International Symposium of the International Council on Systems Engineering (INCOSE 2006), INCOSE International Symposium, vol. 16, pp. 179-192 (2006)

[S227] Hause, M.: The OMG Systems Modeling Language (SysML). In: Proceedings of the Conference on DAta Systems In Aerospace (DASIA 2007), no. 638 in ESA SP (2007)

[S228] Hause, M.: Designing mission-critical systems using OMG SysML. Electronics World 114(1865), 20-22 (2008)

[S229] Hause, M., Hummell, J.: Simulation of an electrical network and control system in SysML. In: Proceedings of the 2012 Symposium on Theory of Modeling and Simulation - DEVS Integrative M\&S Symposium, Orlando, FL, USA, March 26-29, pp. 47:1-47:7. SCS/ACM (2012)

[S230] Hause, M., Thom, F.: Modeling High Level Requirements in UML/SysML. In: Proceedings of the 15th Annual International Symposium of the International Council on Systems Engineering (INCOSE 2005), INCOSE International Symposium, vol. 15, pp. 316327 (2005)

[S231] Hause, M., Thom, F.: An integrated safety strategy to model driven development with SysML. In: Proceedings of the 2nd Institution of Engineering and Technology International Conference on System Safety, pp. 124-129. IET (2007). https://doi.org/10. 1049/cp:20070452

[S232] Hause, M., Thom, F.: Bridging the chasm - tracing from architectural frameworks to SysML. In: Proceedings of the 17th Annual International Symposium of the International Council on Systems Engineering (INCOSE 2007), INCOSE International Symposium, vol. 17, pp. 1317-1332 (2007)

[S233] Hause, M., Thom, F.: HCI aspects of SysML and architectural frameworks. In: Proceedings of the 17th Annual International Symposium of the International Council on Systems Engineering (INCOSE 2007), INCOSE International Symposium, vol. 17, pp. 351366 (2007)

[S234] Hause, M., Thom, F.: Building bridges between systems and software with SysML and UML. In: Proceedings of the 18th Annual International Sym- posium of the International Council on Systems Engineering (INCOSE 2008), INCOSE International Symposium, vol. 18, pp. 797-811 (2008)

[S235] Hause, M., Thom, F., Moore, A.: Inside SysML. IEE Electronics Systems and Software 3(3), 20-25 (2005). https://doi.org/10.1049/ess:20050302

[S236] Hause, M.C., Thom, F.: An Integrated MDA Approach with SysML and UML. In: Proceedings of the 13th International Conference on Engineering of Complex Computer Systems (ICECCS 2008), Belfast, Northern Ireland, March 31-April 3, pp. 249-254. IEEE Computer Society (2008). https:// doi.org/10.1109/ICECCS.2008.21

[S237] Hayden, J., Jeffries, A.: On using SysML, DoDAF 2.0 and UPDM to model the architecture for the NOAA's Joint Polar Satellite System (JPSS) Ground System (GS). In: Proceedings of the 12th International Conference on Space Operations (SpaceOps), Stockholm, Sweden, June 11-15 (2012). https://doi. org/10.2514/6.2012-1289592

[S238] He, Z.H., Wang, M.Z.: Dynamic performance and effectiveness evaluation on SysML design. Xi Tong Gong Cheng Yu Dian Zi Ji Shu/Systems Engineering and Electronics 28(11), 1712-1716 (2006)

[S239] Hecht, M., Dimpfl, E., Pinchak, J.: Automated Generation of Failure Modes and Effects Analysis from SysML Models. In: Proceedings of the 25th IEEE International Symposium on Software Reliability Engineering Workshops, ISSRE Workshops, Naples, Italy, November 3-6, pp. 62-65. IEEE Computer Society (2014). https://doi.org/10.1109/ ISSREW.2014.117

[S240] Hecht, M., Nguyen, E., Chuidian, A., Pinchak, J., Dimpfl, E.: Creation of Failure Modes and Effects Analyses from SysML. In: Proceedings of the SAE 2015 AeroTech Congress \& Exhibition (AEROTECH), no. 2015-01-2444 in SAE Technical Papers, Sept. SAE International (2015). https:// doi.org/10.4271/2015-01-2444

[S241] Hecht, M., Tamaki, J., Lo, D.: Modeling of Failure detection and recovery in SysML. In: Proceedings of the IEEE 24th International Symposium on Software Reliability Engineering, ISSRE 2013, Pasadena, CA, USA, November 4-7, pp. 85-95. IEEE Computer Society (2013). https://doi.org/10. 1109/ISSREW.2013.6688879

[S242] Helle, P.: Automatic SysML-based safety analysis. In: Proceedings of the 5th International Workshop on Model Based Architecting and Construction of Embedded Systems, ACES-MB@MoDELS 2012, Innsbruck, Austria, September 30, pp. 19-24. ACM (2012). https://doi.org/10.1145/2432631.2432635 
[S243] Hernandez, C., M., R., Diaz, I., Sanz, R.: Model Based Engineering of Process Plants using SysML. In: Proceedings of the 26th European Symposium on Computer Aided Process Engineering, Computer Aided Chemical Engineering, vol. 38, pp. 12811286. Elsevier (2016). https://doi.org/10.1016/B9780-444-63428-3.50218-6

[S244] Herzig, S., Karban, R., Trancho, G., Dekens, F., Jankevificius, N., Troy, M.: Analyzing the operational behavior of the alignment and phasing system of the thirty meter telescope using SysML. In: 5th Adaptive Optics for Extremely Large Telescopes, 2017 AO4ELT5, vol. 2017-June, pp. 1-12 (2017). https://doi.org/10.26698/AO4ELT5.0023

[S245] Herzog, E., Andersson, H., Hallonquist, J.: Experience from introducing SysML into a large project organisation. In: Proceedings of the 20th Annual International Symposium of the International Council on Systems Engineering (INCOSE 2010), INCOSE International Symposium, vol. 20, pp. 595-604 (2010)

[S246] Herzog, E., Hallonquist, J., Naeser, J.: Systems Modeling with SysML - an experience report. In: Proceedings of the 22nd Annual International Symposium of the International Council on Systems Engineering (INCOSE 2012) and the 8th Biennial European Systems Engineering Conference (EuSEC 2012), INCOSE International Symposium, vol. 22, pp. 600-611 (2012)

[S247] Herzog, E., Pandikow, A.: SysML - an assessment. In: Proceedings of the 15th Annual International Symposium of the International Council on Systems Engineering (INCOSE 2005), INCOSE International Symposium, vol. 15, pp. 293-305 (2005)

[S248] Hetherinton, D.: SysML requirements for training game design. In: Proceedings of the 17th International IEEE Conference on Intelligent Transportation Systems (ITSC), Qingdao, China, October 8-11, pp. 162-167. IEEE (2014). https://doi.org/10.1109/ ITSC.2014.6957684

[S249] Hilken, C., Peleska, J.: Model-Based Testing Against Complex SysML Models. In: Proceedings of the Formal Modeling and Verification of Cyber-Physical Systems, 1st International Summer School on Methods and Tools for the Design of Digital Systems, Bremen, Germany, Sept., pp. 284-286. Springer (2015). https://doi.org/10.1007/978-3-658-09994-7_14

[S250] Hilken, C., Peleska, J., Wille, R.: A Unified Formulation of Behavioral Semantics for SysML Models. In: Proceedings of the 3rd International Conference on Model-Driven Engineering and Software Development, MODELSWARD 2015, ESEO, Angers, Loire Valley, France, 9-11 February, pp.
263-271. SciTePress (2015). https://doi.org/10.5220/ 0005241602630271

[S251] Hinckel, E., Borsato, M., Schmidt, J., MacCari, F., Storrer, P., Onofre, E.: Driving Product Design and Requirements Management with SysML. In: Proceedings of the 23rd ISPE Inc. International Conference on Transdisciplinary Engineering, At Curitiba, Brazil, Advances in Transdisciplinary Engineering, vol. 4, pp. 1071-1080 (2016). https://doi.org/10. 3233/978-1-61499-703-0-1071

[S252] Hiron, E., Miramont, P.: Process Based on SysML for New Launchers System and Software Developments. In: Proceedings of the Conference on DAta Systems In Aerospace (DASIA 2010), Budapest, Hungary, June 1-4, ESA SP, vol. 682 (2010)

[S253] Hochwallner, M., Hörl, M., Dierneder, S., Scheidl, R.: Some Aspects of SysML Application in the Reverse Engineering of Mechatronic Systems. In: Proceedings of the 13th International Conference on Computer Aided Systems Theory (EUROCAST 2011), Las Palmas de Gran Canaria, Spain, February 6-11, Revised Selected Papers, Part II, Lecture Notes in Computer Science, vol. 6928, pp. 8188. Springer (2012). https://doi.org/10.1007/978-3642-27579-1_11

[S254] Hoffmann, H.P.: SysML-based Systems Engineering Using a Model-Driven Development Approach. In: Proceedings of the 16th Annual International Symposium of the International Council on Systems Engineering (INCOSE 2006), INCOSE International Symposium, vol. 16, pp. 804-814 (2006)

[S255] Hörl, M., Hochwallner, M., Dierneder, S., Scheidl, R.: Integration of SysML and Simulation Models for Mechatronic Systems. In: Proceedings of the 13th International Conference on Computer Aided Systems Theory (EUROCAST 2011), Las Palmas de Gran Canaria, Spain, February 6-11, Revised Selected Papers, Part II, Lecture Notes in Computer Science, vol. 6928, pp. 89-96. Springer (2012). https://doi.org/10.1007/978-3-642-27579-1_12

[S256] Hossein, M., Hemmat, A., Mohamed, O., Boukadoum, M.: Towards code generation for ARM Cortex-M MCUs from SysML activity diagrams. In: Proceedings of the IEEE International Symposium on Circuits and Systems, ISCAS 2016, Montréal, QC, Canada, May 22-25, pp. 970-973. IEEE (2016). https://doi.org/10.1109/ISCAS.2016.7527404

[S257] Hsu, J.: Applying systems modeling language to a simple hardware system. In: Proceedings of the 16th Annual International Symposium of the International Council on Systems Engineering (INCOSE 2006), INCOSE International Symposium, vol. 16, pp. 595605 (2006) 
[S258] Huang, C., Huang, Z., Hu, J., Wu, Z., Wang, S.: A MDE-Based Approach to the Safety Verification of Extended SysML Activity Diagram. JSW 10(1), 5670 (2015)

[S259] Huang, E., Ramamurthy, R., McGinnis, L.F.: System and simulation modeling using SysML. In: Proceedings of the Winter Simulation Conference (WSC 2007), Washington, DC, USA, December 912, pp. 796-803. WSC (2007). https://doi.org/10. 1109/WSC.2007.4419675

[S260] Huang, X., Sun, Q., Li, J., Zhang, T.: MDE-Based Verification of SysML State Machine Diagram by UPPAAL. In: Proceedings of the International Conference on Trustworthy Computing and Services (ISCTCS 2012), Communications in Computer and Information Science, vol. 320, pp. 490-497 (2013). https://doi.org/10.1007/978-3-642-35795-4_62

[S261] Huckaby, J., Christensen, H.: Modeling robot assembly tasks in manufacturing using SysML. In: Proceedings of the ISR/ROBOTIK 2014, Munich, Germany, June 2-3, pp. 743-749 (2014)

[S262] Huckaby, J., Christensen, H.I.: A case for SysML in robotics. In: Proceedings of the 2014 IEEE International Conference on Automation Science and Engineering (CASE), New Taipei, Taiwan, August 18-22, pp. 333-338. IEEE (2014). https://doi.org/ 10.1109/CoASE.2014.6899347

[S263] Ingram, C., Andrews, Z., Payne, R.J., Plat, N.: SysML fault modelling in a traffic management system of systems. In: Proceedings of the 9th International Conference on System of Systems Engineering, SoSE 2014, Glenelg, Australia, June 9-13, pp. 124-129. IEEE (2014)

[S264] Iqbal, M., Khan, M.U., Sher, M.: System Analysis and Modeling Using SysML. In: Proceedings of the International Conference on IT Convergence and Security (ICITCS 2012), Pyeong Chang, Korea, December 5-7, Lecture Notes in Electrical Engineering, vol. 215, pp. 1211-1220. Springer (2012). https://doi.org/10.1007/978-94-007-5860-5_145

[S265] Izukura, S., Yanoo, K., Osaki, T., Sakaki, H., Kimura, D., Xiang, J.: Applying a Model-Based Approach to IT Systems Development Using SysML Extension. In: Proceedings of the 14th International Conference on Model Driven Engineering Languages and Systems (MODELS 2011), Wellington, New Zealand, October 16-21, Lecture Notes in Computer Science, vol. 6981, pp. 563-577. Springer (2011). https://doi. org/10.1007/978-3-642-24485-8_41

[S266] Jackson, M., Fernández, M., McVittie, T., Sindiy, O.: Architecting the Human Space Flight program with Systems Modeling Language (SysML). In: Proceed- ings of the AIAA Infotech at Aerospace Conference and Exhibit 2012 (2012)

[S267] Jacobs, J., Simpson, A.: Towards a Process Algebra Framework for Supporting Behavioural Consistency and Requirements Traceability in SysML. In: Proceedings of the 15th International Conference on Formal Engineering Methods, ICFEM 2013, Queenstown, New Zealand, October 29-November 1, Lecture Notes in Computer Science, vol. 8144, pp. 265-280. Springer (2013). https://doi.org/10.1007/ 978-3-642-41202-8_18

[S268] Jacobs, J., Simpson, A.: A formal model of sysml blocks using CSP for assured systems engineering. In: Proceedings of the 3rd International Workshop on Formal Techniques for Safety-Critical Systems, FTSCS 2014, Luxembourg, November 6-7, Communications in Computer and Information Science, vol. 476, pp. 127-141. Springer (2015). https://doi. org/10.1007/978-3-319-17581-2_9

[S269] Jacobs, J., Simpson, A.: On the formal interpretation and behavioural consistency checking of SysML blocks. Software and System Modeling 16(4), 11451178 (2017). https://doi.org/10.1007/s10270-0150511-Z

[S270] Jacobs, J., Simpson, A.C.: On the Formal Interpretation of SysML Blocks Using a Safety Critical Case Study. In: Proceedings of the 8th Brazilian Symposium on Software Components, Architectures and Reuse, SBCARS 2014, Maceió, Alagoas, Brazil, September 29-30, pp. 95-104. IEEE Computer Society (2014). https://doi.org/10.1109/SBCARS.2014. 14

[S271] Jain, V., Kumar, A., Panda, P.R.: A SysML Profile for Development and Early Validation of TLM 2.0 Models. In: Proceedings of the 7th European Conference on Modelling Foundations and Applications (ECMFA 2011), Birmingham, UK, June 6-9, Lecture Notes in Computer Science, vol. 6698, pp. 299-311. Springer (2011). https://doi.org/10.1007/ 978-3-642-21470-7_21

[S272] Jakjoud, A., Zrikem, M., Baron, C., Ayadi, A.: SysPEM: A SysML and SPEM based process modelling language for systems engineering. International Journal of Services Operations and Informatics 7(4), 330-348 (2012). https://doi.org/10.1504/ IJSOI.2012.052183

[S273] Jakob, F., Mazzini, S., Jung, A.: A sysml-based methodology in a concurrent satellite design process. In: Proceedings of the Aerospace Technology Conference and Exposition, SAE Technical Papers (2011). https://doi.org/10.4271/2011-01-2713

[S274] Jamro, M.: Automatic generation of implementation in SysML-based model-driven development for 
IEC 61131-3 control software. In: Proceedings of the 19th International Conference On Methods and Models in Automation and Robotics, MMAR 2014, Międzyzdroje, Poland, September 2-5, pp. 468-473. IEEE (2014). https://doi.org/10.1109/MMAR.2014. 6957399

[S275] Jamro, M.: SysML modeling of POU-oriented unit tests for IEC 61131-3 control software. In: Proceedings of the 19th International Conference On Methods and Models in Automation and Robotics, MMAR 2014, Międzyzdroje, Poland, September 25, pp. 82-87. IEEE (2014). https://doi.org/10.1109/ MMAR.2014.6957329

[S276] Jamro, M.: SysML Modeling of Functional and Nonfunctional Requirements for IEC 61131-3 Control Systems. In: Progress in Automation, Robotics and Measuring Techniques - Control and Automation, Advances in Intelligent Systems and Computing, vol. 350, pp. 91-100. Springer (2015). https://doi.org/10. 1007/978-3-319-15796-2_10

[S277] Jamro, M., Rzonca, D.: SysML-Based Modeling of Token Passing Paradigm in Distributed Control Systems. In: P. Gaj, A. Kwiecien, P. Stera (eds.) Proceedings of the 22nd International Conference on Computer Networks, CN 2015, Brunów, Poland, June 16-19, Communications in Computer and Information Science, vol. 522, pp. 139-149. Springer (2015). https://doi.org/10.1007/978-3-319-19419-6_13

[S278] Jamro, M., Rzonca, D., Rząsa, W.: Testing communication tasks in distributed control systems with SysML and Timed Colored Petri Nets model. Computers in Industry 71, 77-87 (2015). https://doi.org/ 10.1016/j.compind.2015.03.007

[S279] Jamro, M., Trybus, B.: An approach to SysML modeling of IEC 61131-3 control software. In: Proceedings of 18th International Conference on Methods \& Models in Automation \& Robotics, MMAR 2013, Międzyzdroje, Poland, August 26-29, pp. 217-222. IEEE (2013)

[S280] Jankevicius, N.: Resource Analysis and Automated Verification for the Thirty Meter Telescope using Executable SysML Models. In: Proceedings of the 2nd International Workshop on Executable Modeling co-located with ACM/IEEE 19th International Conference on Model Driven Engineering Languages and Systems (MODELS 2016), Saint-Malo, France, October 3, CEUR Workshop Proceedings, vol. 1760, pp. 2-4. CEUR-WS.org (2016)

[S281] Jarraya, Y., Debbabi, M.: Formal Specification and Probabilistic Verification of SysML Activity Diagrams. In: Proceedings of the 6th International Symposium on Theoretical Aspects of Software Engineering (TASE 2012), Beijing, China, July 4-6, pp. 17-24. IEEE Computer Society (2012). https:// doi.org/10.1109/TASE.2012.34

[S282] Jarraya, Y., Debbabi, M.: Quantitative and qualitative analysis of SysML activity diagrams. International Journal on Software Tools for Technology Transfer 16(4), 399-419 (2014). https://doi.org/10.1007/ s10009-014-0305-6

[S283] Jarraya, Y., Debbabi, M., Bentahar, J.: On the Meaning of SysML Activity Diagrams. In: Proceedings of the 16th Annual IEEE International Conference and Workshop on the Engineering of Computer Based Systems (ECBS 2009), San Francisco, California, USA, April 14-16, pp. 95-105. IEEE Computer Society (2009). https://doi.org/10.1109/ECBS. 2009.25

[S284] Jarraya, Y., Soeanu, A., Debbabi, M., Hassaïne, F.: Automatic Verification and Performance Analysis of Time-Constrained SysML Activity Diagrams. In: Proceedings of the 14th Annual IEEE International Conference and Workshop on Engineering of Computer Based Systems (ECBS 2007), Tucson, Arizona, USA, March 26-29, pp. 515-522. IEEE Computer Society (2007). https://doi.org/10.1109/ ECBS.2007.22

[S285] de Jesus, T.O., Soares, M.S.: An Event-Based Technique to Trace Requirements Modeled with SysML. In: O. Gervasi, B. Murgante, S. Misra, G. Borruso, C.M. Torre, A.M.A.C. Rocha, D. Taniar, B.O. Apduhan, E.N. Stankova, A. Cuzzocrea (eds.) Proceedings of the 17th International Conference on Computational Science and Its Applications (ICCSA), Trieste, Italy, July 3-6, Lecture Notes in Computer Science, vol. 10409, pp. 145-159. Springer (2017). https://doi.org/10.1007/978-3-31962407-5_10

[S286] Jiang, C.Y., Wang, W.P., Li, Q.: SysML: a new systems modeling language. Xitong Fangzhen Xuebao / Journal of System Simulation 18(6), 14831487+1492 (2006)

[S287] Jobe, J., Johnson, T., Paredis, C.: Multi-Aspect Component Models: A framework for model reuse in SysML. In: Proceedings of the ASME International Design Engineering Technical Conferences and Computers and Information in Engineering Conference (DETC 2008), Brooklyn, New York, USA, August 3-6, vol. 3, pp. 943-955 (2008). https://doi. org/10.1115/DETC2008-49339

[S288] Johnson, T., Jobe, J., Paredis, C., Burkhart, R.: Modeling continuous system dynamics in SysML. In: Proceedings of the ASME International Mechanical Engineering Congress and Exposition (IMECE 2007), vol. 3, pp. 197-205 (2008). https://doi.org/ 10.1115/IMECE2007-42754 
[S289] Johnson, T., Kerzhner, A., Paredis, C., Burkhart, R.: Integrating models and simulations of continuous dynamics into SysML. Journal of Computing and Information Science in Engineering 12(1) (2012). https://doi.org/10.1115/1.4005452

[S290] Kakiuchi, Y.: Constraint Analysis of System Requirement in SysML with Formal Methods. IEEJ Transactions on Electronics, Information and Systems 137(6), 809-814 (2017). https://doi.org/10.1541/ ieejeiss. 137.809

[S291] Kanthabhabhajeya, S., Berglund, J., Falkman, P., Lennartson, B.: Interface between SysML and Sequence Planner Language for Formal Verification. In: Proceedings of the 23rd Annual International Symposium of the International Council on Systems Engineering, INCOSE 2013, INCOSE International Symposium, vol. 23, pp. 918-932 (2013)

[S292] Kanthabhabhajeya, S., Falkman, P., Lennartson, B.: System Modeling Specification in SysML and Sequence Planner Language - Comparison Study. In: Proceedings of the 14th IFAC Symposium on Information Control Problems in Manufacturing, IFAC Proceedings Volumes (IFAC-PapersOnline), vol. 14, pp. 1543-1550 (2012). https://doi.org/10. 3182/20120523-3-RO-2023.00189

[S293] Kapos, G.D., Dalakas, V., Nikolaidou, M., Anagnostopoulos, D.: An integrated framework for automated simulation of SysML models using DEVS. Simulation 90(6), 717-744 (2014). https://doi.org/10.1177/ 0037549714533842

[S294] Kapos, G.D., Dalakas, V., Tsadimas, A., Nikolaidou, M., Anagnostopoulos, D.: Model-based system engineering using SysML: Deriving executable simulation models with QVT. In: Proceedings of the IEEE International Systems Conference, SysCon 2014, Ottawa, ON, Canada, March 31-April 3, pp. 531538. IEEE (2014). https://doi.org/10.1109/SysCon. 2014.6819307

[S295] Kapos, G.D., Nikolaidou, M., Dalakas, V., Anagnostopoulos, D.: An integrated framework to simulate SysML models using DEVS simulators. In: Formal Languages for Computer Simulation: Transdisciplinary Models and Applications, pp. 305-332. IGI Global (2013). https://doi.org/10.4018/978-1-46664369-7.ch010

[S296] Karwowski, W., Ahram, T.: Interactive Management of Human Factors Knowledge for Human Systems Integration Using Systems Modeling Language. Information Systems Management 26(3), 262-274 (2009). https://doi.org/10.1080/10580530903018128

[S297] Karwowski, W., Amaba, B., Ahram, T., Bedny, G.: Human reliability assessment using systems modeling language $\&$ tasks based systemic-structural activ- ity theory. In: Proceedings of the 8th International Topical Meeting on Nuclear Plant Instrumentation, Control, and Human-Machine Interface Technologies (NPIC and HMIT 2012): Enabling the Future of Nuclear Energy, vol. 3, pp. 1464-1475 (2012)

[S298] Kawahara, R., Nakamura, H., Dotan, D., Kirshin, A., Sakairi, T., Hirose, S., Ono, K., Ishikawa, H.: Verification of embedded system's specification using collaborative simulation of SysML and simulink models. In: Proceedings of the International Conference on Model-Based Systems Engineering (MBSE 2009), pp. 21-28. IEEE (2009). https://doi.org/10. 1109/MBSE.2009.5031716

[S299] Kernschmidt, K., Barbieri, G., Fantuzzi, C., VogelHeuser, B.: Possibilities and Challenges of an Integrated Development Using a Combined SysMLModel and Corresponding Domain Specific Models. In: Proceedings of the 7th IFAC Conference on Manufacturing Modelling, Management, and Control, MIM 2013, Saint Petersburg, Russia, June 19-21, pp. 1465-1470. International Federation of Automatic Control (2013). https://doi.org/10.3182/201306193-RU-3018.00391

[S300] Kernschmidt, K., Vogel-Heuser, B.: An interdisciplinary SysML based modeling approach for analyzing change influences in production plants to support the engineering. In: Proceedings of the 2013 IEEE International Conference on Automation Science and Engineering, CASE 2013, Madison, WI, USA, August 17-20, pp. 1113-1118. IEEE (2013). https://doi.org/10.1109/CoASE.2013.6654030

[S301] Kerzhner, A., Paredis, C.: Combining SysML and Model Transformations to Support Systems Engineering Analysis. ECEASST 42 (2011)

[S302] Kerzhner, A., Paredis, C.: A SysML-Based Language for Modeling System-Level Architecture Selection Decisions. In: Proceedings of the ASME Design Engineering Technical Conference, vol. 2, pp. 12631276 (2012). https://doi.org/10.1115/DETC201271005

[S303] Khan, A., Mallet, F., Rashid, M.: Combining SysML and Marte/CCSL to Model Complex Electronic Systems. In: Proceedings of the International Conference on Information Systems Engineering (ICISE), pp. 12-17 (2016). https://doi.org/10.1109/ICISE. 2016.13

[S304] Khan, A., Rashid, M.: Generation of SystemVerilog Observers from SysML and MARTE/CCSL. In: Proceedings of the 19th International Symposium on Real-Time Distributed Computing (ISORC), pp. 6168. IEEE Computer Society (2016). https://doi.org/ 10.1109/ISORC.2016.18 
[S305] Kim, H., Fried, D., Menegay, P.: Connecting SysML models with engineering analyses to support multidisciplinary system development. In: Proceedings of the 12th AIAA Aviation Technology, Integration and Operations (ATIO) Conference and 14th AIAA/ISSMO Multidisciplinary Analysis and Optimization Conference, Indianapolis, IN, September 17-19 (2012)

[S306] Kim, S.: Automating building energy system modeling and analysis: An approach based on SysML and model transformations. Automation in Construction 41, 119-138 (2014). https://doi.org/10.1016/j. autcon.2013.10.018

[S307] Kinoshita, S., Nishimura, H., Takamura, H., Mizuguchi, D.: Describing Software Specification by Combining SysML with the B Method. In: Proceedings of the 25th IEEE International Symposium on Software Reliability Engineering Workshops, ISSRE Workshops, Naples, Italy, November 3-6, pp. 146-151. IEEE Computer Society (2014). https:// doi.org/10.1109/ISSREW.2014.66

[S308] Knorreck, D., Apvrille, L., de Saqui-Sannes, P.: TEPE: a SysML language for time-constrained property modeling and formal verification. ACM SIGSOFT Software Engineering Notes 36(1), 1-8 (2011). https://doi.org/10.1145/1921532.1921556

[S309] Korff, A.: UML for Systems Engineering (SysML) Eine Notation zur Beschreibung von Systemen. In: Echtzeitaspekte bei der Koordinierung Autonomer Systeme - PEARL 2005, Fachtagung der GIFachgruppe Echtzeitsysteme und PEARL (EP), Boppard, 1./2. Dezember 2005, Informatik Aktuell, pp. 115-123. Springer (2005). https://doi.org/10.1007/ 3-540-29595-X_11

[S310] Korff, A.: Re-using SysML System Architectures. In: Proceedings of the 4th International Conference on Complex Systems Design \& Management (CSD\&M 2013), Paris, France, December 4-6, pp. 257-266. Springer (2013). https://doi.org/10.1007/ 978-3-319-02812-5_19

[S311] Kößler, J., Paetzold, K.: Supporting SysML model generation in early phases of the development process. In: Proceedings of NordDesign, Trondheim, Norway, 10-12 August, NordDesign, vol. 1, pp. 300309 (2016)

[S312] Kotronis, C., Tsadimas, A., Kapos, G., Dalakas, V., Nikolaidou, M., Anagnostopoulos, D.: Simulating SysML transportation models. In: Proceedings of the International Conference on Systems, Man, and Cybernetics, SMC 2016, Budapest, Hungary, October 9-12, pp. 1674-1679. IEEE (2016). https://doi. org/10.1109/SMC.2016.7844478
[S313] Kretzenbacher, M., Findlay, R., Lange, C., Yan, W.: Model Based Systems Engineering (MBSE) applied through a SysML model to the mascot asteroid lander. In: Proceedings of the 64th International Astronautical Congress (IAC), vol. 10, pp. 80158022 (2013)

[S314] Kruse, B., Gilz, T., Shea, K., Eigner, M.: Systematic comparison of functional models in SysML for design library evaluation. In: Proceedings of the 24th CIRP Design Conference, Procedia CIRP, vol. 21, pp. 34-39 (2014). https://doi.org/10.1016/j.procir. 2014.03.175

[S315] Kruse, B., Münzer, C., Wölkl, S., Canedo, A., Shea, K.: A Model-Based Functional Modeling and Library Approach for Mechatronic Systems in SysML. In: Proceedings of the ASME Design Engineering Technical Conference and Computers and Information in Engineering Conference, Chicago, Illinois, USA, August 12-15, vol. 2, pp. 1217-1227 (2012). https://doi.org/10.1115/DETC2012-70378

[S316] Kruse, B., Shea, K.: Design Library Solution Patterns in SysML for Concept Design and Simulation. In: Proceedings of the 26th CIRP Design Conference, Procedia CIRP, vol. 50, pp. 695-700 (2016). https:// doi.org/10.1016/j.procir.2016.04.132

[S317] Kruus, H., Jervan, G.: Evaluation of SysML software for teaching systems engineering basics. In: Proceedings of the 25th International Conference on European Association for Education in Electrical and Information Engineering, EAEEIE 2014, pp. 2932. IEEE (2014). https://doi.org/10.1109/EAEEIE. 2014.6879379

[S318] Kruus, H., Robal, T., Jervan, G.: SysML in systems engineering course. In: Proceedings of the 10th European Workshop on Microelectronics Education (EWME), pp. 177-181 (2014). https://doi.org/10. 1109/EWME.2014.6877421

[S319] Kruus, H., Robal, T., Jervan, G.: Teaching modeling in SysML/UML and problems encountered. In: Proceedings of the 25th International Conference on European Association for Education in Electrical and Information Engineering, EAEEIE 2014, pp. 33-36 (2014). https://doi.org/10.1109/EAEEIE. 2014.6879380

[S320] Kwon, K.S., McGinnis, L.F.: SysML-based Simulation Framework for Semiconductor Manufacturing. In: Proceedings of the IEEE Conference on Automation Science and Engineering (CASE 2007), Scottsdale, Arizona, USA, September 22-25, pp. 1075-1080. IEEE (2007). https://doi.org/10.1109/ COASE.2007.4341777

[S321] Lafi, S., Champagne, R., Kouki, A., Belzile, J.: Modeling radio-frequency front-ends using SysML: A 
case study of a UMTS transceiver. In: Proceedings of the 1st International Workshop on Model Based Architecting and Construction of Embedded Systems, CEUR Workshop Proceedings, vol. 503, pp. 115-128 (2008)

[S322] Lakhdara, Z., Merniz, S.: A SysML and CLEAN based methodology for RISC processor micro- Architecture design. International Journal of Embedded and Real-Time Communication Systems 6(1), 101-131 (2015). https://doi.org/10.4018/IJERTCS. 2015010105

[S323] Lakhdara, Z., Merniz, S.: A SysML and CLEANbased methodology for digital circuits design. IJHPSA 6(4), 222-237 (2016). https://doi.org/10.1504/ IJHPSA.2016.10002660

[S324] Laleau, R., Semmak, F., Matoussi, A., Petit, D., Hammad, A., Tatibouet, B.: A first attempt to combine SysML requirements diagrams and B. Innovations in Systems and Software Engineering 6(1), 47-54 (2010). https://doi.org/10.1007/s11334-0090119-y

[S325] Lane, J., Bohn, T.: Using SysML modeling to understand and evolve systems of systems. Systems Engineering 16(1), 87-98 (2013). https://doi.org/10. 1002/sys.21221

[S326] de Lange, D., Guo, J., de Koning, H.: Applicability of SysML to the Early Definition Phase of Space Missions in a Concurrent Environment. In: Proceedings of the 2nd International Conference on Complex Systems Design \& Management (CSDM 2011), Paris, France, December 7-9, pp. 173-185. Springer (2011). https://doi.org/10.1007/ 978-3-642-25203-7_12

[S327] Larisch, M., Hänle, A., Siebold, U., Häring, I.: SysML aided functional safety assessment. In: Proceedings of the ESREL 2008 and 17th SRA-Europe Conference, Valencia, Spain, September, pp. 15471554 (2008)

[S328] Lasalle, J., Bouquet, F., Legeard, B., Peureux, F.: SysML to UML model transformation for test generation purpose. ACM SIGSOFT Software Engineering Notes 36(1), 1-8 (2011). https://doi.org/10.1145/ 1921532.1921560

[S329] Lasalle, J., Peureux, F., Fondement, F.: Development of an automated MBT toolchain from UML/SysML models. Innovations in Systems and Software Engineering 7(4), 247-256 (2011). https://doi.org/10. 1007/s11334-011-0164-1

[S330] Le Mair, A., Fraanje, R.: Using SysML to teach Systems Engineering skills. In: Proceedings of the 11th France-Japan 9th Europe-Asia Congress on Mechatronics (MECATRONICS) /17th International Conference on Research and Education in Mechatron- ics (REM), pp. 1-5 (2016). https://doi.org/10.1109/ MECATRONICS.2016.7547106

[S331] Lee, T., Cha, J.M., Kim, J.Y., Shin, J., Kim, J., Yeom, C.: Plant modeling based on SysML domain specific language. In: Proceedings of the IEEE International Systems Engineering Symposium (ISSE), pp. 1-5 (2017). https://doi.org/10.1109/SysEng.2017. 8088289

[S332] Leite, J.C., Oquendo, F., Batista, T.V.: SysADL: A SysML Profile for Software Architecture Description. In: Proceedings of the 7th European Conference on Software Architecture (ECSA 2013), Montpellier, France, July 1-5, Lecture Notes in Computer Science, vol. 7957, pp. 106-113. Springer (2013). https://doi.org/10.1007/978-3-642-39031-9_9

[S333] Lemaire, L., Lapon, J., Decker, B.D., Naessens, V.: A SysML Extension for Security Analysis of Industrial Control Systems. In: Proceedings of the 2nd International Symposium for ICS \& SCADA Cyber Security Research 2014, ICS-CSR 2014, St. Pölten, Austria, September 11-12, Workshops in Computing. BCS (2014)

[S334] Lempia, D., Jorgensen, R.: Practical SysML Applications: A Method to Describe the Problem Space. In: Proceedings of the 21st Annual International Symposium of the International Council on Systems Engineering (INCOSE 2011), INCOSE International Symposium, vol. 21, pp. 85-98 (2011)

[S335] Leserf, P., De Saqui-Sannes, P., Hugues, J.: Multi domain optimization with SysML modeling. In: Proceedings of the IEEE 20th Conference on Emerging Technologies Factory Automation (ETFA), Sept., pp. 1-8 (2015). https://doi.org/10.1109/ETFA.2015. 7301406

[S336] Leserf, P., De Saqui-Sannes, P., Hugues, J., Chaaban, K.: Architecture Optimization with SysML Modeling: A Case Study Using Variability. In: Proceedings of the 3rd International Conference on Model-Driven Engineering and Software Development (MODELSWARD), Angers, France, February 9-11, Communications in Computer and Information Science, vol. 580, pp. 311-327. Springer (2015). https://doi.org/10.1007/978-3-319-27869-8_18

[S337] Leserf, P., De Saqui-Sannes, P., Hugues, J., Chaaban, K.: SysML Modeling for Embedded Systems Design Optimization: A Case Study. In: Proceedings of the 3rd International Conference on Model-Driven Engineering and Software Development (MODELSWARD), ESEO, Angers, Loire Valley, France, 9-11 February, pp. 449-457. SciTePress (2015). https:// doi.org/10.5220/0005229204490457

[S338] Li, G., Wang, B.: SysML Aided Safety Analysis for Safety-Critical Systems. In: Proceedings of the 
3rd International Conference on Artificial Intelligence and Computational Intelligence (AICI 2011), Taiyuan, China, September 24-25, Part I, Lecture Notes in Computer Science, vol. 7002, pp. 270275. Springer (2011). https://doi.org/10.1007/9783-642-23881-9_35

[S339] Li, L., Wang, N., Ma, L., Yang, Q.: Modeling method of military aircraft support process based SysML. In: Proceedings of 9th International Conference on Reliability, Maintainability and Safety (ICRMS 2011), pp. 1247-1251. IEEE (2011). https://doi.org/ 10.1109/ICRMS.2011.5979460

[S340] Li, X., Liu, J.: A method of SysML-based visual transformation of system design-simulation models. Jisuanji Fuzhu Sheji Yu Tuxingxue Xuebao/Journal of Computer-Aided Design and Computer Graphics 28(11), 1973-1981 (2016)

[S341] Lima, L., Didier, A., Cornélio, M.: A Formal Semantics for SysML Activity Diagrams. In: Formal Methods: Foundations and Applications - Proceedings of the 16th Brazilian Symposium, SBMF 2013, Brasilia, Brazil, September 29-October 4, Lecture Notes in Computer Science, vol. 8195, pp. 179194. Springer (2013). https://doi.org/10.1007/9783-642-41071-0_13

[S342] Lima, L., Miyazawa, A., Cavalcanti, A., Cornélio, M., Iyoda, J., Sampaio, A., Hains, R., Larkham, A., Lewis, V.: An integrated semantics for reasoning about SysML design models using refinement. Software and Systems Modeling 26(2), 367-405 (2015). https://doi.org/10.1007/s10270-015-0492-y

[S343] Limère, V., Balachandran, S., McGinnis, L., Van Landeghem, H.: In-plant logistics systems modeling with SysML. In: ESM 2010 - European Simulation and Modelling Conference, pp. 383-387 (2010)

[S344] Lin, C.S., Lu, C.H., Lin, S.W., Chen, Y.R., Hsiung, P.A.: VERTAF/multi-core: A SysML-based application framework for multi-core embedded software development. Journal of Computer Science and Technology 26(3), 448-462 (2011). https://doi.org/ 10.1007/s11390-011-1146-3

[S345] Lin, H., Sorouri, M., Vyatkin, V., Salcic, Z.: Modelbased customisation of intelligent mechatronic systems using SysML. In: Proceedings of 2013 IEEE 18th Conference on Emerging Technologies \& Factory Automation, ETFA 2013, Cagliari, Italy, September 10-13, pp. 1-4. IEEE (2013). https://doi.org/10. 1109/ETFA.2013.6648138

[S346] Lin, H.Y., Sierla, S., Papakonstantinou, N., Vyatkin, V.: A SysML profile supporting change orders in model driven engineering. In: Proceedings of the IEEE International Conference on Automation Science and Engineering (CASE), Aug., pp. 1054-
1059 (2015). https://doi.org/10.1109/CoASE.2015. 7294238

[S347] Lin, J., Shih, P.H., Huang, E., Chiu, C.C.: Airport baggage handling system simulation modeling using SysML. In: Proceedings of the 5th International Conference on Industrial Engineering and Operations Management (IEOM), March, pp. 1-10 (2015). https://doi.org/10.1109/IEOM.2015.7093764

[S348] Linhares, M.V., de Oliveira, R.S., Farines, J., Vernadat, F.: Introducing the modeling and verification process in SysML. In: Proceedings of 12th IEEE International Conference on Emerging Technologies and Factory Automation (ETFA 2007), Patras, Greece, September 25-28, pp. 344-351. IEEE (2007). https://doi.org/10.1109/EFTA.2007. 4416788

[S349] Linhares, M.V., da Silva, A.J., de Oliveira, R.S.: Empirical Evaluation of SysML through the Modeling of an Industrial Automation Unit. In: Proceedings of 11th IEEE International Conference on Emerging Technologies and Factory Automation (ETFA 2006), Diplomat Hotel Prague, Czech Republic, September 20-22, pp. 145-152. IEEE (2006). https://doi.org/ 10.1109/ETFA.2006.355190

[S350] Liu, J., Wang, S., Fu, C.: Design Analysis Method for Multidisciplinary Complex Product using SysML. In: Proceedings of the 3rd International Conference on Mechanical, Electronic and Information Technology Engineering (ICMITE 2017), MATEC Web Conference, vol. 139 (2017)

[S351] Liu, X., Ren, Y., Wang, Z., Liu, L.: Modeling method of SysML-based reliability block diagram. In: Proceedings of the International Conference on Mechatronic Sciences, Electric Engineering and Computer (MEC 2013), pp. 206-209. IEEE (2013). https://doi. org/10.1109/MEC.2013.6885073

[S352] Liu, X.H., Cao, Y.F., Wang, B., Zhuang, L.K., Zhou, Z.H.: Flight control system conceptual prototype design based on SysML and Simulink. Dianzi Keji Daxue Xuebao/Journal of the University of Electronic Science and Technology of China 40(6), 887-891+910 (2011). https://doi.org/10.3969/j.issn. 1001-0548.2011.06.016

[S353] Liu, Y., Irudayaraj, P., Zhou, F., Jiao, R., Goodman, J.: SysML-based Model Driven Discrete-Event Simulation. In: Proceedings of the 21st ISPE Inc. International Conference on Concurrent Engineering, Beijing Jiaotong University, China, September 8-11, Advances in Transdisciplinary Engineering, vol. 1, pp. 617-626. IOS Press (2014). https://doi. org/10.3233/978-1-61499-440-4-617

[S354] Liu, Y., Yuan, W., Fan, H., Cao, Y.: Research on information integration framework of SysML based 
model driven design of complex products. Zhongguo Jixie Gongcheng/China Mechanical Engineering 23(12), 1438-1445 (2012). https://doi.org/10. 3969/j.issn.1004-132X.2012.12.011

[S355] Liu, Y.S., Fan, H.R.: Integration of System-Level Design and Detailed Design Models of Mechatronic Systems Based on SysML and Step AP 203 Standard. In: Applied Mechanics and Mechanical Engineering III, Applied Mechanics and Materials, vol. 249, pp. 1160-1165. Trans Tech Publications (2013). https://doi.org/10.4028/www.scientific.net/ AMM.249-250.1160

[S356] Liu, Y.S., Yuan, W.Q.: Automatic Integration of System-Level Design and System Optimization Based on SysML. In: Applied Mechanics and Mechanical Engineering III, Applied Mechanics and Materials, vol. 249, pp. 1154-1159. Trans Tech Publications (2013). https://doi.org/10.4028/www.scientific.net/ AMM.249-250.1154

[S357] Lopata, A., Ambraziunas, M., Veitaite, I., Masteika, S., Butleris, R.: SysML and UML models usage in knowledge based MDA process. Elektronika ir Elektrotechnika 21(2), 50-57 (2015). https://doi.org/10. 5755/j01.eee.21.2.5629

[S358] Lovric, T., Schneider-Scheyer, M., Sarkic, S.: SysML as backbone for engineering and safety - Practical experience with TRW braking ECU. In: Proceedings of the SAE 2014 World Congress \& Exhibition, SAE Technical Papers, vol. 1 (2014). https://doi.org/10. 4271/2014-01-0212

[S359] Lu, X., Piétrac, L., Niel, E.: A new approach of modeling supervisory control for manufacturing systems based on SysML. In: Proceedings of the 22nd IEEE International Conference on Emerging Technologies and Factory Automation (ETFA), pp. 1-9 (2017). https://doi.org/10.1109/ETFA.2017.8247626

[S360] Lugou, F., Li, L., Apvrille, L., Ameur-Boulifa, R.: SysML Models and Model Transformation for Security. In: Proceedings of the 4th International Conference on Model-Driven Engineering and Software Development - MODELSWARD 2016, Rome, Italy, 19-21 February, pp. 331-338. SciTePress (2016). https://doi.org/10.5220/0005748703310338

[S361] Lukas, S., Lukas, H.: Proposal of System Testing Integration into Safety Critical System Design Process Supported by SysML. In: Proceedings of the UKSim-AMSS 8th European Modelling Symposium on Computer Modelling and Simulation, EMS 2014, Pisa, Italy, October 21-23, pp. 251-256. IEEE (2014). https://doi.org/10.1109/EMS.2014.74

[S362] Machida, F., Andrade, E.C., Kim, D.S., Trivedi, K.S.: Candy: Component-based Availability Modeling Framework for Cloud Service Management
Using SysML. In: Proceedings of the 30th IEEE Symposium on Reliable Distributed Systems (SRDS 2011), Madrid, Spain, October 4-7, pp. 209-218. IEEE Computer Society (2011). https://doi.org/10. 1109/SRDS.2011.33

[S363] Machida, F., Xiang, J., Tadano, K., Maeno, Y.: Composing hierarchical stochastic model from SysML for system availability analysis. In: Proceedings of the IEEE 24th International Symposium on Software Reliability Engineering, ISSRE 2013, Pasadena, CA, USA, November 4-7, pp. 51-60. IEEE Computer Society (2013). https://doi.org/10.1109/ISSRE.2013. 6698904

[S364] Maisenbacher, S., Kernschmidt, K., Kasperek, D., Vogel-Heuser, B., Maurer, M.: Using DSM and MDM methodologies to analyze structural SysML models. In: Proceedings of the IEEE International Conference on Industrial Engineering and Engineering Management, Bangkok, Thailand, pp. 351-355 (2014). https://doi.org/10.1109/IEEM.2013.6962432

[S365] Maissa, Y., Mouline, S.: A SysML profile for wireless sensor networks modeling. In: Proceedings of the 5th International Symposium on I/V Communications and Mobile Networks (ISIVC 2010), pp. 14. IEEE (2010). https://doi.org/10.1109/ISVC.2010. 5656281

[S366] Makartetskiy, D., Sisto, R.: An approach to refinement checking of SysML requirements. In: Proceedings of the 16th Conference on Emerging Technologies \& Factory Automation (ETFA 2011), Toulouse, France, September 5-9, pp. 1-4. IEEE (2011). https://doi.org/10.1109/ETFA.2011.6059147

[S367] Mandutianu, S., Morillo, R., Simpson, K., Liepack, O., Bonanne, K.: Modeling complex cross-systems software interfaces using SysML. In: Proceedings of the AIAA Infotech at Aerospace Conference, Boston, MA, USA, August 19-22 (2013)

[S368] Marco, J., Vaughan, N.: Integration of architectural modelling using the SysML within the traditional automotive CACSD process. In: Proceedings of the UKACC International Conference on Control 2010, pp. 668-673. IET (2010). https://doi.org/10.1049/ic. 2010.0361

[S369] Marco, J., Vaughan, N.: Architectural modelling of an energy management control system using the SysML. International Journal of Vehicle Design 55(1), 1-22 (2011). https://doi.org/10.1504/IJVD. 2011.038044

[S370] Maroui, R., Ayeb, B.: Integrating the SysML and ACME in a Model Driven Engineering Approach to Verify the Web Service Composition. In: Proceedings of the 24th IEEE International Conference on Enabling Technologies: Infrastructure for Collabo- 
rative Enterprises, WETICE 2015, Larnaca, Cyprus, June 15-17, pp. 183-189. IEEE Computer Society (2015). https://doi.org/10.1109/WETICE.2015.41

[S371] Matthiesen, S., Schmidt, S., Moeser, G.: SysKIT 2.0 - Implementation of a SysML teaching approach and observations on systems modelling by mechatronic teams. In: Proceedings of the 17th International Conference on Engineering and Product Design Education: Great Expectations: Design Teaching, Research and Enterprise, Loughborough, UK, E\&PDE, pp. 518-523 (2015)

[S372] Matthiesen, S., Schmidt, S., Moeser, G., Munker, F.: The Karlsruhe SysKIT Approach - A Three-Step SysML Teaching Approach for Mechatronic Students. In: Proceedings of the 24th CIRP Design Conference, Procedia CIRP, vol. 21, pp. 385-390 (2014). https://doi.org/10.1016/j.procir.2014.03.136

[S373] Maurandy, J., Gill, E., Helm, A., Stalford, R.: Cost-Benefit Analysis of SysML Modelling for the Atomic Clock Ensemble in Space (ACES) Simulator. In: Proceedings of the 22nd Annual International Symposium of the International Council on Systems Engineering (INCOSE 2012) and the 8th Biennial European Systems Engineering Conference (EuSEC 2012), INCOSE International Symposium, vol. 22, pp. 1726-1745 (2012)

[S374] Mazzini, S., Stragapede, A.: SysML: A language for space system engineering. In: Proceedings of the Conference on DAta Systems In Aerospace (DASIA 2008), Noordwijk, Netherlands, no. 665 in ESA SP (2008)

[S375] McGinnis, L.F., Ustun, V.: A Simple Example of SysML-driven Simulation. In: Proceedings of the 2009 Winter Simulation Conference (WSC 2009), Hilton Austin Hotel, Austin, TX, USA, December 13-16, pp. 1703-1710. WSC (2009). https://doi.org/ 10.1109/WSC.2009.5429169

[S376] McKelvin Jr., M., Jimenez, A.: Specification and design of electrical flight system architectures with SysML. In: Proceedings of the AIAA Infotech at Aerospace Conference and Exhibit 2012, Garden Grove, CA, USA (2012)

[S377] Meacham, S., Gioulekas, F., Phalp, K.: SysML based design for variability enabling the reusability of legacy systems towards the support of diverse standard compliant implementations or standard updates: the case of IEEE-802.15.6 standard for e-Health applications. In: Proceedings of the 8th International Conference on Simulation Tools and Techniques, Athens, Greece, August 24-26, 2015, pp. 284-289. ICST/ACM (2015). https://doi.org/10.4108/eai.248-2015.2261108
[S378] Mehrpouyan, H., Tumer, I., Hoyle, C., Giannakopoulou, D., Brat, G.: Formal verification of complex systems based on SysML functional requirements. In: Proceedings of the Annual Conference of the Prognostics and Health Management Society 2014 (PHM), pp. 176-187 (2014)

[S379] Mendes, J., Carreira, A., Aleluia, M., Mendes, J.: Formulating strategic problems with Systems Modeling Language. Journal of Enterprise Transformation 6(1), 23-38 (2016). https://doi.org/10.1080/ 19488289.2016.1210705

[S380] Mendieta, R., de la Vara, J.L., Morillo, J.L., Rodríguez, J.M.Á.: Towards Effective SysML Model Reuse. In: L.F. Pires, S. Hammoudi, B. Selic (eds.) Proceedings of the 5th International Conference on Model-Driven Engineering and Software Development, MODELSWARD 2017, Porto, Portugal, February 19-21, pp. 536-541. SciTePress (2017). https://doi.org/10. 5220/0006267605360541

[S381] Meng, C., Kim, S., Son, Y., Kubota, C.: A SysMLbased simulation model aggregation framework for seedling propagation system. In: Proceedings of the Winter Simulations Conference: Simulation Making Decisions in a Complex World, WSC 2013, Washington, DC, USA, December 8-11, pp. 21802191. IEEE (2013). https://doi.org/10.1109/WSC. 2013.6721595

[S382] Mentré, D.: SysML2B: Automatic Tool for B Project Graphical Architecture Design Using SysML. In: Proceedings of the 5th International Conference on Abstract State Machines, Alloy, B, TLA, VDM, and Z (ABZ), Linz, Austria, May 23-27, LNCS, vol. 9675, pp. 308-311. Springer (2016). https://doi.org/ 10.1007/978-3-319-33600-8_26

[S383] Mhenni, F., Choley, J.Y., Nguyen, N.: Extended mechatronic systems architecture modeling with SysML for enhanced safety analysis. In: Proceedings of the IEEE International Systems Conference, SysCon 2014, Ottawa, ON, Canada, March 31-April 3, pp. 378-382. IEEE (2014). https://doi.org/10. 1109/SysCon.2014.6819284

[S384] Mhenni, F., Choley, J.Y., Nguyen, N.: SysML safety profile for mechatronics. In: Proceedings of the 10th France-Japan / 8th Europe-Asia Congress on Mecatronics (MECATRONICS) 2014, pp. 2934 (2014). https://doi.org/10.1109/MECATRONICS. 2014.7018622

[S385] Mhenni, F., Choley, J.Y., Nguyen, N.: SysML extensions for safety-critical mechatronic systems design. In: Proceedings of the 1st IEEE International Symposium on Systems Engineering (ISSE), Sept., pp. 242247 (2015). https://doi.org/10.1109/SysEng.2015. 7302764 
[S386] Mhenni, F., Choley, J.Y., Nguyen, N., Frazza, C.: Flight Control System Modeling with SysML to Support Validation, Qualification and Certification. IFAC-PapersOnLine: Proceedings of the 14th IFAC Symposium on Control in Transportation Systems (CTS), Istanbul, Turkey, 18-20 May 49(3), 453-458 (2016). https://doi.org/10.1016/j.ifacol.2016.07.076

[S387] Mhenni, F., Choley, J.Y., Penas, O., Plateaux, R., Hammadi, M.: A SysML-based methodology for mechatronic systems architectural design. Advanced Engineering Informatics 28(3), 218-231 (2014). https://doi.org/10.1016/j.aei.2014.03.006

[S388] Mhenni, F., Choley, J.Y., Riviere, A., Nguyen, N., Kadima, H.: SysML and safety analysis for mechatronic systems. In: Proceedings of the 9th FranceJapan and 7th Europe-Asia Congress on Mechatronics (MECATRONICS 2012) / 13th International Workshop on Research and Education in Mechatronics (REM 2012), pp. 417-424. IEEE (2012). https:// doi.org/10.1109/MECATRONICS.2012.6451042

[S389] Mhenni, F., Nguyen, N., Choley, J.Y.: Towards the Integration of Safety Analysis in a ModelBased System Engineering Approach with SysML. In: Proceedings of the 5th International Conference Design and Modeling of Mechanical Systems (CMSM 2013), Djerba, Tunisia, March 25-27, Lecture Notes in Mechanical Engineering, vol. 1, pp. 61-68 (2013). https://doi.org/10.1007/978-3-64237143-1_8

[S390] Mhenni, F., Nguyen, N., Choley, J.Y.: Automatic fault tree generation from SysML system models. In: Proceedings of the IEEE/ASME International Conference on Advanced Intelligent Mechatronics (AIM), pp. 715-720 (2014). https://doi.org/10.1109/ AIM.2014.6878163

[S391] Mhenni, F., Nguyen, N., Kadima, H., Choley, J.: Safety analysis integration in a SysML-based complex system design process. In: Proceedings of the IEEE International Systems Conference, SysCon 2013, Orlando, FL, USA, April 15-18, pp. 70-75. IEEE (2013). https://doi.org/10.1109/SysCon.2013. 6549861

[S392] Min, B., Kerzhner, A., Paredis, C.: Process Integration and Design Optimization for Model-Based Systems Engineering with SysML. In: Proceedings of the ASME Design Engineering Technical Conference and Computers and Information in Engineering Conference, vol. 2, pp. 1361-1369 (2011). https:// doi.org/10.1115/DETC2011-48453

[S393] Miyazawa, A., Cavalcanti, A.: Formal Refinement in SysML. In: Proceedings of the 11th International Conference on Integrated Formal Methods, IFM 2014, Bertinoro, Italy, September 9-11, Lecture
Notes in Computer Science, vol. 8739, pp. 155170. Springer (2014). https://doi.org/10.1007/9783-319-10181-1_10

[S394] Miyazawa, A., Lima, L., Cavalcanti, A.: Formal Models of SysML Blocks. In: Proceedings of the 15th International Conference on Formal Engineering Methods, ICFEM 2013, Queenstown, New Zealand, October 29-November 1, Lecture Notes in Computer Science, vol. 8144, pp. 249-264. Springer(2013). https://doi.org/10.1007/978-3-64241202-8_17

[S395] Monica, F.D., Patalano, S., Choley, J.Y., Mhenni, F., Gerbino, S.: A hierarchical set of SysML Modelbased objects for tolerance specification. In: Proceedings of the 2016 IEEE International Symposium on Systems Engineering (ISSE), Oct., pp. 1-7 (2016). https://doi.org/10.1109/SysEng.2016. 7753143

[S396] Morelli, M.: Automated generation of robotics applications from simulink and SysML models. In: Proceedings of the 30th Annual ACM Symposium on Applied Computing, Salamanca, Spain, April 1317, pp. 1948-1954. ACM (2015). https://doi.org/10. $1145 / 2695664.2695882$

[S397] Morgan, D., Waldock, A., Corne, D.: Efficient systems analysis by combining SysML and coevolution. In: Proceedings of the 7th International Conference on System of Systems Engineering (SoSE 2012), pp. 83-88. IEEE (2012). https://doi.org/10.1109/ SYSoSE.2012.6384141

[S398] Mori, M., Ceccarelli, A., Lollini, P., Bondavalli, A., Frömel, B.: A Holistic Viewpoint-Based SysML Profile to Design Systems-of-Systems. In: Proceedings of the 17th IEEE International Symposium on High Assurance Systems Engineering HASE 2016, Orlando, FL, USA, January 7-9, pp. 276-283. IEEE Computer Society (2016). https://doi.org/10.1109/ HASE.2016.21

[S399] Mori, M., Ceccarelli, A., Lollini, P., Frömel, B., Brancati, F., Bondavalli, A.: Systems-of-systems modeling using a comprehensive viewpoint-based SysML profile. Journal of Software: Evolution and Process p. e1878 (2017). https://doi.org/10.1002/ smr.1878

[S400] Morkevicius, A., Jankevicius, N.: An approach: SysML-based automated requirements verification. In: Proceedings of the 1st IEEE International Symposium on Systems Engineering (ISSE), Sept., pp. 92-97 (2015). https://doi.org/10.1109/SysEng. 2015.7302739

[S401] Müller, M., Roth, M., Lindemann, U.: The hazard analysis profile: Linking safety analysis and SysML. In: Proceedings of the 10th Annual International Sys- 
tems Conference, SysCon 2016, Orlando, FL, USA, April 18-21, pp. 1-7. IEEE (2016). https://doi.org/ 10.1109/SYSCON.2016.7490532

[S402] Müller, W., He, D., Mischkalla, F., Wegele, A., Larkham, A., Whiston, P., Peñil, P., Villar, E., Mitas, N., Kritharidis, D., Azcarate, F., Carballeda, M.: The SATURN Approach to SysML-Based HW/SW Codesign. In: Proceedings of the IEEE Computer Society Annual Symposium on VLSI (ISVLSI 2010), Lixouri Kefalonia, Greece, July 5-7, Lecture Notes in Electrical Engineering, vol. 105, pp. 151-164. Springer (2011). https://doi.org/10.1007/978-94-0071488-5_9

[S403] Mura, M., Murillo, L.G., Prevostini, M.: Modelbased Design Space Exploration for RTES with SysML and MARTE. In: Proceedings of the Forum on specification and Design Languages (FDL 2008), Stuttgart, Germany, September 23-25, pp. 203-208. IEEE (2008). https://doi.org/10.1109/FDL. 2008.4641446

[S404] Muşat, L., Hübl, M., Buzo, A., Pelz, G., Kandl, S., Puschner, P.: Semi-formal representation of requirements for automotive solutions using SysML, vol. 361, pp. 57-81. Springer International Publishing (2016). https://doi.org/10.1007/978-3319-24457-0_4

[S405] Nakajima, S., Furukawa, S., Ueda, Y.: Co-analysis of SysML and Simulink Models for Cyber-Physical Systems Design. In: Proceedings of the 18th IEEE International Conference on Embedded and RealTime Computing Systems and Applications (RTCSA 2012), Seoul, Korea (South), August 19-22, pp. 473478. IEEE Computer Society (2012). https://doi.org/ 10.1109/RTCSA.2012.22

[S406] Nasraoui, K., Lakhoua, N., Amraoui, L.E.: Study and analysis of micro smart grid using the modeling language SysML. In: Proceedings of the International Conference on Green Energy Conversion Systems (GECS), pp. 1-8 (2017). https://doi.org/10.1109/ GECS.2017.8066142

[S407] Nejati, S., Sabetzadeh, M., Arora, C., Briand, L., Mandoux, F.: Automated change impact analysis between SysML models of requirements and design. In: Proceedings of the 24th ACM SIGSOFT International Symposium on Foundations of Software Engineering, FSE 2016, Seattle, WA, USA, November 13-18, pp. 242-253. ACM (2016). https://doi. org/10.1145/2950290.2950293

[S408] Nejati, S., Sabetzadeh, M., Falessi, D., Briand, L., Coq, T.: A SysML-based approach to traceability management and design slicing in support of safety certification: Framework, tool support, and case studies. Information and Software Technol- ogy 54(6), 569-590 (2012). https://doi.org/10.1016/ j.infsof.2012.01.005

[S409] Ngo, V., Soriano, T.: A model transformation process to realize controllers of ship autopilot systems by the specialized MDA's features with UML/SysML. In: Proceeding of the 9th France-Japan and 7th Europe-Asia Congress on Mechatronics (MECATRONICS 2012) / 13th International Workshop on Research and Education in Mechatronics (REM 2012), pp. 20-26. IEEE (2012). https://doi.org/10. 1109/MECATRONICS.2012.6450983

[S410] Nguyen, N., Kadima, H.: SysML Parametric Models for Complex System Performance Analysis - A Case Study. In: SIMULTECH 2012 - Proceedings of the 2nd International Conference on Simulation and Modeling Methodologies, Technologies and Applications, Rome, Italy, July 28-31, pp. 321-327. SciTePress (2012)

[S411] Nigischer, C., Gerhard, D.: Lightweight visualization of SysML models in PDM systems. In: Proceedings of the 21st International Conference on Engineering Design (ICED 17): Product, Services and Systems Design, Vancouver, Canada, 21-25.08, vol. 3, pp. 61-70 (2017)

[S412] Nikolaidou, M., Dalakas, V., Mitsi, L., Kapos, G., Anagnostopoulos, D.: A SysML Profile for Classical DEVS Simulators. In: Proceedings of the 3rd International Conference on Software Engineering Advances (ICSEA 2008), Sliema, Malta, October 26-31, pp. 445-450. IEEE Computer Society (2008). https://doi.org/10.1109/ICSEA.2008.24

[S413] Nikolaidou, M., Kapos, G., Dalakas, V., Anagnostopoulos, D.: Basic guidelines for simulating SysML models: An experience report. In: Proceedings of the 7th International Conference on System of Systems Engineering (SoSE 2012), Genova, Italy, July 16-19, pp. 95-100. IEEE (2012). https://doi.org/10.1109/ SYSoSE.2012.6384172

[S414] Nikolaidou, M., Kapos, G.D., Tsadimas, A., Dalakas, V., Anagnostopoulos, D.: Simulating SysML models: Overview and challenges. In: Proceedings of the 10th System of Systems Engineering Conference, SoSE 2015, San Antonio, TX, USA, May 17-20, pp. 328-333. IEEE (2015). https://doi.org/10.1109/ SYSOSE.2015.7151961

[S415] Nikolaidou, M., Michalakelis, C.: Techno-economic analysis of SysML models. In: Proceedings of the IEEE International Systems Engineering Symposium (ISSE), pp. 1-6 (2017). https://doi.org/10. 1109/SysEng.2017.8088276

[S416] Nonsiri, S., Christophe, F., Coataneéa, E., Mokammel, F.: A combined design structure matrix (DSM) and discrete differential evolution (DDE) approach 
for scheduling and organizing system development tasks modelled using SysML. Journal of Integrated Design \& Process Science 18(3), 19-40 (2014). https://doi.org/10.3233/jid-2014-0013

[S417] Noten, J.V., Gadeyne, K., Witters, M.: Model-based Systems Engineering of Discrete Production Lines Using SysML: An Experience Report. In: Complex Systems Engineering and Development Proceedings of the 27th CIRP Design Conference Cranfield University, UK 10th - 12th May, Procedia CIRP, vol. 60, pp. 157 - 162 (2017). https://doi.org/10. 1016/j.procir.2017.01.018

[S418] Nottage, D., Corns, S., Soylemezoglu, A., Kinnevan, K.: A SysML framework for modeling contingency basing. Systems Engineering 18(2), 162-177 (2015). https://doi.org/10.1002/sys.21297

[S419] Nottage, D., Corns, S.M.: SysML profiling for handling army base camp planning. In: Proceedings of the Complex Adaptive Systems 2011 Conference, Chicago, Illinois, USA, October 31-November 2, Procedia Computer Science, vol. 6, pp. 6368. Elsevier (2011). https://doi.org/10.1016/j.procs. 2011.08 .014

[S420] Oates, R.F., Thom, F., Herries, G.: Security-Aware, Model-Based Systems Engineering with SysML. In: Proceedings of the 1st International Symposium for ICS \& SCADA Cyber Security Research 2013, ICS-CSR 2013, Leicester, UK, September 16-17, Workshops in Computing. BCS (2013)

[S421] Ober, I., Ober, I., Dragomir, I., Aboussoror, E.: UML/SysML semantic tunings. Innovations in Systems and Software Engineering 7(4), 257-264 (2011). https://doi.org/10.1007/s11334-011-0163-2

[S422] Ohara, K., Iwane, K., Takubo, T., Mae, Y., Arai, T.: Component-based robot software design for pickand-place task described by SysML. In: Proceedings of the 8th International Conference on Ubiquitous Robots and Ambient Intelligence (URAI 2011), Incheon, Korea (South), November 23-26, pp. 124127. IEEE (2011). https://doi.org/10.1109/URAI. 2011.6145945

[S423] Ollinger, L., Zühlke, D., Theorin, A., Johnsson, C.: A reference architecture for service-oriented control procedures and its implementation with SysML and Grafchart. In: Proceedings of 2013 IEEE 18th Conference on Emerging Technologies \& Factory Automation, ETFA 2013, Cagliari, Italy, September 10-13, pp. 1-8. IEEE (2013). https://doi.org/10. 1109/ETFA.2013.6648044

[S424] Ono, K., Nakamura, H., Ishikawa, H.: A dynamic verification method of executable UML/SysML models with timed-functional constraints. Computer Software 27(2), 33-49 (2010)
[S425] Orellana, D., Turso, J., McClure, C.: Architecting a Nuclear Power Plant with SysML and a Model Driven Engineering Environment. In: Proceedings of the ANS Annual Winter Meeting and Embedded Topical Meetings: 1st ANS SMR 2011 Conference and Young Professionals Congress, TransactionsAmerican Nuclear Society, vol. 105, pp. 323-324 (2011)

[S426] Orr, K., Ramakrishnan, S., Dagli, C.: Can systems modeling language impact systems engineering? In: Proceedings of the 16th Annual International Symposium of the International Council on Systems Engineering (INCOSE 2006), INCOSE International Symposium, vol. 16, pp. 1688-1699 (2006)

[S427] Ortega-Míguez, C., Hein, A.: A methodology for Rapid Preliminary Space Mission Design using SysML. In: Proceedings of the International Astronautical Congress (IAC), vol. 10, pp. 8225-8236 (2012)

[S428] Ouchani, S., Aït Mohamed, O., Debbabi, M.: A property-based abstraction framework for SysML activity diagrams. Knowledge-Based Systems 56, 328-343 (2014). https://doi.org/10.1016/j.knosys. 2013.11.016

[S429] Ouchani, S., Lenzini, G.: Generating attacks in SysML activity diagrams by detecting attack surfaces. Journal of Ambient Intelligence and Humanized Computing 6(3), 361-373 (2015). https://doi. org/10.1007/s12652-015-0269-8

[S430] Ouchani, S., Mohamed, O., Debbabi, M.: A formal verification framework for SysML activity diagrams. Expert Systems with Applications 41(6), 2713-2728 (2014). https://doi.org/10.1016/j.eswa.2013.10.064

[S431] Ouchani, S., Mohamed, O.A., Debbabi, M.: A Probabilistic Verification Framework for SysML Activity Diagrams. In: New Trends in Software Methodologies, Tools and Techniques - Proceedings of the 11th SoMeT '12, Genoa, Italy, September 26-28, Frontiers in Artificial Intelligence and Applications, vol. 246, pp. 108-123. IOS Press (2012). https://doi.org/ 10.3233/978-1-61499-125-0-108

[S432] Ouchani, S., Mohamed, O.A., Debbabi, M.: Efficient probabilistic abstraction for sysml activity diagrams. In: G. Eleftherakis, M. Hinchey, M. Holcombe (eds.) Software Engineering and Formal Methods 10th International Conference, SEFM 2012, Thessaloniki, Greece, October 1-5, 2012. Proceedings, Lecture Notes in Computer Science, vol. 7504, pp. 263-277. Springer (2012). https://doi.org/10.1007/ 978-3-642-33826-7_18

[S433] Ouchani, S., Mohamed, O.A., Debbabi, M.: A probabilistic verification framework of SysML activity diagrams. In: Proceedings of the IEEE 12th 
International Conference on Intelligent Software Methodologies, Tools and Techniques, SoMeT 2013, Budapest, Hungary, September 22-24, pp. 165-170. IEEE (2013). https://doi.org/10.1109/SoMeT.2013. 6645657

[S434] Ouchani, S., Mohamed, O.A., Debbabi, M.: A Security Risk Assessment Framework for SysML Activity Diagrams. In: Proceedings of the IEEE 7th International Conference on Software Security and Reliability, SERE 2013, Gaithersburg, MD, USA, June 18-20, pp. 227-236. IEEE (2013). https://doi. org/10.1109/SERE.2013.11

[S435] Ouerdi, N., Azizi, M., Ziane, M., Azizi, A., Lanet, J., Savary, A.: Security vulnerabilities tests generation from SysML and event-B models for EMV cards. International Journal of Security and its Applications 8(1), 373-388 (2014). https://doi.org/10. 14257/ijsia.2014.8.1.35

[S436] Ouerdi, N., Ziane, M., Azizi, A., Azizi, M.: Modeling embedded systems with SysML. In: Proceedings of International Conference on Multimedia Computing and Systems (ICMCS 2012), pp. 905-910. IEEE (2012). https://doi.org/10.1109/ICMCS.2012. 6320272

[S437] Ouerdi, N., Ziane, M., Azizi, A., Azizi, M., Lanet, J.L.: Abstract tests based on SysML models for EMV Card. In: Proceedings of the National Security Days (JNS3), pp. 1-6 (2013). https://doi.org/10. 1109/JNS3.2013.6595461

[S438] Pais, R., Barros, J., Gomes, L.: From SysML State Machines to Petri Nets Using ATL Transformations. In: Proceedings of Technological Innovation for Collective Awareness Systems - 5th IFIP WG 5.5/SOCOLNET Doctoral Conference on Computing, Electrical and Industrial Systems, DoCEIS 2014, Costa de Caparica, Portugal, April 7-9, IFIP Advances in Information and Communication Technology, vol. 423, pp. 227-236. Springer (2014). https://doi.org/10.1007/978-3-642-54734-8_26

[S439] Palachi, E., Cohen, C., Takashi, S.: Simulation of cyber physical models using SysML and numerical solvers. In: Proceedings of the IEEE International Systems Conference, SysCon 2013, Orlando, FL, USA, April 15-18, pp. 671-675. IEEE (2013). https://doi.org/10.1109/SysCon.2013.6549954

[S440] Pantsar-Syväniemi, S., Ovaska, E.: Model based architecting with MARTE and SysML profiles. In: Proceedings of the IASTED International Conference on Software Engineering (SE 2010), pp. 1-8 (2010)

[S441] Papakonstantinou, N., Sierla, S.: Generating an Object Oriented IEC 61131-3 software product line architecture from SysML. In: C. Seatzu (ed.) Pro- ceedings of 2013 IEEE 18th Conference on Emerging Technologies \& Factory Automation, ETFA 2013, Cagliari, Italy, September 10-13, pp. 1-8. IEEE (2013). https://doi.org/10.1109/ETFA.2013. 6648057

[S442] Paredis, C., Bernard, Y., Burkhart, R., de Koning, H.P., Friedenthal, S., Fritzson, P., Rouquette, N., Schamai, W.: An overview of the SysML-Modelica transformation specification. In: Proceedings of the 20th Annual International Symposium of the International Council on Systems Engineering (INCOSE 2010), INCOSE International Symposium, vol. 20, pp. 709-722 (2010)

[S443] Paredis, C., Johnson, T.: Using OMG'S SysML to support simulation. In: Proceedings of the 2008 Winter Simulation Conference, Global Gateway to Discovery (WSC 2008), InterContinental Hotel, Miami, Florida, USA, December 7-10, pp. 2350 2352. WSC (2008). https://doi.org/10.1109/WSC. 2008.4736341

[S444] Patel, V., McGregor, J., Goasguen, S.: SysML-based domain-specific executable workflows. In: Proceedings of the IEEE International Systems Conference (SysCon 2010), pp. 505-509 (2010). https://doi.org/ 10.1109/SYSTEMS.2010.5482335

[S445] Patwari, P., Chaudhuri, S.R., Banerjee, A., Natarajan, S., Pandey, S.: A complementary domain specific design environment aiding SysML. In: Proceedings of the 2016 IEEE International Symposium on Systems Engineering (ISSE), Oct., pp. 1-8 (2016). https://doi.org/10.1109/SysEng.2016.7753164

[S446] Peak, R., Burkhart, R., Friedenthal, S., Wilson, M., Bajaj, M., Kim, I.: Simulation-based design using SysML part 1: A parametrics primer. In: Proceedings of the 17th Annual International Symposium of the International Council on Systems Engineering (INCOSE 2007), INCOSE International Symposium, vol. 17, pp. 1516-1535 (2007)

[S447] Peak, R., Burkhart, R., Friedenthal, S., Wilson, M., Bajaj, M., Kim, I.: Simulation-based design using SysML part 2: Celebrating diversity by example. In: Proceedings of the 17th Annual International Symposium of the International Council on Systems Engineering (INCOSE 2007), INCOSE International Symposium, vol. 17, pp. 1536-1557 (2007)

[S448] Pedroza, G., Apvrille, L., Knorreck, D.: AVATAR: A SysML environment for the formal verification of safety and security properties. In: Proceedings of the 11th Annual International Conference on New Technologies of Distributed Systems (NOTERE 2011), pp. 1-10. IEEE (2011). https://doi.org/10. 1109/NOTERE.2011.5957992 
[S449] Petrinca, P., Gammaldi, M., Tirone, L.: A SysMLbased approach for the specification of complex systems. In: Proceedings of the 22nd Annual International Symposium of the International Council on Systems Engineering (INCOSE 2012) and the 8th Biennial European Systems Engineering Conference (EuSEC 2012), vol. 2, pp. 817-830 (2012)

[S450] Peukert, A.: S/C behavior modeling using SysML for model-based systems engineering support. In: Proceedings of the AIAA Space 2008 Conference \& Exposition, San Diego, California, USA (2008)

[S451] Phaoharuhansa, D., Shimada, A.: An approach to SysML and Simulink based motion controller design for inverted pendulum robots. In: Proceedings of the SICE Annual Conference, pp. 2190-2193. IEEE (2011)

[S452] Piétrac, L., Lelevé, A., Henry, S.: On the use of SysML for manufacturing execution system design. In: Proceedings of the 16th Conference on Emerging Technologies \& Factory Automation (ETFA 2011), Toulouse, France, September 5-9, pp. 1-8. IEEE (2011). https://doi.org/10.1109/ETFA.2011. 6058984

[S453] Pihlanko, P., Sierla, S., Thramboulidis, K., Viitasalo, M.: An industrial evaluation of SysML: The case of a nuclear automation modernization project. In: Proceedings of 2013 IEEE 18th Conference on Emerging Technologies \& Factory Automation, ETFA 2013, Cagliari, Italy, September 10-13, pp. 1-8. IEEE (2013). https://doi.org/10.1109/ETFA.2013. 6647945

[S454] Pires, A.F., Duprat, S., Besseyre, C.: Approche UML/SysML pour la spécification logicielle de systèmes embarqués aéronautiques. Travaux et retours d'expérience. Technique et Science Informatiques 31(7), 897-916 (2012). https://doi.org/10.3166/tsi. 31.897-916

[S455] Polit-Casillas, R., Howe, A.S.: Virtual construction of space habitats: Connecting Building Information Models (BIM) and SysML. In: Proceedings of the AIAA SPACE Conference and Exposition, San Diego, CA, United States, September 10-12 (2013)

[S456] Prevostini, M., Ganesan, S.: Bridging the Gap Between SysML and Design Space Exploration. In: Proceedings of the Forum on specification and Design Languages (FDL 2006), Darmstadt, Germany, September 19-22, pp. 389-395. ECSI (2006)

[S457] Qamar, A., During, C., Wikander, J.: Designing mechatronic systems, a model-based perspective, an attempt to achieve SysML-Matlab/Simulink model integration. In: Proceedings of the IEEE/ASME International Conference on Advanced Intelligent
Mechatronics (AIM 2009), pp. 1306-1311 (2009). https://doi.org/10.1109/AIM.2009.5229869

[S458] Qiao, D., Liu, X., Li, H.: Research on SysML-based modeling for production management system. In: Proceedings of the 3rd International Conference on Advanced Engineering Materials and Technology (AEMT 2013), Advanced Materials Research, vol. 753-755, pp. 1868-1874 (2013). https://doi.org/10. 4028/www.scientific.net/AMR.753-755.1868

[S459] Rabelo, L., Clark, T.: Modeling Space Operations Systems Using SysML as to Enable Anomaly Detection. SAE International Journal of Aerospace 8(2) (2015). https://doi.org/10.4271/2015-01-2388

[S460] Raher, A., Pangaro, P.: Cybernetics and SysML: First steps. In: Proceedings of the 22nd Annual International Symposium of the International Council on Systems Engineering (INCOSE 2012) and the 8th Biennial European Systems Engineering Conference (EuSEC 2012), INCOSE International Symposium, vol. 22, pp. 1846-1855 (2012)

[S461] Rahim, M., Ahmed, H., Ioualalen, M.: Modular and Distributed Verification of SysML Activity Diagrams. In: Proceedings of the 1st International Conference on Model-Driven Engineering and Software Development (MODELSWARD 2013), Barcelona, Spain, February 19-21, pp. 202-205. SciTePress (2013). https://doi.org/10.5220/0004320602020205

[S462] Rahim, M., Boukala-Ioualalen, M., Ahmed, H.: Petri Nets Based Approach for Modular Verification of SysML Requirements on Activity Diagrams. In: Proceedings of the International Workshop on Petri Nets and Software Engineering, co-located with 35th International Conference on Application and Theory of Petri Nets and Concurrency (PetriNets 2014) and 14th International Conference on Application of Concurrency to System Design (ACSD 2014), Tunis, Tunisia, June 23-24, CEUR Workshop Proceedings, vol. 1160, pp. 233-248. CEUR-WS.org (2014)

[S463] Rahim, M., Hammad, A., Boukala-Ioualalen, M.: Towards the formal verification of SysML specifications: Translation of activity diagrams into modular Petri nets. In: Proceedings of the 3rd International Conference on Applied Computing and Information Technology and 2nd International Conference on Computational Science and Intelligence, ACIT-CSI, pp. 509-516 (2015). https://doi.org/10.1109/ACITCSI.2015.97

[S464] Rahim, M., Hammad, A., Ioualalen, M.: A methodology for verifying SysML requirements using activity diagrams. Innovations in Systems and Software Engineering (ISSE) 13(1), 19-33 (2017). https://doi. org/10.1007/s11334-016-0281-y 
[S465] Rahim, M., Kheldoun, A., Boukala-Ioualalen, M., Hammad, A.: Recursive ECATNets-based approach for formally verifying system modelling language activity diagrams. IET Software 9(5), 119-128 (2015). https://doi.org/10.1049/iet-sen.2014.0087

[S466] Rahman, M., Mizukawa, M.: Model-based development and simulation for robotic systems with SysML, Simulink and Simscape profiles. International Journal of Advanced Robotic Systems 10 (2013). https://doi.org/10.5772/55533

[S467] Rahman, M., Mizukawa, M.: Modeling and design of mechatronics system with SysML, Simscape and Simulink. In: Proceedings of the IEEE/ASME International Conference on Advanced Intelligent Mechatronics: Mechatronics for Human Wellbeing, AIM 2013, pp. 1767-1773 (2013). https://doi.org/ 10.1109/AIM.2013.6584353

[S468] Rahman, M., Mizukawa, M., Phaoharuhansa, D., Shimada, A.: Modelling and Simulation of Robotic Systems using SysML. International Journal of Modelling and Simulation 33(3), 152-161 (2013). https:// doi.org/10.2316/Journal.205.2013.3.205-5797

[S469] Rahman, M., Nor, N., Mizukawa, M.: Evaluation for SysML-based design and analysis models using PCE. In: Proceedings of the IEEE International Conference on Control System, Computing and Engineering (ICCSCE 2012), pp. 339-344. IEEE (2013). https://doi.org/10.1109/ICCSCE.2012.6487167

[S470] Ramirez, S.: SysML model of exoplanet archive functionality and activities. In: Proceedings of SPIE 9911, Modeling, Systems Engineering, and Project Management for Astronomy VII, 991129 (2016). https://doi.org/10.1117/12.2232862

[S471] Ramos, A., Ferreira, J.: SysML: The dialect for model-based systems engineering. In: Systems Engineering: Concepts, Tools and Applications, pp. 63104. Nova Science Publishers (2016)

[S472] Rao, M.: SysML with ARTiSAN Studio. In: Proceedings of the IEEE Symposium on Visual Languages and Human-Centric Computing (VL/HCC 2005), Dallas, TX, USA, September 21-24, p. 15. IEEE Computer Society (2005). https://doi.org/10.1109/ VLHCC.2005.59

[S473] Rao, M., Ramakrishnan, S., Dagli, C.: Modeling and simulation of net centric system of systems using systems modeling language and Colored Petri-nets: A demonstration using the Global Earth Observation System of Systems. Systems Engineering 11(3), 203-220 (2008). https://doi.org/10.1002/sys.20095

[S474] Raslan, W., Sameh, A.: Accelerating SoC Design Using SysML and SystemC. In: Proceedings of the 5th International Industrial Simulation Conference
(ISC 2007), Delft, Netherland, June 11-13, pp. 247251 (2007)

[S475] Raslan, W., Sameh, A.: Mapping SysML to SystemC. In: Proceedings of the Forum on specification and Design Languages (FDL 2007), Barcelona, Spain, September 18-20, pp. 225-230. ECSI (2007)

[S476] Raslan, W., Sameh, A.: System-level modeling and design using SysML and SystemC. In: Proceedings of the International Symposium on Integrated Circuits, ISIC, pp. 504-507. IEEE (2007). https://doi. org/10.1109/ISICIR.2007.4441909

[S477] Raymond, C., Prun, D.: Extending MBSE methodology and SysML formalism to integrate human considerations. In: Proceedings of the International Conference on Human-Computer Interaction in Aerospace, HCI-Aero 2016, Paris, France, September 14-16, 2016, pp. 18:1-18:4. ACM (2016). https://doi.org/10.1145/2950112.2951852

[S478] Reichwein, A., Paredis, C., Canedo, A., Witschel, P., Stelzig, P.E., Votintseva, A., Wasgint, R.: Maintaining consistency between system architecture and dynamic system models with SysML4Modelica. In: Proceedings of the 6th International Workshop on Multi-Paradigm Modeling (MPM@MoDELS 2012), Innsbruck, Austria, October 1-5, pp. 43-48. ACM (2012). https://doi.org/10.1145/2508443.2508451

[S479] Ribeiro, F., Pereira, C., Rettberg, A., Soares, M.: Model-based requirements specification of real-time systems with UML, SysML and MARTE. Software \& Systems Modeling pp. 1-19 (2016). https://doi. org/10.1007/s10270-016-0525-1

[S480] Ribeiro, F.G.C., Misra, S., Soares, M.S.: Application of an Extended SysML Requirements Diagram to Model Real-Time Control Systems. In: Proceedings of the 13th International Conference on Computational Science and Its Applications (ICCSA 2013), Ho Chi Minh City, Vietnam, June 24-27, Part III, Lecture Notes in Computer Science, vol. 7973, pp. 70-81. Springer (2013). https://doi.org/10.1007/ 978-3-642-39646-5_6

[S481] Ribeiro, F.G.C., Soares, M.S.: An Approach for Modeling Real-time Requirements with SysML and MARTE Stereotypes. In: Proceedings of the 15th International Conference on Enterprise Information Systems (ICEIS 2013), Volume 2, Angers, France, July 4-7, pp. 70-81. SciTePress (2013). https://doi. org/10.5220/0004449800700081

[S482] Ribeiro, Q.A.D.S., Ribeiro, F.G.C., Soares, M.S.: A Technique to Architect Real-time Embedded Systems with SysML and UML through Multiple Views. In: S. Hammoudi, M. Smialek, O. Camp, J. Filipe (eds.) ICEIS 2017 - Proceedings of the 19th International Conference on Enterprise Information 
Systems, Volume 2, Porto, Portugal, April 26-29, 2017, pp. 287-294. SciTePress (2017). https://doi. org/10.5220/0006294802870294

[S483] Riccobene, E., Scandurra, P.: Integrating the SysML and the SystemC-UML profiles in a model-driven embedded system design flow. Design Automation for Embedded Systems 16(3), 53-91 (2012). https:// doi.org/10.1007/s10617-012-9097-7

[S484] Richards, D., Stuart, A., Hause, M.: Testing solutions through SysML/UML. In: Proceedings of the 19th Annual International Symposium of the International Council on Systems Engineering (INCOSE 2009), INCOSE International Symposium, vol. 19, pp. 760774 (2009)

[S485] Robol, M., Salnitri, M., Giorgini, P.: Toward GDPRCompliant Socio-Technical Systems: Modeling Language and Reasoning Framework. In: G. Poels, F. Gailly, E.S. Asensio, M. Snoeck (eds.) The Practice of Enterprise Modeling - 10th IFIP WG 8.1. Working Conference, PoEM 2017, Leuven, Belgium, November 22-24, Lecture Notes in Business Information Processing, vol. 305, pp. 236250. Springer (2017). https://doi.org/10.1007/9783-319-70241-4_16

[S486] Romaniw, Y., Bras, B., Guldberg, T.: Sustainable Manufacturing Analysis Using Activity Based Costing in SysML. In: Proceedings of the ASME Design Engineering Technical Conferences and Computers and Information in Engineering Conference, vol. 2, pp. 1019-1028 (2011). https://doi.org/10. 1115/DETC2011-48867

[S487] Roth, N.: An architectural assessment of bitcoin: Using the systems modeling language. In: Proceedings of the Conference on Systems Engineering Research, Procedia Computer Science, vol. 44, pp. 527-536 (2015). https://doi.org/10.1016/j.procs. 2015.03.066

[S488] Roudier, Y., Apvrille, L.: SysML-Sec - A Model Driven Approach for Designing Safe and Secure Systems. In: Proceedings of the 3rd International Conference on Model-Driven Engineering and Software Development, MODELSWARD 2015, ESEO, Angers, Loire Valley, France, 9-11 February, pp. 655-664. SciTePress (2015). https://doi.org/10.5220/ 0005402006550664

[S489] Ruin, T., Levrat, E., Iung, B.: Modeling Framework based on SysML and AltaRica Data Flow languages for developing models to support complex maintenance program quantification. In: Proceedings of the 2nd IFAC Workshop on Advanced Maintenance Engineering, Services and Technology, IFAC Proceedings Volumes (IFAC-PapersOnline), vol. 45, pp.
169-174 (2012). https://doi.org/10.3182/201211222-ES-4026.00018

[S490] Ruin, T., Levrat, E., Iung, B., Despujols, A.: Using SysML language for maintenance decision-making model development to support complex maintenance program quantification. In: Proceedings of the 11th International Probabilistic Safety Assessment and Management Conference and the Annual European Safety and Reliability Conference (PSAM11 ESREL 2012), vol. 2, pp. 1485-1494 (2012)

[S491] Sabetzadeh, M., Nejati, S., Briand, L.C., Mills, A.E.: Using SysML for Modeling of Safety-Critical Software-Hardware Interfaces: Guidelines and Industry Experience. In: Proceedings of the 13th IEEE International Symposium on High-Assurance Systems Engineering (HASE 2011), Boca Raton, FL, USA, November 10-12, pp. 193-201. IEEE Computer Society (2011). https://doi.org/10.1109/HASE. 2011.23

[S492] Sadovykh, A., Bagnato, A., Quadri, I., Mady, A.E.D., Couto, L.D., Basagiannis, S., Hasanagic, M.: SysML As a Common Integration Platform for CoSimulations: Example of a Cyber Physical System Design Methodology in Green Heating Ventilation and Air Conditioning Systems. In: Proceedings of the 12th Central and Eastern European Software Engineering Conference in Russia, CEE-SECR '16, pp. 1:1-1:5. ACM, New York, NY, USA (2016). https:// doi.org/10.1145/3022211.3022212

[S493] Sakairi, T., Palachi, E., Cohen, C., Hatsutori, Y., Shimizu, J., Miyashita, H.: Designing a control system using SysML and Simulink. In: Proceedings of the SICE Annual Conference, pp. 2011-2017. IEEE (2012)

[S494] Sakairi, T., Palachi, E., Cohen, C., Hatsutori, Y., Shimizu, J., Miyashita, H.: Model Based Control System Design Using SysML, Simulink, and Computer Algebra System. Journal of Control Science and Engineering 2013 (2013). https://doi.org/10. $1155 / 2013 / 485380$

[S495] Scanniello, G., Staron, M., Burden, H., Heldal, R.: On the effect of using SysML requirement diagrams to comprehend requirements: Results from two controlled experiments. In: Proceedings of the 18th International Conference on Evaluation and Assessment in Software Engineering, EASE '14, London, England, United Kingdom, May 13-14, pp. 49:1-49:10. ACM (2014). https://doi.org/10.1145/ 2601248.2601259

[S496] Schlecht, S., Alt, O.: Strategien zur Testfallgenerierung aus SysML Modellen. In: Software Engineering 2007 - Beiträge zu den Workshops, Fachtagung des GI-Fachbereichs Softwaretechnik, 27.- 
30.3.2007 in Hamburg, LNI, vol. 106, pp. 101-106. GI (2007)

[S497] Schönherr, O., Moss, J., Rehm, M., Rose, O.: A free simulator for modeling production systems with SysML. In: Proceedings of the Winter Simulation Conference, pp. 1-12 (2012). https://doi.org/ 10.1109/WSC.2012.6465090

[S498] Schönherr, O., Pappert, F., Rose, O.: Domain specific simulation modeling with SysML and model-tomodel transformation for discrete processes. In: Formal Languages for Computer Simulation: Transdisciplinary Models and Applications, pp. 267-304. IGI Global (2013). https://doi.org/10.4018/978-14666-4369-7.ch009

[S499] Schönherr, O., Rose, O.: First Steps Towards a General SysML Model for Discrete Processes in Production Systems. In: Proceedings of the 2009 Winter Simulation Conference (WSC 2009), Hilton Austin Hotel, Austin, TX, USA, December 1316, pp. 1711-1718. WSC (2009). https://doi.org/10. 1109/WSC.2009.5429164

[S500] Schönherr, O., Rose, O.: Important Components for Modeling Production Systems with SysML. In: Proceedings of the IIE Annual Conference and Expo, pp. 1-6 (2010)

[S501] Schütz, D., Aicher, T., Vogel-Heuser, B.: Automatic generation of shop floor gateway configurations from systems modeling language. In: Proceedings of the IEEE International Systems Engineering Symposium (ISSE), pp. 1-8 (2017). https://doi.org/10. 1109/SysEng.2017.8088288

[S502] Schütz, D., Legat, C., Vogel-Heuser, B.: MDE of manufacturing automation software - Integrating SysML and standard development tools. In: Proceedings of the 12th IEEE International Conference on Industrial Informatics, INDIN 2014, Porto Alegre, RS, Brazil, July 27-30, pp. 267-273. IEEE (2014). https://doi.org/10.1109/INDIN.2014.6945519

[S503] Schütz, D., Obermeier, M., Vogel-Heuser, B.: SysMLBased Approach for Automation Software Development - Explorative Usability Evaluation of the Provided Notation. In: Proceedings of the 2nd International Conference on Design, User Experience, and Usability. Web, Mobile, and Product Design, DUXU 2013, Held as Part of HCI International 2013, Las Vegas, NV, USA, July 21-26, Part IV, Lecture Notes in Computer Science, vol. 8015, pp. 568574. Springer (2013). https://doi.org/10.1007/9783-642-39253-5_63

[S504] Scippacercola, F., Pietrantuono, R., Russo, S., Silva, N.: SysML-based and Prolog-supported FMEA. In: Proceedings of the IEEE International Symposium on Software Reliability Engineering Work- shops, ISSRE Workshops, Gaithersburg, MD, USA, November 2-5, pp. 174-181. IEEE Computer Society (2015). https://doi.org/10.1109/ISSREW.2015. 7392064

[S505] Seal, D.: Promise and progress of SysML and merit functions as applied to systems engineering at JPL. In: Proceedings of the 61st International Astronautical Congress (IAC 2010), vol. 8, pp. 6226-6232 (2010)

[S506] Seki, K., Muraoka, Y., Nishimura, H.: System level thermal design-process modeling for functional/ structure design using SysML and MDM. In: Proceedings of the 17th International DSM Conference, Modeling and Managing Complex Systems, pp. 149-159. Carl Hanser Verlag (2015)

[S507] Selvy, B., Claver, C., Angeli, G.: Using SysML for verification and validation planning on the Large Synoptic Survey Telescope (LSST). In: Modeling, Systems Engineering, and Project Management for Astronomy VI, Montréal, Quebec, Canada, June 22, Proceedings of SPIE, vol. 9150, pp. 91,500N-91,500N-13 (2014). https://doi.org/10.1117/ 12.2056773

[S508] Sena Marques, M., Siegert, E., Brisolara, L.: Integrating UML, MARTE and SysML to improve requirements specification and traceability in the embedded domain. In: Proceedings of the 12th IEEE International Conference on Industrial Informatics, INDIN 2014, Porto Alegre, RS, Brazil, July 27-30, pp. 176-181. IEEE (2014). https://doi.org/10.1109/ INDIN.2014.6945504

[S509] Sha, Z., Le, Q., Panchal, J.: Using SysML for Conceptual Representation of Agent-Based Models. In: Proceedings of the ASME Design Engineering Technical Conference and Computers and Information in Engineering Conference, Washington, DC, USA, August 28-31, vol. 2, pp. 39-50 (2011). https://doi. org/10.1115/DETC2011-47476

[S510] Shah, A., Kerzhner, A., Schaefer, D., Paredis, C.: Multi-view Modeling to Support Embedded Systems Engineering in SysML. In: Graph Transformations and Model-Driven Engineering - Essays Dedicated to Manfred Nagl on the Occasion of his 65th Birthday, Lecture Notes in Computer Science, vol. 5765, pp. 580-601. Springer (2010). https://doi.org/10. 1007/978-3-642-17322-6_25

[S511] Shah, A., Paredis, C., Burkhart, R., Schaefer, D.: Combining Mathematical Programming and SysML for Component Sizing of Hydraulic Systems. In: Proceedings of the ASME Design Engineering Technical Conference and Computers and Information in Engineering Conference (IDETC/CIE2010), August 
15-18, vol. 3, pp. 1231-1245 (2010). https://doi.org/ 10.1115/DETC2010-28960

[S512] Shah, A., Paredis, C., Burkhart, R., Schaefer, D.: Combining Mathematical Programming and SysML for Automated Component Sizing of Hydraulic Systems. Journal of Computing and Information Science in Engineering 12(4), 041,006-1 - 041,006-14 (2012). https://doi.org/10.1115/1.4007764

[S513] Shames, P., Sarrel, M., Friedenthal, S.: Modeling systems-of-systems interfaces with SysML. In: Proceedings of the 14th International Conference on Space Operations (SpaceOps), Daejon, Korea, 1620 May (2016)

[S514] Shinozaki, M., Mhenni, F., Choley, J., Ming, A.: Reuse of SysML model to support innovation in mechatronic systems design. In: Proceedings of the Annual IEEE International Systems Conference, SysCon 2017, Montreal, QC, Canada, April 24-27, 2017, pp. 1-6. IEEE (2017). https://doi.org/10.1109/ SYSCON.2017.7934709

[S515] Siebold, U., Häring, I.: Semi-formal safety requirement specification using SysML state machine Diagrams. In: Proceedings of the 11th International Probabilistic Safety Assessment and Management Conference and the Annual European Safety and Reliability Conference (PSAM11 ESREL 2012), Helsinki, Finland, June 25-29, vol. 3, pp. 2102-2111 (2012)

[S516] Silva, R.F., Fragal, V.H., de Oliveira Junior, E.A., de Souza Gimenes, I.M., Oquendo, F.: SyMPLES - A SysML-based Approach for Developing Embedded Systems Software Product Lines. In: Proceedings of the 15th International Conference on Enterprise Information Systems (ICEIS 2013), Volume 2, Angers, France, July 4-7, pp. 257-264. SciTePress (2013). https://doi.org/10.5220/0004446802570264

[S517] Sindico, A., Natale, M.D., Panci, G.: Integrating SysML with Simulink using Open-source Model Transformations. In: Proceedings of 1st International Conference on Simulation and Modeling Methodologies, Technologies and Applications (SIMULTECH 2011), Noordwijkerhout, The Netherlands, July 29 - 31, pp. 45-56. SciTePress (2011)

[S518] Sjöstedt, C., Chen, D., Cuenot, P., Frey, P., Johansson, R., Lönn, H., Servat, D., Törngren, M.: Developing Dependable Automotive Embedded Systems using the EAST-ADL; representing continuous time systems in SysML. In: Proceedings of the 1st International Workshop on Equation-Based ObjectOriented Languages and Tools (EOOLT 2007), Berlin, Germany, July 30, Linköping Electronic Conference Proceedings, vol. 24, pp. 25-36. Linköping University Electronic Press (2007)
[S519] Soares, M., Vrancken, J.: Requirements specification and modeling through SysML. In: Proceedings of the IEEE International Conference on Systems, Man and Cybernetics 2007, Montréal, Canada, October 7-10 October, pp. 1735-1740. IEEE (2007). https://doi. org/10.1109/ICSMC.2007.4413936

[S520] Soares, M., Vrancken, J.: A Proposed Extension to the SysML Requirements Diagram. In: Proceedings of the IASTED International Conference on Software Engineering (SE 2008), Innsbruck, Austria, pp. 220-225. ACTA Press (2008)

[S521] Soares, M., Vrancken, J.: Model-driven user requirements specification using SysML. Journal of Software 3(6), 57-68 (2008)

[S522] Soares, M.S., do Nascimento, R.P.C.: Evaluation of SysML diagrams to document requirements using TAM. In: Proceedings of the 7th Euro American Conference on Telematics and Information Systems, EATIS'14, Valparaiso, Chile, April 02 - 04, pp. 9:19:6. ACM (2014). https://doi.org/10.1145/2590651. 2590661

[S523] Spyropoulos, D., Baras, J.S.: Extending Design Capabilities of SysML with Trade-off Analysis: Electrical Microgrid Case Study. In: Proceedings of the Conference on Systems Engineering Research, CSER 2013, Atlanta, Georgia, USA, March 19-22, Procedia Computer Science, vol. 16, pp. 108-117. Elsevier (2013). https://doi.org/10.1016/j.procs.2013. 01.012

[S524] Stancescu, S., Neagoe, L., Marinescu, R., Enoiu, E.: A SysML model for code correction and detection systems. In: Proceedings of the 33rd International Convention on Information and Communication Technology, Electronics and Microelectronics (MIPRO 2010), pp. 189-191 (2010)

[S525] Steimer, C., Fischer, J., Aurich, J.C.: Model-based Design Process for the Early Phases of Manufacturing System Planning using SysML. In: Complex Systems Engineering and Development Proceedings of the 27th CIRP Design Conference Cranfield University, UK 10th - 12th May, Procedia CIRP, vol. 60, pp. 163-168 (2017)

[S526] Tadano, K., Xiang, J., Kawato, M., Maeno, Y.: Synthesizing SRN Models from System Operations with SysML Diagrams for Availability Analysis. In: Proceedings of the 5th International Conference on Secure Software Integration and Reliability Improvement (SSIRI 2011), Jeju Island, Korea, June 27-29, pp. 5-6. IEEE Computer Society (2011). https://doi.org/10.1109/SSIRI-C.2011.44

[S527] Tamura, Y., Nishigaki, H., Miyoshi, K., Huang, H., Kawata, S.: A proposal of home continuity plan service system, modeling by SysML and validating 
by discrete event simulation. In: Proceedings of the SICE Annual Conference, pp. 137-144. IEEE (2012)

[S528] Tarawneh, H.: SysML-based web engineering a successful way to design web applications. In: Proceedings of the 1st International Conference on Software and Data Technologies (ICSOFT 2006), Setúbal, Portugal, September 11-14, pp. 269-272. INSTICC Press (2006)

[S529] Tenbergen, B., Bohn, P., Weyer, T.: Ein strukturierter Ansatz zur Ableitung methodenspezifischer UML/SysML-Profile am Beispiel des SPES 2020 Requirements Viewpoints. In: Software Engineering 2013 - Workshopband (inkl. Doktorandensymposium), Fachtagung des GI-Fachbereichs Softwaretechnik, 26. Februar - 1. März 2013 in Aachen, $L N I$, vol. 215, pp. 235-244. GI (2013)

[S530] Thom, F.: Modelling distributed integrated modular systems using the $\mathrm{UML}^{\mathrm{TM}}$ and the SysML ${ }^{\mathrm{TM}}$. In: Proceedings of DASIA 2005 : Data Systems In Aerospace, Edinburgh, Scotland, 30 May-2 June, no. 602 in ESA SP, pp. 55-62. ESA Publications Division (2005)

[S531] Thoma, A., Kormann, B., Vogel-Heuser, B.: Faultcentric system modeling using SysML for reliability testing. In: Proceedings of 17th International Conference on Emerging Technologies \& Factory Automation, ETFA 2012, Krakow, Poland, September 17-21, pp. 1-8. IEEE (2012). https://doi.org/10. 1109/ETFA.2012.6489543

[S532] Thramboulidis, K.: The 3+1 SysML View-Model in Model Integrated Mechatronics. JSEA 3(2), 109118 (2010). https://doi.org/10.4236/jsea.2010.32014

[S533] Thramboulidis, K., Buda, A.: 3+1 SysML view model for IEC61499 Function Block control systems. In: Proceedings of the 8th IEEE International Conference on Industrial Informatics (INDIN), pp. 175-180. IEEE (2010). https://doi.org/ 10.1109/INDIN.2010.5549440

[S534] Thramboulidis, K., Scholz, S.: Integrating the 3+1 SysML view model with safety engineering. In: Proceedings of 15th IEEE International Conference on Emerging Technologies and Factory Automation (ETFA 2010), Bilbao, Spain, September 13-16, pp. 1-8. IEEE (2010). https://doi.org/10.1109/ETFA. 2010.5641353

[S535] Trancho, G., Wang, L., Herzig, S., Karban, R., Boyer, C., Herriot, G., Anderson, D., Ellerbroek, B.: Analyzing the operational behavior of NFIRAOS LGS MCAO acquisition on the thirty meter telescope using SysML. In: 5th Adaptive Optics for Extremely Large Telescopes, 2017 AO4ELT5, vol. 2017-June, pp. 1-9 (2017). https://doi.org/10.26698/AO4ELT5. 0168
[S536] Trapp, S., Ramollari, E., Heintz, M., Weber, S., Dranidis, D., Börstler, J.: Collaborative Learning of UML and SysML. iJEP 1(2), 6-12 (2011)

[S537] Tsadimas, A.: Model-based enterprise information system architectural design with SysML. In: Proceedings of the 9th IEEE International Conference on Research Challenges in Information Science, RCIS 2015, Athens, Greece, May 13-15, pp. 492497. IEEE (2015). https://doi.org/10.1109/RCIS. 2015.7128911

[S538] Tsadimas, A., Kapos, G.D., Dalakas, V., Nikolaidou, M., Anagnostopoulos, D.: Integrating simulation capabilities into SysML for enterprise information system design. In: Proceedings of the 9th International Conference on System of Systems Engineering, SoSE 2014, Glenelg, Australia, June 9-13, pp. 272-277. IEEE (2014)

[S539] Tsadimas, A., Kapos, G.D., Dalakas, V., Nikolaidou, M., Anagnostopoulos, D.: Simulating simulationagnostic SysML models for enterprise information systems via DEVS. Simulation Modelling Practice and Theory 66, 243-259 (2016). https://doi.org/10. 1016/j.simpat.2016.04.001

[S540] Tsadimas, A., Nikolaidou, M., Anagnostopoulos, D.: Extending SysML to explore non-functional requirements: the case of information system design. In: Proceedings of the ACM Symposium on Applied Computing (SAC 2012), Riva, Trento, Italy, March 26-30, pp. 1057-1062. ACM (2012). https://doi.org/ $10.1145 / 2245276.2231941$

[S541] Tsadimas, A., Nikolaidou, M., Anagnostopoulos, D.: Model-Based system design using SysML: The role of the evaluation diagram. In: Formal Languages for Computer Simulation: Transdisciplinary Models and Applications, pp. 236-266. IGI Global (2013). https://doi.org/10.4018/978-1-4666-4369-7.ch008

[S542] Tueno, S., Laleau, R., Mammar, A., Frappier, M.: Towards Using Ontologies for Domain Modeling within the SysML/KAOS Approach. In: Proceedings of the IEEE 25th International Requirements Engineering Conference Workshops, RE 2017 Workshops, Lisbon, Portugal, September 4-8, pp. 1-5. IEEE Computer Society (2017). https://doi.org/10. 1109/REW.2017.22

[S543] Turki, S., Soriano, T., Sghaier, A.: Mechatronic systems modeling with SysML: A bond graphs addendum for energy analysis. WSEAS Transactions on Systems 4(5), 617-624 (2005)

[S544] Väljaots, E., Sell, R.: Unmanned ground vehicle SysML navigation model conducted by energy efficiency. In: Proceedings of the 3rd International Conference on Applied Materials and Electronics Engineering, Advanced Materials Research, vol. 
905, pp. 443-447 (2014). https://doi.org/10.4028/ www.scientific.net/AMR.905.443

[S545] Valles-Barajas, F.: A Formal Model for the Requirements Diagrams of SysML. IEEE Latin America Transactions 8(3), 259-268 (2010). https://doi.org/ 10.1109/TLA.2010.5538400

[S546] Vanderperren, Y., Dehaene, W.: The SysML profile for embedded system modelling. In: Proceedings of the Forum on specification and Design Languages (FDL 2005), Lausanne, Switzerland, September 2730, pp. 589-598. ECSI (2005)

[S547] Vanderperren, Y., Dehaene, W.: UML 2 and SysML: An Approach to Deal with Complexity in SoC/NoC Design. In: Proceedings of the Design, Automation and Test in Europe Conference and Exposition (DATE 2005), Munich, Germany, March 7-11, pp. 716-717. IEEE Computer Society (2005). https:// doi.org/10.1109/DATE.2005.319

[S548] Vernoosfaderani, M.: Generic satellite model libraries: Rapid Move to SysML. In: Proceedings of the 68th International Astronautical Congress: Unlocking Imagination, Fostering Innovation and Strengthening Security (IAC 2017), vol. 3, pp. 1373-1377 (2017)

[S549] Verries, J., Sahraoui, A.: Case study on SysML and VHDL-AMS for designing and validating systems. In: Proceedings of the World Congress on Engineering \& Computer Science (WCECS 2013), London, UK, July 3 - 5, Lecture Notes in Engineering and Computer Science, vol. 1, pp. 90-95 (2013)

[S550] Viehl, A., Bringmann, O., Rosenstiel, W.: Virtual Prototyping und frühe Evaluierung von Systemson-Chip mit UML2 und SysML. In: Methoden und Beschreibungssprachen zur Modellierung und Verifikation von Schaltungen und Systemen (MBMV 2006), Dresden, Germany, February 20-22, pp. 266270. Fraunhofer Institut für Integrierte Schaltungen (2006)

[S551] Viehl, A., Schönwald, T., Bringmann, O., Rosenstiel, W.: Formal performance analysis and simulation of UML/SysML models for ESL design. In: Proceedings of the Conference on Design, Automation and Test in Europe (DATE 2006), Munich, Germany, March 6-10, pp. 242-247. European Design and Automation Association, Leuven, Belgium (2006). https://doi.org/10.1109/DATE.2006.244110

[S552] Vogel-Heuser, B., Schütz, D., Frank, T., Legat, C.: Model-driven engineering of Manufacturing Automation Software Projects - A SysML-based approach. Mechatronics 24(7), 883-897 (2014). https://doi. org/10.1016/j.mechatronics.2014.05.003

[S553] Wagner, D., Bennett, M., Karban, R., Rouquette, N., Jenkins, S., Ingham, M.: An ontology for state analysis: Formalizing the mapping to SysML. In: Proceedings of the IEEE Aerospace Conference, pp. 1-16. IEEE (2012). https://doi.org/10.1109/AERO. 2012.6187335

[S554] Walker, L., Thomas, D.: Integrated System Modeling in SysML for Small Satellites. In: Proceedings of the AIAA Modeling and Simulation Technologies Conference, Grapevine, Texas (2017)

[S555] Wan, W., Cheong, H., Li, W., Zeng, Y., Iorio, F.: Automated transformation of design text ROM diagram into SysML models. Advanced Engineering Informatics 30(3), 585-603 (2016). https://doi.org/ 10.1016/j.aei.2016.07.003

[S556] Wang, R., Dagli, C.: An executable system architecture approach to discrete events system modeling using SysML in conjunction with Colored Petri Net. In: Proceedings of the 2nd Annual IEEE International Systems Conference (SysCon 2008), pp. 118125 (2008). https://doi.org/10.1109/SYSTEMS.2008. 4518997

[S557] Wang, R., Dagli, C.: Executable system architecting using systems modeling language in conjunction with colored Petri nets in a model-driven systems development process. Systems Engineering 14(4), 383-409 (2011). https://doi.org/10.1002/sys.20184

[S558] Wang, W., Liu, X.: Research on MDS method based on DEVS and SysML. In: Proceedings of the International Conference on System Science, Engineering Design and Manufacturing Informatization (ICSEM 2011), vol. 1, pp. 180-182. IEEE (2011). https://doi. org/10.1109/ICSSEM.2011.6081177

[S559] Wang, W., Zhao, B.: Research on construction method of DoDAF view based on DEVS and SysML. In: Proceedings of the World Automation Congress, pp. 1-4. IEEE (2012)

[S560] Warniez, A., Penas, O., Plateaux, R., Soriano, T.: SysML geometrical profile for integration of mechatronic systems. In: Proceedings of the IEEE/ASME International Conference on Advanced Intelligent Mechatronics, AIM, pp. 709-714(2014). https://doi. org/10.1109/AIM.2014.6878162

[S561] Watson, M.E., Rusnock, C.F., Colombi, J.M., Miller, M.E.: Human-centered design using system modeling language. Journal of Cognitive Engineering and Decision Making 11(3), 252-269 (2017). https://doi. org/10.1177/1555343417705255

[S562] Wei, Q., Jiao, J., Zhou, S., Zhao, T.: Research on accident process meta-modeling based on SysML. In: Proceedings of the 1st International Conference on Reliability Systems Engineering (ICRSE), Oct.,pp. 1-6(2015). https://doi.org/10.1109/ICRSE. 2015.7366487 
[S563] Wells, W., Karwowski, W., Sala-Diakanda, S., Williams, [S571] Yamada, T.: A Generic Method for Defining ViewK., Ahram, T., Pharmer, J.: Application of Systems Modeling Language (SysML) for Cognitive Work Analysis in Systems Engineering Design Process. Journal of Universal Computer Science 17(9), 12611280 (2011). https://doi.org/10.3217/jucs-017-091261

[S564] Weyprecht, P., Rose, O.: Model-driven development of simulation solution based on SysML starting with the simulation core. In: Proceedings of the Spring Simulation Multi-conference, SpringSim '11, Boston, MA, USA, April 03-07, 2011. Volume 4: Proceedings of the 2011 Symposium on Theory of Modeling \& Simulation: DEVS Integrative M\&S Symposium (TMS-DEVS)., pp. 189-192. SCS/ACM (2011)

[S565] Wölkl, S., Shea, K.: A Computational Product Model for Conceptual Design Using SysML. In: Proceedings of the ASME Design Engineering Technical Conference and Computers and Information in Engineering Conference (DETC 2009), vol. 2, pp. 635-645 (2009). https://doi.org/10.1115/ DETC2009-87239

[S566] Wrycza, S., Marcinkowski, B.: SysML Parametric Diagrams in Business Applications. In: Information Systems Development, Business Systems and Services: Modeling and Development [Proceedings of ISD 2010, Charles University in Prague, Czech Republic, August 25-27], pp. 791-798. Springer (2010). https://doi.org/10.1007/978-1-44199790-6_64

[S567] Wrycza, S., Marcinkowski, B.: SysML Requirement Diagrams: Banking Transactional Platform Case Study. In: Research in Systems Analysis and Design: Models and Methods - 4th SIGSAND/PLAIS EuroSymposium 2011, Gdańsk, Poland, September 29, Revised Selected Papers, Lecture Notes in Business Information Processing, vol. 93, pp. 1522. Springer (2011). https://doi.org/10.1007/978-3642-25676-9_2

[S568] Wrycza, S., Marcinkowski, B.: Systems requirements specification with SysML. In: Proceedings of the 8th International Conference on Perspectives in Business Informatics Research (BIR 2009) (2014)

[S569] Wu, D., Zhang, L., Jiao, R., Lu, R.: SysML-based design chain information modeling for variety management in production reconfiguration. Journal of Intelligent Manufacturing 24(3), 575-596 (2013). https://doi.org/10.1007/s10845-011-0585-6

[S570] Wu, J., Wang, M.Z., Fang, H.J.: Product design of systems architecture using SysML. Xi Tong Gong Cheng Yu Dian Zi Ji Shu/Systems Engineering and Electronics 28(4), 594-598 (2006) points in SysML. In: Proceedings of the 19th Annual International Symposium of the International Council on Systems Engineering (INCOSE 2009), INCOSE International Symposium, vol. 19, pp. 844852 (2009)

[S572] Yerushalmi, R., Felice, R.: Implementing AUTOSAR atomic software components using UML/SysML in C. In: Proceedings of the SAE 2010 World Congress \& Exhibition, SAE Technical Papers (2010). https:// doi.org/10.4271/2010-01-0265

[S573] Yin, S.Y., Yang, Y., Miao, X.W., Zhao, T.D.: SysMLbased safety analysis of thrust reverser. Hangkong Dongli Xuebao/Journal of Aerospace Power 26(3), 498-504 (2011)

[S574] Yin, Y., Xu, Y., Miao, W., Chen, Y.: An automated test case generation approach based on activity diagrams of SysML. International Journal of Performability Engineering 13(6), 922-936 (2017). https:// doi.org/10.23940/ijpe.17.06.p13.922936

[S575] Yue, G., Rao, A., Jones, R.: Architectural and functional modelling of an automotive driver information system using SysML. In: Proceedings of the IEEE/ASME International Conference on Mechatronics and Embedded Systems and Applications (MESA 2008), pp. 552-557. IEEE (2008). https:// doi.org/10.1109/MESA.2008.4735654

[S576] Zdanis, L., Cloutier, R.: The use of behavioral diagrams in SysML. In: Proceedings of the IEEE Long Island Systems, Applications and Technology Conference (LISAT 2007), pp. 1-1 (2007). https://doi. org/10.1109/LISAT.2007.4312634

[S577] Zhang, W.Z., Wang, Z.X., Zhu, W.X., Chen, J.: Supporting study on modeling C4ISR systems based on SysML. Nanjing Li Gong Daxue Xuebao/Journal of Nanjing University of Science and Technology 35(3), 386-391 (2011)

[S578] Zhou, S., Sun, Q., Jiao, J.: A safety modeling method based on SysML. In: Proceedings of the 10th International Conference on Reliability, Maintainability and Safety: More Reliable Products, More Secure Life (ICRMS), pp. 1180-1185 (2014). https://doi. org/10.1109/ICRMS.2014.7107390

[S579] Zingel, C., Albers, A., Matthiesen, S., Maletz, M.: Experiences and Advancements from One Year of Explorative Application of an Integrated ModelBased Development Technique Using $C \& C^{2}-A$ in SysML. IAENG International Journal of Computer Science 39(2), 165-181 (2012) 


\section{B Books and theses (not used)}

\section{SysML-Books}

[B1] Debbabi, M., Hassaïne, F., Jarraya, Y., Soeanu, A., Alawneh, L.: Verification and Validation in Systems Engineering: Assessing UML/SysML Design Models. Springer (2010). https://doi.org/10.1007/978-3642-15228-3

[B2] Dori, D.: Model-Based Systems Engineering with OPM and SysML. Springer (2016). https://doi.org/10. 1007/978-1-4939-3295-5

[B3] Friedenthal, S., Moore, A., Steiner, R.: A Practical Guide to SysML: Systems Modeling Language. Morgan Kaufmann Publishers Inc., San Francisco, CA, USA (2008)

[B4] Friedenthal, S., Moore, A., Steiner, R.: A Practical Guide to SysML, second edition edn. Morgan Kaufmann Publishers Inc. (2012). https://doi.org/10.1016/ C2010-0-66331-0

[B5] Holt, J., Perry, S.: SysML for Systems Engineering: A Model-Based Approach, second edition edn. Computing and Networks (2014)

[B6] Oquendo, F., Leite, J.C., Batista, T.: Software Architecture in Action - Designing and Executing Architectural Models with SysADL grounded on the OMG SysML Standard. Undergraduate Topics in Computer Science. Springer (2016). https://doi.org/10. 1007/978-3-319-44339-3

[B7] Weilkiens, T.: Systems Engineering mit SysML / UML - Modellierung, Analyse, Design. dpunkt.verlag (2006)

[B8] Weilkiens, T.: Systems Engineering with SysML/UML. Morgan Kaufmann Publishers Inc. (2007)

\section{SysML-Theses}

[T1] Abdulhameed, A.: Combining SysML and SystemC to Simulate and Verify Complex Systems. (Utilisation conjointé de SysML et systemC pour simmuler et vérifier les systèmes complexes). Ph.D. thesis, University of Franche-Comté, Besançon, France (2016)

[T2] Bouaziz, H.: Adaptation of SysML Blocks and Verification of Temporal Properties. (Adptation des Blocs SysML et verification des propriétés temporelles). Ph.D. thesis, University of Franche-Comté, France (2016)

[T3] Fontan, B.: Méthodologie de conception de systèmes temps réel et distribués en contexte UML/SysML. Ph.D. thesis, Paul Sabatier University, Toulouse, France (2008)
[T4] Frank, T.: Entwicklung und Evaluation einer Modellierungssprache für den Architekturentwurf von verteilten Automatisierungsanlagen auf Basis der Systems Modeling Language (SysML). Ph.D. thesis, Technical University Munich (2014)

[T5] Gauthier, J.: Combining Discrete and Continuous Domains for SysML-Based Simulation and Test Generation. (Combinaison des domaines discret et continu pour la simulation et la génération de tests à partir de modèle SysML). Ph.D. thesis, University of FrancheComté, Besançon, France (2015)

[T6] Huang, C.: Discrete event system modeling using SysML and model transformation. Ph.D. thesis, Georgia Institute of Technology, Atlanta, GA, USA (2011)

[T7] Lasalle, J.: Génération automatique de tests à partir de modèles SysML pour la validation fonctionnelle de systèmes embarqués. (Automatic tests generation from SysML models for the functionnal validation of embedded). Ph.D. thesis, University of FrancheComté, Besançon, France (2012)

[T8] Rozo, O.C.: Formal and incremental verification of SysML for the design of component-based system. (Vérification formelle et incrémentale de spécifications SysML pour la conception de systèmes à base de composants). Ph.D. thesis, University of FrancheComté, Besançon, France (2015)

[T9] Schönherr, O.: Modellierung, Simulation und Transformation von diskreten Prozessen in der Produktion und Logistik auf der Basis von SysML. Ph.D. thesis, Bundeswehr University Munich (2014)

[T10] Schütz, D.: Automatische Generierung von Softwareagenten für die industrielle Automatisierungstechnik der Steuerungsebene des Maschinen- und Anlagenbaus auf Basis der Systems Modeling Language. Ph.D. thesis, Technical University Munich (2015)

[T11] Turki, S.: Ingénierie système guidée par les modèles: Application du standard IEEE 15288, de l'architecture MDA et du langage SysML à la conception des systèmes mécatroniques. Ph.D. thesis, University of the South, Toulon-Var, France (2008)

\section{References}

1. Ameller, D., Burgués, X., Collell, O., Costal, D., Franch, X., Papazoglou, M.P.: Development of service-oriented architectures using model-driven development: a mapping study. Inf. Softw. Technol. 62, 42-66 (2015)

2. Assar, S.: Model driven requirements engineering: mapping the field and beyond. In: Proceedings of the 4th International ModelDriven Requirements Engineering Workshop (MoDRE), pp. 1-6. IEEE (2014)

3. Badreddin, O., Abdelzad, V., Lethbridge, T., Elaasar, M.: fSysML: Foundational executable SysML for cyber-physical system mod- 
eling. In: Proceedings of the 4th International Workshop on the Globalization Of Modeling Languages co-located with ACM/IEEE 19th International Conference on Model Driven Engineering Languages and Systems (MODELS 2016), Saint Malo, France, October 4th, CEUR Workshop Proceedings, vol. 1731, pp. 38-51. CEUR-WS.org (2016)

4. Barbieri, G., Kernschmidt, K., Fantuzzi, C., Vogel-Heuser, B.: A SysML based design pattern for the high-level development of mechatronic systems to enhance re-usability. In: Proceedings of the 19th IFAC World Congress, IFAC Proceedings Volumes, vol. 47, pp. 3431-3437 (2014)

5. Barmi, Z.A., Ebrahimi, A.H., Feldt, R.: Alignment of requirements specification and testing: a systematic mapping study. In: Proceedings of the 4th International Conference on Software Testing, Verification and Validation Workshops (ICSTW), pp. 476-485. IEEE (2011)

6. Batarseh, O., McGinnis, L.: SysML to discrete-event simulation to analyze electronic assembly systems. In: Proceedings of the 2012 Symposium on Theory of Modeling and Simulation-DEVS Integrative M\&S Symposium, Orlando, FL, USA, March 26-29, pp. 48:1-48:8. SCS/ACM (2012)

7. Baumgart, S., Fröberg, J.: Functional safety in product lines-a systematic mapping study. In: Proceedings of the 42th Euromicro Conference on the Software Engineering and Advanced Applications (SEAA), pp. 313-322. IEEE (2016)

8. Budgen, D., Turner, M., Brereton, P., Kitchenham, B.: Using mapping studies in software engineering. In: Proceedings of PPIG, vol. 8, pp. 195-204. Lancaster University (2008)

9. Budgen, D., Burn, A.J., Brereton, O.P., Kitchenham, B.A., Pretorius, R.: Empirical evidence about the UML: a systematic literature review. Softw. Pract. Exp. 41(4), 363-392 (2011)

10. Bundesverband Informationswirtschaft, Telekomunikation und neue Medien e.V., Verband Deutscher Maschinen- und Anlagenbau e.V.: Umsetzungsstrategie Industrie 4.0 Ergebnisbericht der Plattform Industrie 4.0. Zentralverband Elektrotechnik und Elektronikindustrie e.V. (2015) (in German)

11. Da Silva, F.Q., Santos, A.L., Soares, S., França, A.C.C., Monteiro, C.V., Maciel, F.F.: Six years of systematic literature reviews in software engineering: an updated tertiary study. Inf. Softw. Technol. 53(9), 899-913 (2011)

12. David, P., Idasiak, V., Kratz, F.: Reliability study of complex physical systems using SysML. Reliab. Eng. Syst. Saf. 95(4), 431-450 (2010). https://doi.org/10.1016/j.ress.2009.11.015

13. do Nascimento, L.M., Viana, D.L., Neto, P.A.S., Martins, D.A., Garcia, V.C., Meira, S.R.: A systematic mapping study on domainspecific languages. In: Proceedings of the 7th International Conference Software Engineering Advances (ICSEA'12), pp. 179-187 (2012)

14. Doğan, S., Betin-Can, A., Garousi, V.: Web application testing: a systematic literature review. J. Syst. Softw. 91, 174-201 (2014)

15. Engström, E., Runeson, P.: Software product line testing-a systematic mapping study. Inf. Softw. Technol. 53(1), 2-13 (2011)

16. Essaadi, F., Maissa, Y.B., Dahchour, M.: MDE-based languages for wireless sensor networks modeling: a systematic mapping study. In: Advances in Ubiquitous Networking 2, pp. 331-346. Springer (2017)

17. Fernández-Sáez, A.M., Genero, M., Chaudron, M.R.: Empirical studies concerning the maintenance of UML diagrams and their use in the maintenance of code: a systematic mapping study. Inf. Softw. Technol. 55(7), 1119-1142 (2013)

18. Garousi, V., Shahnewaz, S., Krishnamurthy, D.: UML-driven software performance engineering: a systematic mapping and trend analysis. Progressions and Innovations in Model-Driven Software Engineering (2013)

19. Gauthier, J.M., Bouquet, F., Hammad, A., Peureux, F.: A SysML formal framework to combine discrete and continuous simulation for testing. In: Proceedings of the 17th International Conference on Formal Engineering Methods, ICFEM 2015, Paris, France, November 3-5, Lecture Notes in Computer Science, vol. 9407, pp. 134-152. Springer (2015). https://doi.org/10.1007/978-3-31925423-4_9

20. Guessi, M., Neto, V.V., Bianchi, T., Felizardo, K.R., Oquendo, F., Nakagawa, E.Y.: A systematic literature review on the description of software architectures for systems of systems. In: Proceedings of the 30th Annual ACM Symposium on Applied Computing, pp. 1433-1440. ACM (2015)

21. Huang, E., Ramamurthy, R., McGinnis, L.F.: System and simulation modeling using SysML. In: Proceedings of the Winter Simulation Conference (WSC), Washington, DC, USA, December 9-12, pp. 796-803. WSC (2007). https://doi.org/10.1109/WSC. 2007.4419675

22. Ingibergsson, J.T.M., Schultz, U.P., Kuhrmann, M.: On the use of safety certification practices in autonomous field robot software development: a systematic mapping study. In: Proceedings of the International Conference on Product-Focused Software Process Improvement, pp. 335-352. Springer (2015)

23. Johnson, T., Kerzhner, A., Paredis, C., Burkhart, R.: Integrating models and simulations of continuous dynamics into sysml. J. Comput. Inf. Sci. Eng. 12(1), 011002 (2012). https://doi.org/10. $1115 / 1.4005452$

24. Kernschmidt, K., Vogel-Heuser, B.: An interdisciplinary SysML based modeling approach for analyzing change influences in production plants to support the engineering. In: Proceedings of the 2013 IEEE International Conference on Automation Science and Engineering, CASE 2013, Madison, WI, USA, August 17-20, pp. 1113-1118. IEEE (2013). https://doi.org/10.1109/CoASE.2013. 6654030

25. Kitchenham, B., Charters, S.: Guidelines for performing systematic literature reviews in software engineering, version 2.3. EBSE Technical Report EBSE-2007-01. Keele University and University of Durham (2007)

26. Kitchenham, B.: Procedure for undertaking systematic reviews. Computer Science Department, Keele University (TRISE-0401) and National ICT Australia Ltd (0400011T. 1), Joint Technical Report (2004)

27. Kitchenham, B., Brereton, O.P., Budgen, D., Turner, M., Bailey, J., Linkman, S.: Systematic literature reviews in software engineering - a systematic literature review. Inf. Softw. Technol. 51(1), 7-15 (2009)

28. Kitchenham, B.A., Budgen, D., Brereton, O.P.: Using mapping studies as the basis for further research-a participant-observer case study. Inf. Softw. Technol. 53(6), 638-651 (2011)

29. Korff, A.: Modellierung von eingebetteten Systemen mit UML und SysML. Springer Spektrum Akademischer Verlag, Berlin (2008). (in German)

30. Kosar, T., Bohra, S., Mernik, M.: A systematic mapping study driven by the margin of error. J. Syst. Softw. 144, 439-449 (2018). https://doi.org/10.1016/j.jss.2018.06.078

31. Kuhrmann, M., Méndez Fernández, D., Tiessler, M.: A mapping study on the feasibility of method engineering. J. Softw. Evol. Process 26(12), 1053-1073 (2014). https://doi.org/10.1002/smr.1642

32. Laguna, M.A., Crespo, Y.: A systematic mapping study on software product line evolution: from legacy system reengineering to product line refactoring. Sci. Comput. Program. 78(8), 1010-1034 (2013)

33. Lucas, F.J., Molina, F., Toval, A.: A systematic review of UML model consistency management. Inf. Softw. Technol. 51(12), 1631-1645 (2009)

34. Lúcio, L., Mustafiz, S., Denil, J., Meyers, B., Vangheluwe, H.: The Formalism Transformation Graph as a Guide to Model Driven Engineering. Tech. rep. McGill University (2012) 
35. Majikes, J.J., Pandita, R., Xie, T.: Literature review of testing techniques for medical device software. In: Proceedings of the 4th Medical Cyber-Physical Systems Workshop (MCPS'13), Philadelphia, USA (2013)

36. Mazak, A., Wimmer, M.: Towards liquid models: an evolutionary modeling approach. In: Kornyshova, E., Poels, G., Huemer, C., Wattiau, I., Matthes, F., Sanz, J.L.C. (eds.) Proceedings of the 18th IEEE Conference on Business Informatics, CBI 2016, 29th August - 1st September 2016, Paris, France, Volume 1 - Conference Papers, pp. 104-112. IEEE (2016). https://doi.org/10.1109/CBI.2016.20

37. Nelson, M., Piattini, M.: A systematic literature review on the quality of UML models. Innovations in Database Design, Web Applications, and Information Systems Management pp. 310-334 (2012)

38. Neto, P.A.d.M.S., do Carmo Machado, I., McGregor, J.D., De Almeida, E.S., de Lemos Meira, S.R.: A systematic mapping study of software product lines testing. Inf. Softw. Technol. 53(5), 407$423(2011)$

39. Nguyen, P.H., Kramer, M., Klein, J., Le Traon, Y.: An extensive systematic review on the model-driven development of secure systems. Inf. Softw. Technol. 68, 62-81 (2015)

40. Nguyen, P.H., Ali, S., Yue, T.: Model-based security engineering for cyber-physical systems: a systematic mapping study. Inf. Softw. Technol. 83, 116-135 (2017)

41. Ormeño, Y.I., Panach, J.I.: Mapping study about usability requirements elicitation. In: Proceedings of the International Conference on Advanced Information Systems Engineering, pp. 672-687. Springer (2013)

42. Paredis, C., Bernard, Y., Burkhart, R., de Koning, H.P., Friedenthal, S., Fritzson, P., Rouquette, N., Schamai, W.: An overview of the SysML-Modelica transformation specification. In: Proceedings of the 20th Annual International Symposium of the International Council on Systems Engineering (INCOSE 2010), INCOSE International Symposium, vol. 20, pp. 709-722 (2010)

43. Peak, R., Burkhart, R., Friedenthal, S., Wilson, M., Bajaj, M., Kim, I.: Simulation-based design using SysML part 1: A parametrics primer. In: Proceedings of the 17th Annual International Symposium of the International Council on Systems Engineering (INCOSE), INCOSE International Symposium, vol. 17, pp. 15161535 (2007)

44. Petersen, K., Feldt, R., Mujtaba, S., Mattsson, M.: Systematic mapping studies in software engineering. In: Proceedings of the 12th International Conference on Evaluation and Assessment in Software Engineering, EASE'08, pp. 68-77. British Computer Society, Swinton, UK, UK (2008)

45. Petersen, K., Vakkalanka, S., Kuzniarz, L.: Guidelines for conducting systematic mapping studies in software engineering: an update. Inf. Softw. Technol. 64, 1-18 (2015)

46. Petticrew, M., Roberts, H.: Systematic Reviews in the Social Sciences: A Practical Guide. Wiley, New York (2008)

47. Pretorius, R., Budgen, D.: A mapping study on empirical evidence related to the models and forms used in the UML. In: Proceedings of the Second ACM-IEEE International Symposium on Empirical Software Engineering and Measurement, pp. 342-344. ACM (2008)

48. Rashid, M., Anwar, M.W., Azam, F., Kashif, M.: Model-based requirements and properties specifications trends for early design verification of embedded systems. In: Proceedings of the 11th System of Systems Engineering Conference (SoSE), pp. 1-7. IEEE (2016)

49. Rashid, M., Anwar, M.W., Khan, A.M.: Toward the tools selection in model based system engineering for embedded systems-a systematic literature review. J. Syst. Softw. 106, 150-163 (2015)

50. Reichwein, A., Paredis, C.J.J., Canedo, A., Witschel, P., Stelzig, P.E., Votintseva, A., Wasgint, R.: Maintaining consistency between system architecture and dynamic system models with
SysML4Modelica. In: Proceedings of the 6th International Workshop on Multi-Paradigm Modeling (MPM@MoDELS 2012), Innsbruck, Austria, October 1-5, pp. 43-48. ACM (2012). https://doi. org/10.1145/2508443.2508451

51. Roques, P.: SysML vs. UML2: A Detailed Comparison (2011). http://ecs.victoria.ac.nz/foswiki/pub/Events/MODELS2011/ Material/MODELS_2011_T2-Roques-SysML_UML2.pdf. Talk at 14th International Conference on Model Driven Engineering Languages and Systems (MODELS 2011), Wellington, New Zealand, October 16-21

52. Rusli, H.M., Ibrahim, S.: Testing web services composition: a mapping study. Communications of the IBIMA (2011)

53. Shaw, M.: Writing good software engineering research paper. In: Proceedings of the 25th International Conference on Software Engineering, Portland, Oregon, USA, May 3-10, pp. 726-737. IEEE Computer Society (2003). https://doi.org/10.1109/ICSE. 2003.1201262

54. Siavashi, F., Truscan, D.: Environment modeling in model-based testing: concepts, prospects and research challenges: a systematic literature review. In: Proceedings of the 19th International Conference on Evaluation and Assessment in Software Engineering, p. 30. ACM (2015)

55. Souag, A., Mazo, R., Salinesi, C., Comyn-Wattiau, I.: Reusable knowledge in security requirements engineering: a systematic mapping study. Requir. Eng. 21(2), 251-283 (2016)

56. Torre, D., Labiche, Y., Genero, M.: UML consistency rules: a systematic mapping study. In: Proceedings of the 18th International Conference on Evaluation and Assessment in Software Engineering, p. 6. ACM (2014)

57. Valença, G., Alves, C., Alves, V., Niu, N.: A systematic mapping study on business process variability. Int. J. Comput. Sci. Inf. Technol. 5(1), 1 (2013)

58. VDI Verein Deutscher Ingenieure: https://www.vdi.de/2206. Accessed: 2017-03-14

59. Wieringa, R., Maiden, N., Mead, N., Rolland, C.: Requirements engineering paper classification and evaluation criteria: a proposal and a discussion. Requir. Eng. 11(1), 102-107 (2005). https://doi. org/10.1007/s00766-005-0021-6

60. Wohlin, C.: Guidelines for snowballing in systematic literature studies and a replication in software engineering. In: Proceedings of the 18th International Conference on Evaluation and Assessment in Software Engineering, p. 38. ACM (2014)

61. Wohlin, C., Runeson, P., Höst, M., Ohlsson, M.C., Regnell, B.: Experimentation in Software Engineering. Springer, Berlin (2012). https://doi.org/10.1007/978-3-642-29044-2

62. Wortmann, A., Combemale, B., Barais, O.: A systematic mapping study on modeling for industry 4.0. In: Proceedings of the 20th ACM/IEEE International Conference on Model Driven Engineering Languages and Systems (MODELS), Austin, TX, USA, September 17-22, pp. 281-291. IEEE Computer Society (2017). https://doi.org/10.1109/MODELS.2017.14

63. Zhang, H., Babar, M.A., Tell, P.: Identifying relevant studies in software engineering. Inf. Softw. Technol. 53(6), 625-637 (2011). https://doi.org/10.1016/j.infsof.2010.12.010

Publisher's Note Springer Nature remains neutral with regard to jurisdictional claims in published maps and institutional affiliations. 


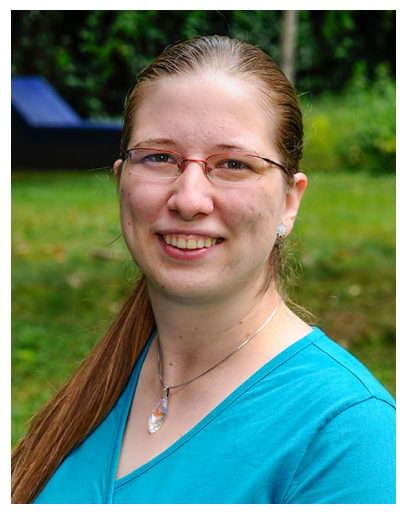

Sabine Wolny is a Ph.D. student working in the Christian Doppler Laboratory for Model-Integrated Smart Production (CDL-MINT) at the JKU Linz in the module Reactive Model Repositories. Before she was a doctoral student at the Doctoral College for CyberPhysical Production Systems (CPPS) at TU Wien. Her topic of interest is SysML-based modeling and execution of systems. In addition to CDL-MINT, she is working since 2013 in the Research Unit of Building Physics at TU Wien with a focus on project management and developing software solutions. For more information, please visit https://www.se.jku.at/ sabine-wolny/.

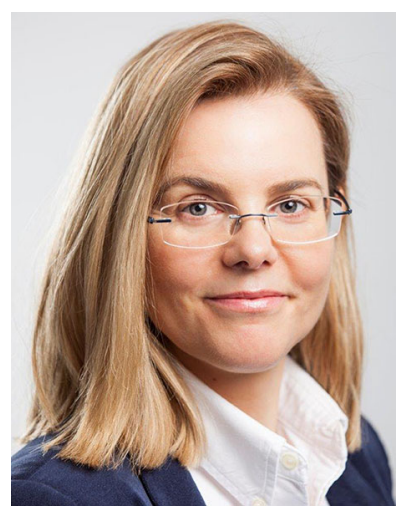

Alexandra Mazak is a senior researcher, heading the module Reactive Model Repositories in the Christian Doppler Laboratory for Model-Integrated Smart Production (CDL-MINT) at the Johannes Kepler University Linz and is also working as a scientific advisor for technology policy in the Austrian Council for Research and Technology Development. Her research interests comprise data integration, statistical modeling and forecast as well as model-driven systems and software engineering in the research field of Industry 4.0. She headed numerous national funded projects in this research field. For more information, please visit https://www.se.jku.at/alexandramazak-huemer/.

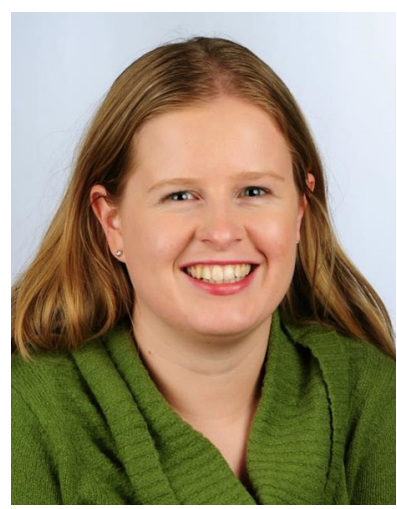

Christine Carpella was an industrial researcher at $\mathrm{SCCH}$, working primarily in business process and systems modeling. She holds an M.Sc. and an M.A. in Computer Science from the University of Applied Sciences of Upper Austria and a Ph.D. from the Johannes-Kepler-University Linz. Since 2017, she is working at ENGEL AUSTRIA GmbH, a company producing injection molding machines.

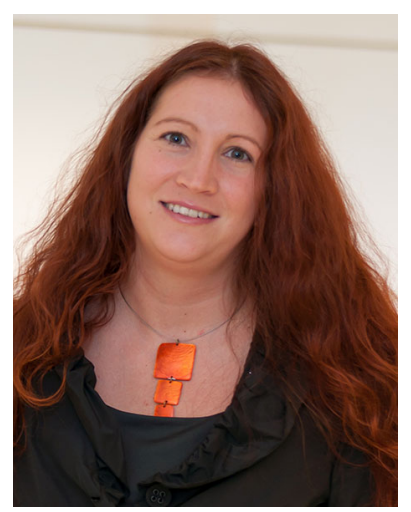

Verena Geist holds a Diploma in Software Engineering from the University of Applied Sciences Upper Austria, Hagenberg, and a $\mathrm{Ph} . \mathrm{D}$. from the Johannes Kepler University Linz, Austria. Since 2005, she is a researcher at the Software Competence Center Hagenberg (SCCH). Her main research areas are business process modeling, information systems, formal methods, and modelbased systems engineering.

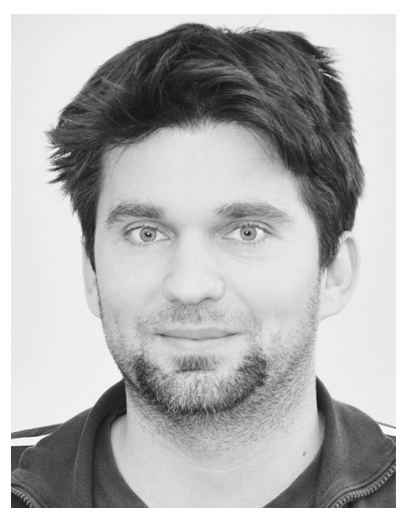

Manuel Wimmer is full professor leading the Institute of Business Informatics-Software Engineering at the Johannes Kepler University Linz, and he is the head of the Christian Doppler Laboratory CDL-MINT. His research interests comprise foundations of model engineering techniques as well as their application in domains such as tool interoperability, legacy modeling tool modernization, model versioning and evolution, and industrial engineering. For more information, please visit https://www.se.jku.at/manuel-wimmer/ 